University of Louisville

ThinkIR: The University of Louisville's Institutional Repository

Electronic Theses and Dissertations

$5-2021$

\title{
School improvement grant: analysis of Kentucky cohort I schools.
}

Ryan Rodosky

University of Louisville

Follow this and additional works at: https://ir.library.louisville.edu/etd

Part of the Educational Leadership Commons

\section{Recommended Citation}

Rodosky, Ryan, "School improvement grant: analysis of Kentucky cohort I schools." (2021). Electronic Theses and Dissertations. Paper 3633.

https://doi.org/10.18297/etd/3633

This Doctoral Dissertation is brought to you for free and open access by ThinkIR: The University of Louisville's Institutional Repository. It has been accepted for inclusion in Electronic Theses and Dissertations by an authorized administrator of ThinkIR: The University of Louisville's Institutional Repository. This title appears here courtesy of the author, who has retained all other copyrights. For more information, please contact thinkir@louisville.edu. 


\title{
SCHOOL IMPROVEMENT GRANT: ANALYSIS OF KENTUCKY COHORT I SCHOOLS
}

\author{
By \\ Ryan Rodosky \\ B.A., Western Kentucky University, 1997 \\ M.A., University of Louisville, 2006

\begin{abstract}
A Dissertation
Submitted to the Faculty of the College of Education and Human Development of the University of Louisville In Partial Fulfillment of the Requirements for the Degree of
\end{abstract} \\ Doctor of Education \\ in Educational Leadership and Organizational Development \\ Department of Educational Leadership, \\ Evaluation, and Organizational Development \\ University of Louisville \\ Louisville, Kentucky
}

May 2021 
Copyright 2021 by Ryan Rodosky

All rights reserved 



\section{SCHOOL IMPROVEMENT GRANT:}

\section{ANALYSIS OF KENTUCKY COHORT I SCHOOLS}

By

Ryan Rodosky

B.A., Western Kentucky University, 1997

M.A., University of Louisville, 2006

A Dissertation Approved on

April 23, 2020

By the following Dissertation Committee:

Dr. W. Kyle Ingle (Co-Chair)

Dr. Deborah Powers (Co-Chair)

Dr. Marco Munoz

Dr. R. Aaron Wisman 


\section{DEDICATION}

This dissertation is dedicated to my amazing family. To my wife Kim, and my kids Michael and Kate, I love you more than words can express. Thank you for your encouragement and continued support throughout this journey. 


\section{ACKNOWLEDGMENTS}

I would like to thank the following people, without whom I would not have been able to complete this research.

Many thanks to my co-chairs, Dr. Kyle Ingle and Dr. Deborah Powers, for your feedback and support throughout this journey. In addition, many thanks to Dr. Powers for sharing your experience and insights from your time in school turnaround work.

To Dr. Marco Munoz, thank you for your support and encouragement throughout this process. Your positive attitude is contagious, and for that, I thank you.

To Dr. Richard A. Wisman, I am proud of our accomplishments while working at Frederick Law Olmsted Academy North. Your guidance and support will not be forgotten.

To the members of my cohort, I will always value the relationships made and remember the support you have shown me over the past two years.

Finally, to my family, there is nothing in life I love more than our circle of four. I love you! 


\title{
ABSTRACT \\ SCHOOL IMPROVEMENT GRANT: \\ ANALYSIS OF KENTUCKY COHORT I SCHOOLS
}

\author{
Ryan Rodosky
}

April 23, 2021

In December of 2009, President Barack Obama and U.S. Secretary of Education Arne Duncan announced the School Improvement Grant (SIG) program would expand as part of the American Recovery and Reinvestment Act. The United States Department of Education (USDOE) awarded an initial allocation of \$8,610,752 in SIG funds to the Commonwealth of Kentucky to turnaround their lowest performing schools (United States Department of Education, 2016). In 2010, the Kentucky Department of Education (KDE) received funding with the goal of moving targeted schools out of PLA status successfully within the three-year window outlined in the SIG application.

Ten schools in Cohort I identified as a Tier I school or Tier II school. Each school received $\$ 500,000$ per year for three years beginning with FY2010. Of the 10 schools identified for the first cohort, six were from the Jefferson County Public School (JCPS) district, which is a large urban school district encompassing the city of Louisville, Kentucky that serves approximately 100,000 students. The other schools were from rural areas of the state with two in the rural eastern half of the state and two in the rural 
western half of the state. After three years of SIG implementation and KDE support, no JCPS school successfully exited PLA status; however, three (75\%) of the non-JCPS schools did. This document analysis explored how some Kentucky Cohort I schools were able to exit PLA status successfully within the three-year timeframe outlined in the SIG application, while others were not. 


\section{TABLE OF CONTENTS}

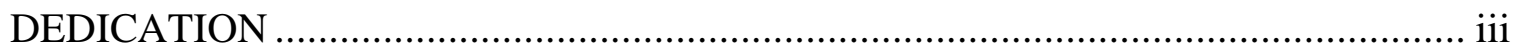

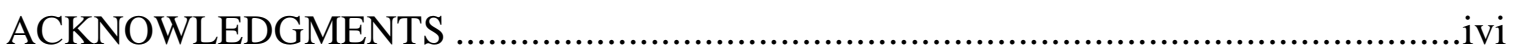

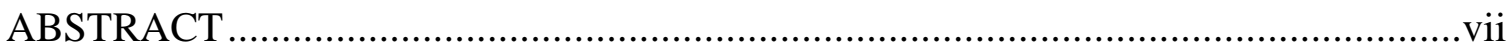

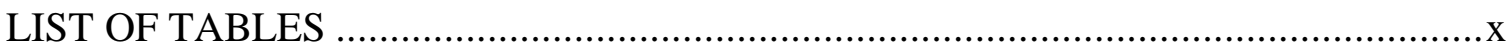

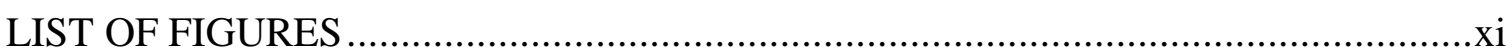

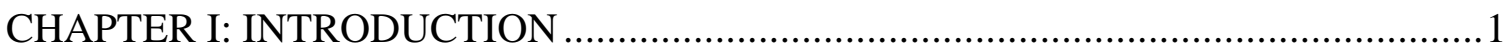

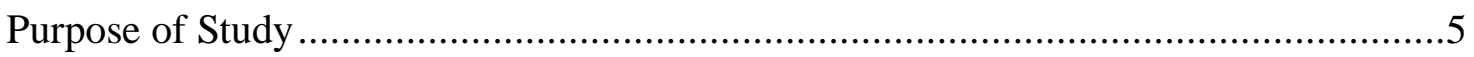

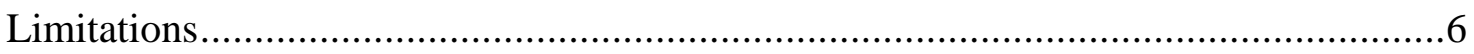

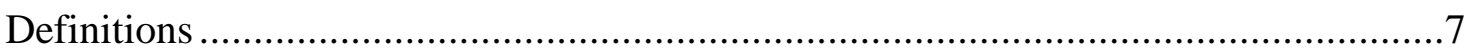

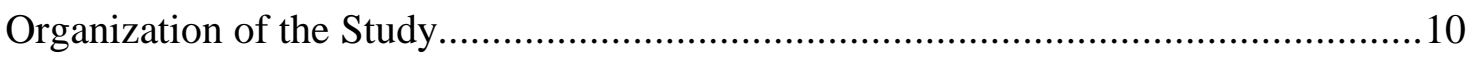

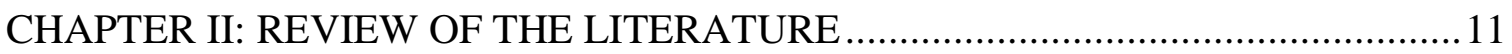

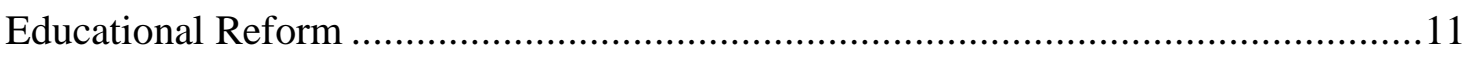

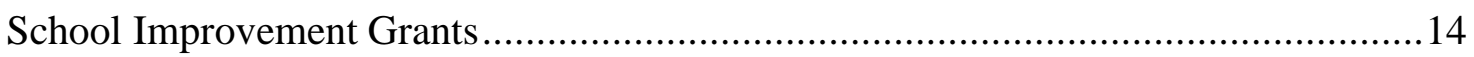

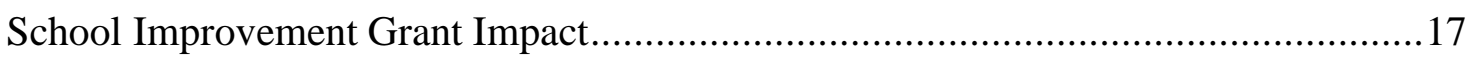

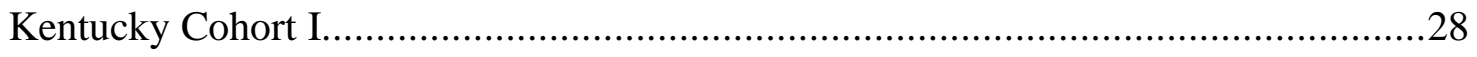

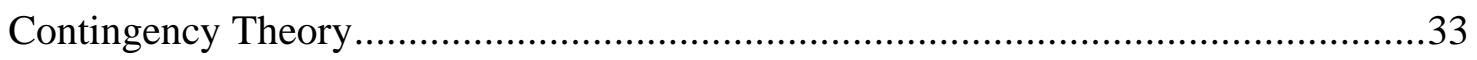

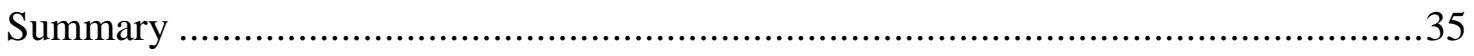

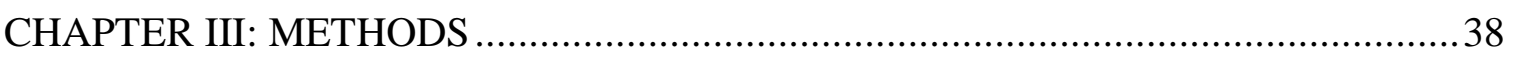

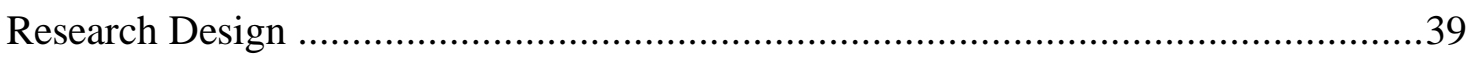

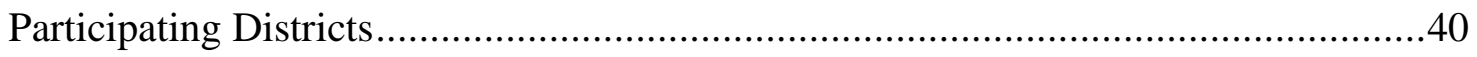

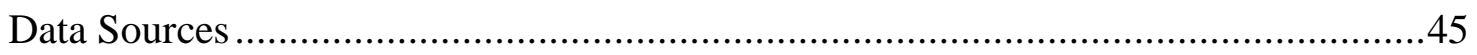

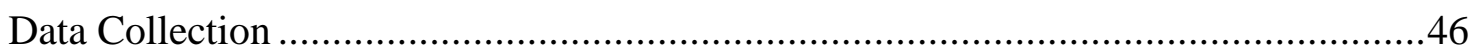

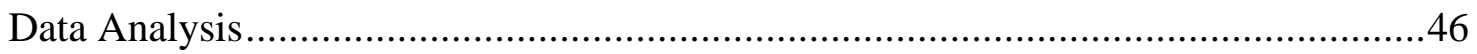

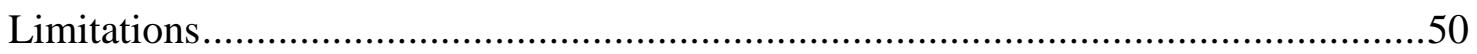

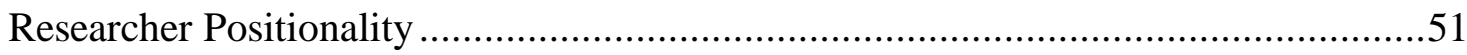

Strategies for Ensuring Credibility, Transferability, Dependability, and Confirmability

Foreshadowing the Presentation of Findings in Chapter IV …….................................53

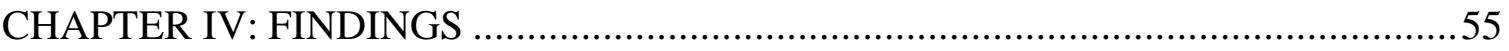

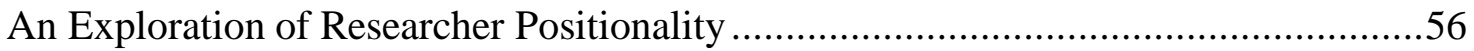

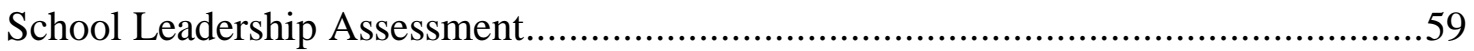

SISI Standard One 


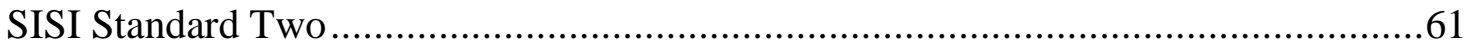

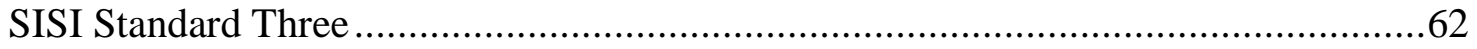

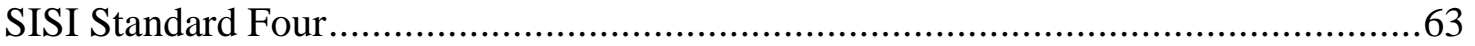

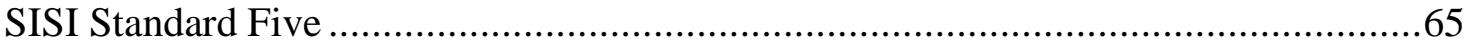

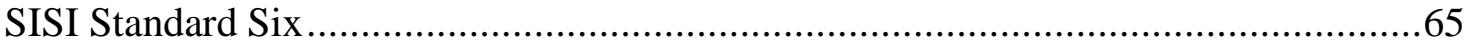

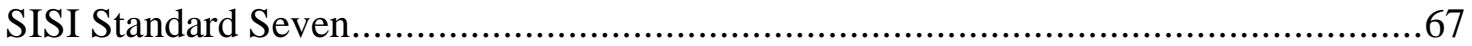

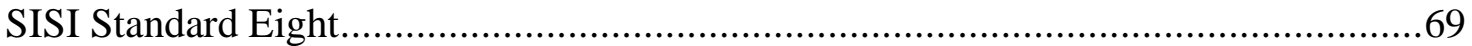

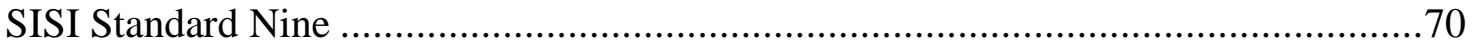

District Leadership Assessment SISI Standard One ...................................................73

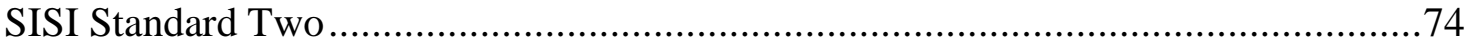

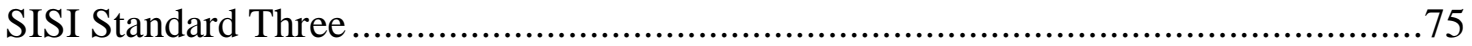

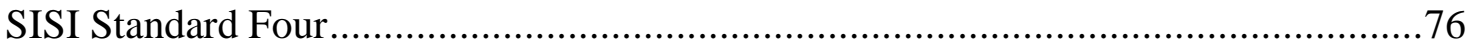

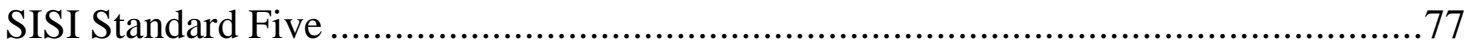

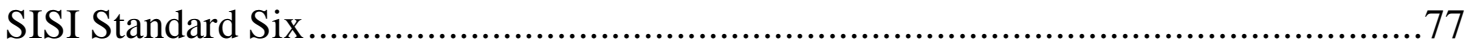

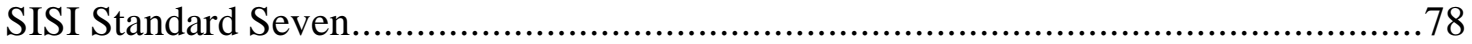

SISI Standard Eight

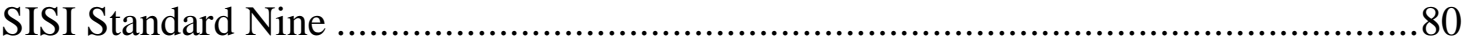

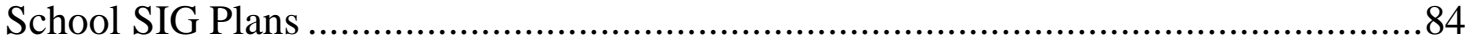

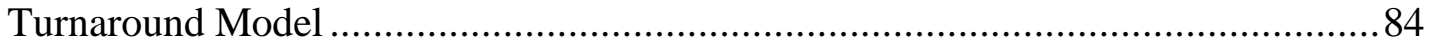

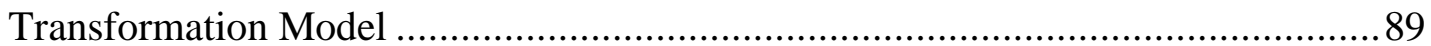

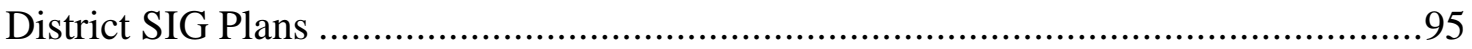

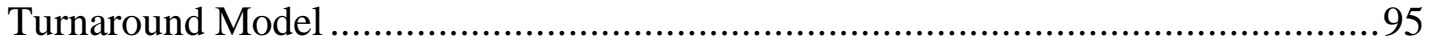

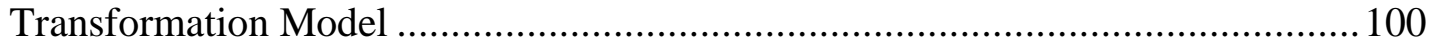

Contingency Factors: Demographic Characteristics of JCPS Cohort I Tier I and Tier II

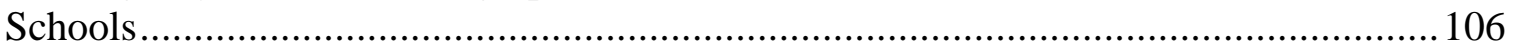

Contingency Factors: Cohort I District and School Size ........................................... 109

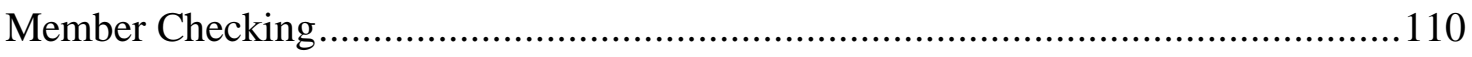

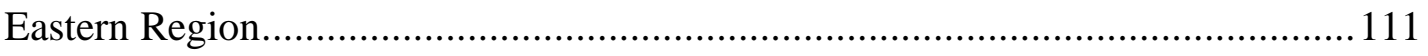

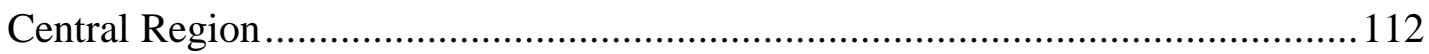

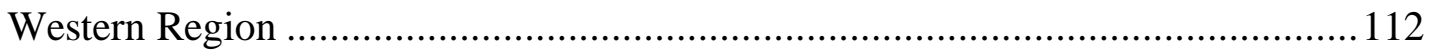

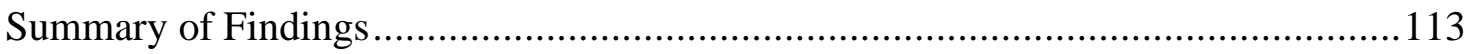

CHAPTER V: SUMMARY OF FINDINGS AND IMPLICATIONS...........................118

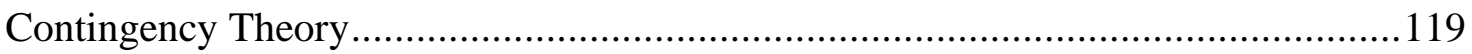

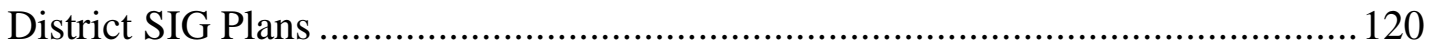

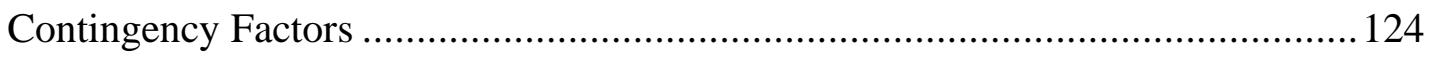




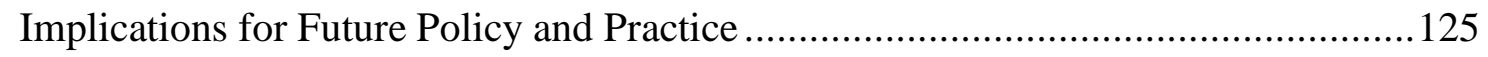

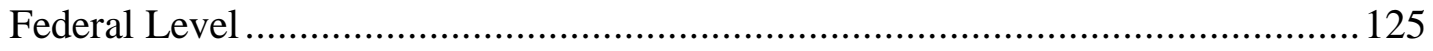

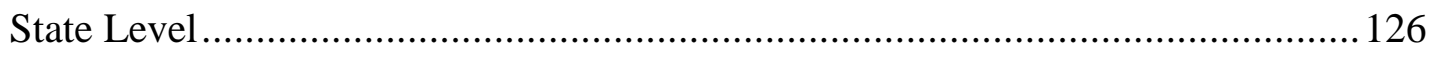

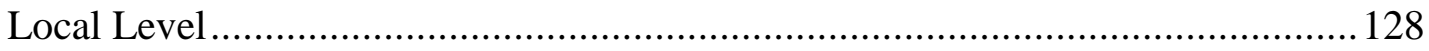

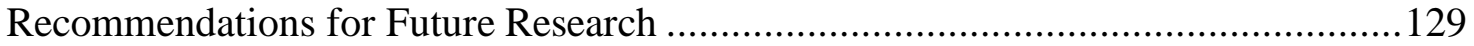

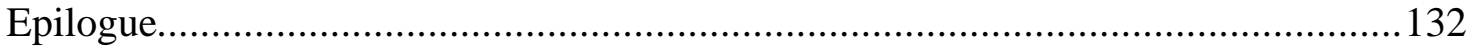

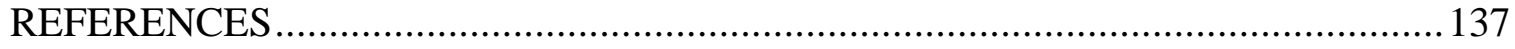

APPENDIX A: STRUCTURED ETHICAL REFLECTION GRID ...............................145

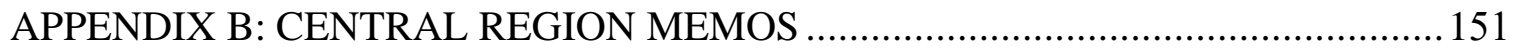

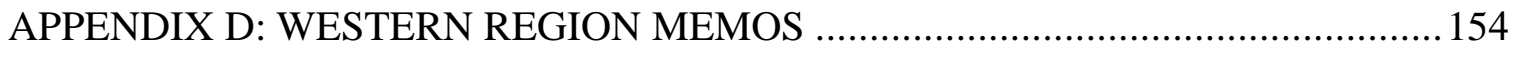

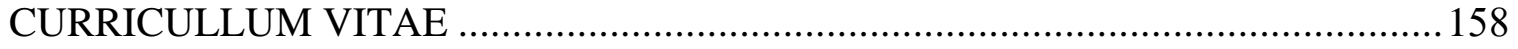




\section{LIST OF TABLES}

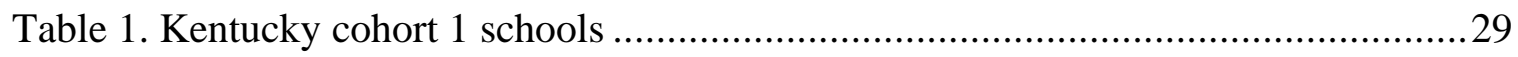

Table 2. Total SIG applications cohort I.................................................... 42

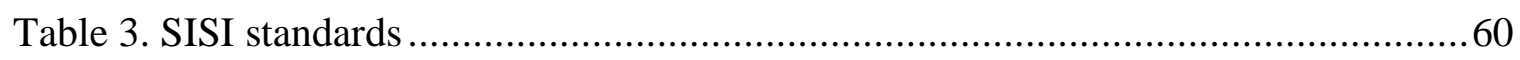

Table 4. Number of Deficiencies per SISI Standard - School Level...........................73

Table 5. Number of Deficiencies per SISI Standard - District Level .......................... 84

Table 6. Tier II Fern Creek student variables contributing to low achievement............. 106

Table 7. Tier I Frost student variables contributing to low achievement ...................... 107

Table 8 . Tier I Shawnee student variables contributing to low achievement ............... 107

Table 9 . Tier I Valley student variables contributing to low achievement .................. 108

Table 10 . Tier I Western High student variables contributing to low achievement....... 108

Table 11 . Tier I Western Middle student variables contributing to low achievement ... 108

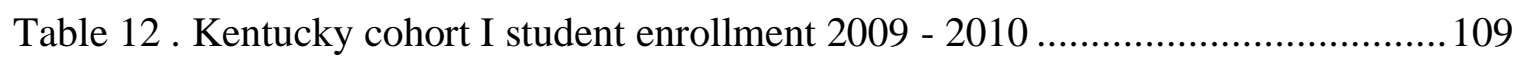

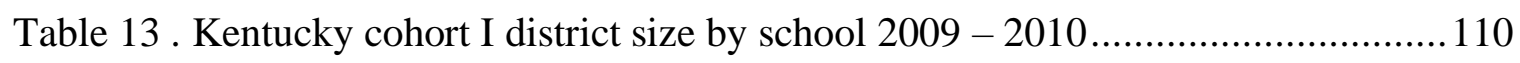




\section{LIST OF FIGURES}

Figure 1. The contingency theory of structural adaptation to regain fit (SARFIT) ..........35

Figure 2. Hanson's (1979) Differentiated and Integrated Subsystems..........................50 


\section{CHAPTER I: INTRODUCTION}

Instead of funding the status quo, we (will) only invest in reform - reform that raises student achievement (Obama, 2010).

In December of 2009, President Barack Obama and U.S. Secretary of Education Arne Duncan announced the School Improvement Grant (SIG) program would expand as part of the American Recovery and Reinvestment Act. Prior to his appointment in the Obama administration, Secretary Duncan served as the CEO of Chicago Public Schools from June 2001 through December 2008, becoming the longest serving urban education superintendent in the country. A focal part of his work in Chicago was to close down “dropout factories" and improve educational outcomes for those most in need (United States Department of Education, 2010).

The SIG program expansion allowed states to apply for a portion of $\$ 3.5$ billion in federal funds. Nationally, states identified 2,172 Persistently Low Achieving (PLA) schools. Of these, 1,228 schools received SIG funds as part of the first cohort of federally identified SIG schools (Le Floch et al., 2014). In the first national cohort, 27\% of the schools were elementary, $18 \%$ middle, $47 \%$ high school, and $8 \%$ other (National School Improvement Grant Summary, 2013). These SIG schools shared common demographic characteristics. An examination of Cohort I SIG schools revealed that $68 \%$ of students qualified for the free or reduced lunch program and $73 \%$ of the students were 
students of color, compared to $45 \%$ nationally. In addition, $56 \%$ of the SIG schools were located in large or mid-sized cities (Le Floch et al., 2014).

On April 21, 2010, the United States Department of Education (USDOE) awarded an initial allocation of $\$ 8,610,752$ in SIG funds to the Commonwealth of Kentucky to turnaround their lowest performing schools (United States Department of Education, 2016). Having secured funding, the Kentucky Department of Education (KDE) opened the application process to school districts throughout the state. The grant detailed the application steps, selection process, and success criteria. Only schools deemed PLA were eligible for SIG funding. PLA schools were sorted into one of three categories. As defined by the School Improvement Grants; American Recovery and Reinvestment Act of 2009 (ARRA); Title I of the Elementary and Secondary Education Act of 1965, as Amended (ESEA) (2010), a Tier I school is a Title I school in improvement, corrective action, or restructuring that is identified by the state education agency (SEA) under paragraph (a)(1) of the definition of "persistently lowest-achieving schools": has not made adequate yearly progress for at least two consecutive years; or is in the State's lowest quintile of performance based on proficiency rates on the State's assessments. A Tier II school is a secondary school that is eligible for, but does not receive, Title I: has not made adequate yearly progress for at least two consecutive years; or is in the State's lowest quintile of performance based on proficiency rates on the State's assessments; or is a high school that has had a graduation rate that is less than 60 percent over a number of years. A Tier III school is a Title I school in improvement, corrective action, or restructuring that is not a Tier I or Tier II school; or eligible for Title I and has failed to 
make adequate year progress for two years; or is in the state's lowest quintile of performance based on proficiency rates on the State's assessments.

KDE received funding with the goal of moving targeted secondary schools out of PLA status successfully within the three-year window outlined in the SIG application. Although permitted by SIG guidelines, KDE did not include elementary schools in Cohort I. Ten schools in Cohort I identified as a Tier I school or Tier II school. Each school received $\$ 500,000$ per year for three years beginning with FY2010. Of the 10 schools identified for the first cohort, six were from the Jefferson County Public School (JCPS) district, a large urban school district encompassing the city of Louisville, Kentucky that serves approximately 100,000 students. The other schools identified for inclusion in the first cohort were from rural areas of the state with two in the rural eastern half of the state and two in the rural western half of the state. Five of the six JCPS schools were designated as Tier I schools. The eastern and western region schools all qualified as Tier II. As part of the application process, schools awarded a SIG had to select and implement one of four SIG required intervention models: Transformation, Turnaround, School Closure, or Restart.

All Cohort I schools were supported by an Education Recovery Team (ERT). The purpose of the three-person ERT was to increase the number of qualified and skilled school turnaround leaders in Kentucky (United States Department of Education, n.d.). ERTs focused on the immediate need for training and on-site leadership coaching for SIG Tier I and Tier II principals. The ERT was comprised of a team leader and two content specialists. The team leader was responsible for working directly with the school 
principal, while the content specialists supported instructional staff with reading and mathematical expertise. The ERT also provided coaching and professional development to teachers, reviewed instructional data, and helped to embed systems of support allowing for continuous school improvement. Regional Centers for Learning Excellence located on the campus of geographically appropriate universities provided an additional level of support (Kentucky Schools' Improvement Grant Application, 2010). Each ERT leader connected to these university-based centers for ensuring alignment, to provide training, and to support to the SIG principals and school-based team leaders. These centers were recipients of federal SIG dollars and were housed at the University of Louisville, Western Kentucky University and Eastern Kentucky University. Each had an operating budget of $\$ 250,000$ per year for three years beginning with FY2010 to support the schools in their region, regardless of the number of schools they were supporting

After three years of SIG implementation and KDE support, no JCPS school successfully exited PLA status; however, three (75\%) of the non-JCPS schools did. In Kentucky's Cohort I, all JCPS schools implemented the Turnaround SIG model, while the non-JCPS schools implemented the Transformation model. Was the selected SIG model the determining factor for a school's success or lack of success in exiting PLA status? A national study by Dragoset et al. (2017) argues otherwise. Their report concluded that implementing any SIG-funded model had no significant impacts on math or reading test scores or high school graduation. This is further supported by Redding and Nguyen (2020) findings that there is little indication of one model being more effective than the others. Perhaps the determining factor for success corresponds with a school's SIG Tier, since only Tier II schools successfully exited PLA status. 
Alternatively, the determining factor for success may relate to district support and intentionality on implementing the school-wide improvement plans.

\section{Purpose of Study}

Using structural contingency theory as the theoretical lens, the purpose of this qualitative study was to determine how some Kentucky Cohort I schools were able to exit PLA status successfully within the three-year timeframe outlined in the SIG application, while others were not successful in exiting PLA status. The basis of the contingency theory model is that organizational effectiveness results from fitting characteristics of the organization, such as its structure, to contingencies that reflect the situation of the organization (Donaldson, 2001). Contingencies can include the environment, organizational size, and organizational strategy. This study examined the various SIG intervention models, SIG tiers, and district support and intentionality when implementing school-wide improvement plans. The specific research questions guiding this study include:

- How were district SIG plans for the Transformation Model similar in the support of the school turnaround work?

- How were district SIG plans for the Turnaround Model similar in the support of the school turnaround work?

- How were school SIG plans for the Transformation Model similar in the support of the school turnaround work?

- How were school SIG plans for the Turnaround Model similar in the support of the school turnaround work? 


\section{Limitations}

The purpose of this qualitative study was to determine how some Kentucky Cohort I schools were able to exit PLA status successfully within a three-year timeframe while others were not. The data were specific to Kentucky's first SIG cohort, which was comprised of eight PLA high schools and two PLA middle schools. Elementary schools were not in included in Cohort I. Although limited to Kentucky's first SIG cohort, the findings may have implications for current educational leaders considering implementing school-wide reform models.

Document analyses was conducted to determine the findings of this study. Merriam (1992) alliterates both limitations and benefits of using documents. Limitations include: the data attained from certain documents are not developed for research purposes and therefore could be incomplete from a research perspective; and it is often difficult to determine the authenticity and accuracy of documents. Member checking, through a process of written feedback, was implemented to further validate the document findings. Member checking feedback was limited for multiple reasons. First, this work took place a decade ago, resulting in a turnover of personnel at the state, district, and school levels. Furthermore, due to the current Covid-19 pandemic, there was moratorium on research activities within the JCPS district, where many of the schools in this study reside.

Although there are limitations, documents are an appropriate source of data if it contains information or insights relevant to the research questions and if it can be acquired in a reasonably practical systematic manner. Merriam (1992) notes that documents often yield better and more data than other methods. Documents may be the only means of studying particular problems, such as historical events. Furthermore, 
documents can be used in the same manner as data from interviews or observations, and data can produce descriptive information, which is useful for theory building.

\section{Definitions}

The following key terms are used in the context of this study:

Closure - School Improvement Grant intervention model occurs when an LEA closes a school and enrolls the students who attended that school in other schools in the LEA that are higher achieving. These other schools should be within reasonable proximity to the closed school. Charter schools or new schools without available achievement data are permitted.

Kentucky Cohort I - The cohort of 10 Kentucky schools selected to receive School Improvement Grant funds in FY2010. The selected schools were identified as being in the bottom $5 \%$ of secondary schools in Kentucky per their overall achievement scores.

Local Education Agency - A public board of education or other public authority legally constituted within a State for either administrative control or direction of, or to perform a service function for, public elementary schools or secondary schools in a city, county, township, school district, or other political subdivision of a State, or for a combination of school districts or counties as are recognized in a state as an administrative agency for its public elementary schools, secondary schools, or PLA schools.

Restart - School Improvement Grant intervention model in which an LEA converts a school or closes and reopens a school under a charter school operator, a charter management organization (CMO), or an education management organization (EMO) selected through a rigorous review process. A restart model must enroll within the grades 
it serves. In addition, the new school must continue to serve any former student who wishes to attend the school.

School Improvement Grant (SIGs) - Grants authorized under section 1003(g) of Title I of the Elementary and Secondary Education Act of 1965 (ESEA) to state educational agencies (SEAs) for competitive subgrants to local educational agencies (LEAs). LEAs must demonstrate the greatest need for the funds and the strongest commitment to use the funds to provide adequate resources in order to raise the achievement of students in their lowest-performing schools substantially.

State Education Agency - The State board of education or other agency or officer primarily responsible for the State supervision of public elementary schools and secondary schools, or, if there is no such officer or agency, an officer or agency designated by the Governor or by State law.

Tier I - A Title I school in improvement, corrective action, or restructuring that is identified by the state education agency (SEA) under paragraph (a) (1) of the definition of “persistently lowest-achieving schools": has not made adequate yearly progress for at least two consecutive years; or is in the State's lowest quintile of performance based on proficiency rates on the State's assessments

Tier II - A secondary school that is eligible for, but does not receive, Title I: has not made adequate yearly progress for at least two consecutive years; or is in the State's lowest quintile of performance based on proficiency rates on the State's assessments; or is a high school that has had a graduation rate that is less than 60 percent over a number of years. 
Tier III - A Title I school in improvement, corrective action, or restructuring that is not a Tier I or Tier II school; or eligible for Title 1 and has failed to make adequate year progress for two years; or is in the state's lowest quintile of performance based on proficiency rates on the State's assessments.

Title I - Title I, Part A (Title I) of the Elementary and Secondary Education Act, as amended by the Every Student Succeeds Act (ESEA) provides financial assistance to local educational agencies for children from low-income families to help ensure that all children meet challenging state academic standards.

Transformation Model - School Improvement Grant model in which the LEA replace the principal; provide job-embedded professional development; implement a rigorous teacher-evaluation and reward system; offer financial and career advancement incentives; implement comprehensive instructional reform; extend learning- and teacher-planning time; create a community-orientation; and provide operating flexibility and sustained support.

Turnaround Model - School Improvement Grant model in which the LEA replace the principal and rehire no more than $50 \%$ of the school's staff; adopt a new governance structure; provide job-embedded professional development; offer staff financial and career-advancement incentives; implement a research-based, aligned instructional program; extend learning and teacher planning time; and create a community-orientation; and provide operating flexibility. 


\section{Organization of the Study}

Chapter I includes the introduction, purpose, limitations, research questions, definition of terms, and a description of the organizational structure of the study. Chapter II reviews the existing literature related to comprehensive school reform and the impact of School Improvement Grants on schools and districts. Chapter III explains the research methodology, the data collection protocol, and procedures for analysis. Chapter IV is a presentation of the findings from that analysis and a discussion of the results of the study. Chapter V concludes the study with a summary of major findings, possible implications for practice, and recommendations for future research. 


\section{CHAPTER II: REVIEW OF THE LITERATURE}

This literature review probes three main areas related to the overall research questions. The first section reviews past educational reform efforts. The second section of the literature review provides an overview of the SIG program, the SIG intervention models, and the impact of SIG on schools and districts from across the nation. Finally, this literature review concludes by examining the impact of SIG on Kentucky's first cohort.

The research questions for this study are:

- How were district SIG plans for the Transformation Model similar in the support of the school turnaround work?

- How were district SIG plans for the Turnaround Model similar in the support of the school turnaround work?

- How were school SIG plans for the Transformation Model similar in the support of the school turnaround work?

- How were school SIG plans for the Turnaround Model similar in the support of the school turnaround work?

\section{Educational Reform}

The federal Elementary and Secondary Education Act (ESEA), enacted in 1965, sought to improve educational equity for students from lower socio-economic households 
by providing federal funds to school districts across the country (United States Department of Education, n.d.). With this funding, school districts engaged in comprehensive school reform (CSR) initiatives with the goal of better serving their students in need. CSR focused on making coherent school wide improvements that affect virtually all aspects of a school's operation, rather than using a piecemeal, fragmented approach to reform (Office of Elementary and Secondary Education, 2000). Effective reform sought to integrate curriculum and instruction, assessment, professional development, parental involvement, and effective school operational systems.

CSR expanded throughout the 1990s (Patterson et al., 2013). In 1998, President Clinton and Congress launched the Comprehensive School Reform Demonstration (CSRD) program. The goal of the program was to build upon and leverage ongoing efforts at the state and local level to connect challenging academic standards with school improvement for high-poverty and low-achieving schools (Office of Elementary and Secondary Education, 2000). The CSRD provided grants to school districts for schools willing to adopt the reforms. Approximately 2000 elementary and secondary schools received at least $\$ 50,000$ per year for a three-year period. Qualifying school reforms had to address nine key elements, which were: comprehensive design with aligned components; effective, research-based methods and strategies; ongoing, high-quality professional development for teachers and staff; measurable parent and community involvement; high-quality external technical support and assistance from an external partner; evaluation strategies; and coordination of financial and other resources to support and sustain reform efforts (Office of Elementary and Secondary Education, 2000). 
The 2001 reauthorization of ESEA, No Child Left Behind (NCLB), put in place measures that exposed achievement gaps among traditionally underserved students and their peers and created a national dialogue on education improvement (U.S. Department of Education, n.d.). This reauthorization mandated increased accountability through annual standardized tests. Schools were now held accountable and required to meet Adequate Yearly Progress targets (AYP). Schools identified for improvement for failing to make AYP for three years, and states without assessment systems, faced corrective actions under NCLB (Paul, 2018). NCLB highlighted the disparities in achievement, but an emphasis on high-stakes testing and highly qualified teachers was not enough to eliminate achievement gaps and other social and economic factors that hinder learning (Steen \& Noguera, 2010). The law was scheduled for revision in 2007, and over time, NCLB's prescriptive requirements became increasingly unworkable for schools and educators (U.S. Department of Education, n.d.).

On December 10, 2015, President Obama reauthorized ESEA as the Every Student Succeeds Act (ESSA). ESSA, which replaced NCLB, moved education authority back to states and local education agencies. ESSA gave flexibility to states regarding specific requirements of NCLB in exchange for rigorous and comprehensive statedeveloped plans designed to close achievement gaps, increase equity, improve the quality of instruction, and increase outcomes for all students (United States Department of Education, n.d.). The overarching goal of ESSA was to ensure each state had: set high college and career standards; enable states to maintain accountability by directing resources towards schools that require improvement; empower states to use appropriate, evidenced-based interventions that foster school improvement; continue annual 
assessments that monitor student growth; increase access to quality preschool programs for more children; secure new resources to identify and investigate promising educational practices; and to replicate proven strategies that enhance students' educational outcomes (Sharp, 2016).

\section{School Improvement Grants}

The SIG, a component of ESEA, received \$ 3.5 billion during the Obama administration through the American Recovery and Reinvestment Act (ARRA) in 2009 (Quillin, 2011). Through the SIG program, the federal government provided funds to state educational agencies (SEAs). In turn, subgrants were awarded to local educational agencies (LEAs) that demonstrated the greatest need for the funds and the strongest commitment to use the funds to provide adequate resources in order to substantially raise the achievement of students in their lowest-performing schools (U.S. Department of Education, 2018). Only schools deemed PLA were eligible for SIG funding. PLA schools were sorted into one of three categories. (Kentucky Schools' Improvement Grant Application, 2010): Tier I school, those in the lowest five percent of all Title I schools; Tier II schools, any secondary school that is eligible for, but does not receive, Title I

funds that are in the lowest five percent of all schools eligible for, but not receiving, Title I funds; and Tier III schools, which were Title I schools that had been identified for improvement, corrective action or restructuring and are not in Tier I.

As part of the application process, schools awarded a SIG were required to select and implement one of four SIG intervention models. The available models were Turnaround, Restart, Closure, and Transformation. Per the School Improvement Grants; American Recovery and Reinvestment Act of 2009 (ARRA); Title I of the Elementary 
and Secondary Education Act of 1965, as Amended (ESEA) (2010), a turnaround model is one in which an LEA must: replace the principal and grant the principal sufficient operational flexibility (including in staffing, calendars/time, and budgeting) to implement fully a comprehensive approach in order to substantially improve student achievement outcomes and increase high school graduation rates; use locally adopted competencies to measure the effectiveness of staff who can work within the turnaround environment to meet the needs of students; screen all existing staff and rehire no more than 50 percent and select new staff; implement such strategies as financial incentives, increased opportunities for promotion and career growth, and more flexible work conditions that are designed to recruit, place, and retain staff with the skills necessary to meet the needs of the students in the turnaround school; provide staff ongoing, high-quality, jobembedded professional development that is aligned with the school's comprehensive instructional program and designed with school staff to ensure that they are equipped to facilitate effective teaching and learning and have the capacity to successfully implement school reform strategies; adopt a new governance structure, which may include, but is not limited to, requiring the school to report to a new "turnaround office", in the LEA or SEA, hire a "turnaround leader" who reports directly to the Superintendent or Chief Academic Officer, or enter into a multi-year contract with the LEA or SEA to obtain added flexibility in exchange for greater accountability; use data to identify and implement an instructional program that is research-based and vertically aligned from one grade to the next as well as aligned with state academic standards; promote the continuous use of student data (such as from formative, interim, and summative assessments) to inform and differentiate instruction in order to meet the academic needs 
of individual students; establish schedules and implement strategies that provide increased learning time (as defined in this notice); and provide appropriate socialemotional and community-oriented services and supports for students.

A restart model is one in which an LEA converts a school or closes and reopens a school under a charter school operator, a charter management organization (CMO), or an education management organization (EMO) that has been selected through a rigorous review process. A restart model must enroll within the grades it serves. In addition, the new school must continue to serve any former student who wishes to attend the school.

School closure occurs when an LEA closes a school and enrolls the students who attended that school in other schools in the LEA that are higher achieving. These other schools should be within reasonable proximity to the closed school. Charter schools or new schools without available achievement data are permitted.

A transformation model is one in which an LEA implements each of the following strategies: develop and increase teacher and school leader effectiveness; replace the principal who led the school prior to commencement of the transformation model; use rigorous, transparent, and equitable evaluation systems for teachers and principals; identify and reward school leaders, teachers, and other staff who, in implementing this model, have increased student achievement and high school graduation rates; identify and remove those who, after ample opportunities have been provided for them to improve their professional practice, have not done so; provide staff ongoing, high quality, job-embedded professional development; and implement such strategies as financial incentives, increased opportunities for promotion and career growth, and more flexible work conditions that are designed to recruit, place, and retain staff with the skills 
necessary to meet the needs of the students in a transformation school (School Improvement Grants; American Recovery and Reinvestment Act of 2009 (ARRA); Title I of the Elementary and Secondary Education Act of 1965, as Amended (ESEA), 2010). The Transformation model was the most widely implemented model across the nation, implemented by $74 \%$ of SIG schools, followed by the Turnaround model $20 \%$, Restart 5\%, and School Closure 2\% (Lachlan-Hache et al., 2012). School districts with nine or more Tier I and Tier II schools were prohibited from using this model on more than half of its SIG schools. No explanation for this restriction was provided.

With the $\$ 3.5$ billion injection of funds in 2009 , the USDOE created new rules and guidance for the SIG program, as well as a requirement that one of four intervention models be implemented in order to receive the funds. These intervention models first appeared in a Notice of Proposed Priorities published by the USDOE in 2009 (LachlanHache et al., 2012). While the $\$ 3.5$ billion infusion was considered significant at the time, questions persist regarding the overall impact of the SIG program and the effectiveness of the grant mandated intervention models.

\section{School Improvement Grant Impact}

A national study conducted by Dragoset et al. (2017) investigated four questions related to the SIG. Did schools implementing a SIG funded model use the practices tied to the model, and how did that compare to schools not implementing a SIG funded

model? Did the implemented strategies focus on English language learners (ELLs)? Did SIG funding affect student achievement positively? Finally, did the chosen SIG model (transformation, turnaround, restart, or closure) relate to improvements in outcomes? 
In order to answer these questions, Dragoset et al. (2017) conducted a descriptive analysis that compared the use of SIG practices for schools that implemented a SIG model and schools that did not. Furthermore, a regression discontinuity design (RDD) was used to examine the overall impact of the SIG program on student outcomes, including test scores, high school graduation, and college enrollment. Finally, correlational analysis examined the relationship between the type of model implemented and changes in student achievement.

Dragoset et al.'s results did not support the effectiveness of the SIG program. Through descriptive analysis, they found that schools implementing a SIG model did use more SIG practices (which include comprehensive instructional reform strategies, increasing principal and teacher effectiveness, increasing learning time, creating community-oriented schools, and having operational flexibility) but that the increases in SIG practices were not statistically significant. There were no significant differences in the use of ELL focused practices between schools receiving SIG and those that did not. Overall, the implementation of any SIG model had no significant impacts on math or reading test scores or high school graduation.

In 2012, the Council of Great City Schools (CGCS) surveyed its member districts to gather information about school turnaround and learn specifically about early experiences in implementing SIG funding (Lachlan-Hache et al., 2012). CGCS consisted of 76 of the nation's largest urban public-school systems. Together their goal was to improve educational outcomes for children in urban school settings. The five districts involved with the survey with the most schools identified as Tier I or Tier II were Detroit, Boston, St. Louis, Pittsburgh, and Providence. Of the identified schools, 
$31 \%$ awarded SIG funding during the first rollout. Responses to the Council's survey varied considerably in the number and percent of their schools identified as either Tier I or Tier II under the SIG program (Lachlan-Hache et al., 2012).

Students enrolled in Tier I and Tier II schools were more diverse than non-Tier I and non-Tier II schools. A high proportion of students enrolled in urban schools were African American or Hispanic. According to Lachlan-Hache et al. (2012), of the 1.4 million students enrolled in Tier I and Tier II schools across the nation, 44\% were African American, 32\% are Hispanic and 19\% are White. Great City member Tier I and Tier II schools were 55\% African American, 33\% Hispanic and 8\% White. By comparison, student enrollment nationwide was 17\% African American, 22\% Hispanic and 55\% White. Seventy-two percent of CGCS students were eligible for Free and Reduced - Price Lunch (FRLP). The transformation model, which required the adoption of a teacher and principal evaluation system tied to student achievement growth, was the model most often selected. In total, 74\% of SIG schools nationwide used this model; 54\% of CGCS districts used this model (Lachlan-Hache et al., 2012).

Lachlan-Hache et al.'s (2012) survey responses indicated an issue with grant timelines. The delay in announcing the grant award negatively affected the ability for districts and states to effectively plan. Over a quarter of survey respondents indicated that the award announcements were not made until after August, which was typically the beginning of the school year. In addition, $43 \%$ did not receive the initial award until July or August, after the regular Title I plans were due to the state and just weeks before the school year. 
In Washington, Yatsko et al. (2012) conducted a field study on school districts receiving SIG funds. Of the 48 schools that applied, 18 schools received grant funding. For their analysis, Yatsko et al. (2012) conducted 44 interviews and made nine site visits. Interviewees included state department of education officials, teachers' union executives, superintendents, principals, vice principals and teachers. The SIG application process, selected turnaround models, the development of turnaround plans, SIG goals, district supports, general perceptions, and SIG impact were included in the analysis. The findings correspond in part with Lachlan-Hache et al. (2012) in that at the district level, SIG timelines rushed planning and implementation.

The districts' perception of state-level support was mostly compliance driven. Overall, districts lacked a coherent plan for school improvement strategies. Their plans often mirrored past efforts, which did not include the creation of an internal turnaround office that would align and coordinate district supports. Overall, district personnel lacked the capacity to assist in changing practice at poor-performing schools. For example, in one interview, a district SIG director asked the interviewer if they had any information regarding how to turn around a failing school successfully? The director did not know how to lead such an effort. Furthermore, district oversight by in large, was often focused on compliance with the terms of the grant.

At the school level, a lack of autonomy often led to frustration and stagnation. District policies, especially in the area of human resources, limited the removal of ineffective teachers and staff. Plans to develop and implement new teacher evaluation rubrics, stop forced teacher placements, and provide an expedited path for removing ineffective teachers often stalled. Results also showed, for schools and 
principals granted some autonomy, the connection between the stated turnaround strategy and the actual use of SIG funds was often weak. School plans often added new interventions to existing ones, lacked focus, and did not align with the overall SIG goal. Overall, SIG money was viewed as an extra, instead of seed money for a new long-term strategy. Sustainability was also an issue. None of the schools in this study were able to develop a plan for paying for the extra staff and extended days after the grant was finished in three years.

Surprisingly to the researchers, interviews with state officials painted a different narrative. State officials discussed with enthusiasm their school turnaround office, expertise and resources, and professional development supports. As Yatsko et al. (2012) notes, the districts predominately viewed their state supports as compliance protocols to ensure federal grant terms were met, not support for school-level efforts.

An evaluation of outcomes in Michigan from 2010 - 2013 did not support the effectiveness of the SIG program. Rice et al. (2014) used a mixed methods approach to evaluate the impact of SIG on students attending 28 schools in the state of Michigan from 2010 to 2013. This report compared student achievement outcomes between SIG schools and schools that were eligible for a SIG but not awarded one. In addition, perception data were collected from teachers in the form of surveys, and case studies were performed at 11 SIG schools to focus on specific elements of SIG. The results of this report align with the findings of Dragoset et al. (2017) in that there were no statistically significant differences found in the implementation of SIG or in student outcomes.

Student academic achievement was measured using scores from the Michigan Educational Assessment Program (MEAP) and the Michigan Merit Examination 
(MME). A hierarchical linear model was used to conduct the analysis, which accounts for baseline scores as well as student demographic characteristics. Rice et al. (2014) did note that there were large differences between SIG schools and non-SIG schools on several characteristics therefore caution should be used when interpreting differences between students' scores on the MEAP and MME between the two types of schools after three years. These characteristics include demographic and average baseline MEAP and MME scores. A closer look at the characteristics shows that SIG schools had a higher percentage of students with limited English proficiency included in the MEAP analysis. In addition, SIG schools included in the analysis of MME scores had a larger percentage of White students and a smaller percentage of African American students compared to non-SIG schools.

Rice et al. (2014) suggest that students in schools receiving SIG funds over the three-year window had similar scores on MEAP mathematics, reading, and science to schools that were eligible for SIG funds but not awarded the grant. None of the differences on MEAP scores were found to be statistically significant. Furthermore, students at SIG funded schools had similar scores on MME mathematics, reading, and science after three years compared to students at schools eligible, but not awarded SIG funding. Again, none of the differences were statistically significant.

Feedback from participants illustrated that the districts supported their schools' implementation of SIG by providing principals with autonomy to carry out SIG activities, including supporting decisions to remove ineffective teachers. In one case, the district supported a school by helping them find a high-quality change agent to assist with their turnaround efforts. However, there is little evidence in the report that shows intentional 
district planning to support the effective use of SIG. Most examples of program support were in the form of granting principal autonomy.

The Study of School Turnaround (SST) examined how a variety of lowperforming schools approached the improvement process during the three years in which they received SIG funds, and how SIG funds contributed to this process. The case study analysis by Le Floch et al. (2016) documented the experiences of schools in the initial phases of SIG. The experiences of 25 schools from across the country were examined for the 2009 - 2010 school year, and a smaller subset of 12 schools were further analyzed through 2012 - 2013. The SST did not examine the impact of SIG on student achievement outcomes.

Results of the case study revealed that 21 of the 25 schools replaced their principal within one year of receiving SIG funds. In addition, nine schools replaced their principal twice. Half of the survey respondents (school staff) described the new principal as an improvement from past leadership. Nearly half of the schools implemented the turnaround model and replaced 50\% of their teachers during the three-year period. Almost all schools used SIG funds to hire non-teaching instructional, data, or technology coaches. In addition, $75 \%$ of respondents reported difficulty recruiting and retaining staff.

A closer look at school perception revealed most district supports included professional learning activities (20 schools), principal professional learning activities (15 schools), supportive teacher staffing policies (14 schools), and structures to support data use (13 schools). Professional learning provided by the district mainly focused on the effective use of data, literacy and math instructional strategies, and district-funded 
instructional coaching. Respondents from $69 \%$ of the sample districts reported having sub-districts or designated district staff in place to support SIG schools during the second year of the grant. Respondents, that received support from sub-district or designated staff, reported receiving support in more areas than the schools that reported not receiving any specialized district support. Overall, only $45 \%$ of schools perceived their district's support as helpful in their school improvement efforts.

In contradiction to the previously discussed findings, LiCalsi et al. (2015), Moro (2017), and Sun et al. (2017) revealed positive outcomes related to SIG. Common themes across all three studies were coherent plans and district support. In 2015, the American Institute for Research (AIR) contracted with the Massachusetts Department of Elementary and Secondary Education (Massachusetts ESE) to evaluate the effectiveness of their school turnaround plan, which included a school district liaison from the Massachusetts Office of District and School Turnaround (ODST), priority partners, and SIG funding. A comparative interrupted time series (CITTS) design was used to control for background characteristics and compare SIG schools with non-SIG schools. The focus of the ODST was to build capacity to facilitate school turnaround for their schools with the highest needs. This model included five-stages: developing a school plan for improvement, implementation and monitoring, evaluating success, analyzing data, and using the results to guide future decisions. The results of their analysis showed that SIG students in SIG schools outgained their peers in the non-SIG schools when considering prior achievement trends (LiCalsi et al., 2015). Furthermore, SIG schools decreased the achievement gap on both ELA and mathematics between English Language Learners (ELL) and non-ELL students compared with the change in achievement gaps at non-SIG 
schools. Similar to the outcomes from San Francisco, students in the schools receiving grant funding demonstrated statistically significant academic achievement gains compared to their non-grant peers, but their non-grant peers still outperformed them by a large margin.

Sun et al. (2017) found statistically positive gains for SIG schools from the San Francisco Unified School District (SFUD) between the years of 2011 - 2013. The SFUD serves approximately 58,000 students in which student demographics are: 26\% Latino, 41\% Asian, 11\% White, 10\% African American, 1\% Native American, and 10\% other. The SFUD received \$45 million in SIG funds to support its 10 PLA schools. Specific demographic data on the 10 PLA schools was not included in this report. In preparation of the SIG proposal, SFUD leadership performed a needs assessment to identify areas needing improvement within each of their PLA schools. This needs assessment indicated that 10 schools had incoherent curricula, assessments, and instructional guidance; insufficient resources and classroom materials; a lack of comprehensive interventions and monitoring of student progress; and haphazard implementation of improvement strategies (Sun et al., 2017).

In order to address these deficiencies, district leadership designed SIG plans using five essential supports adopted by the Chicago Public Schools. The five essential supports were: (a) activating school leadership as the driver for change; (b) developing professional capacity among teachers; (c) cultivating cohesive instructional guidance that promotes ambitious academic achievement for every child; (d) nurturing a studentcentered learning climate; (e) and fostering parent-community ties. In addition, the district restructured its leadership to ensure PLA schools received direct administrative 
and curricular support. Of the 10 PLA schools, it was determined that five schools would implement the transformation model, four schools would implement the turnaround, and the lowest performing school would close.

Sun et al. (2017) found gradual improvements during the first two years of SIG reforms and increased gains during the third year. Specifically, SIG reforms were found to reduce the achievement gap between the lowest performing schools and the rest of the schools in the district. Furthermore, unexcused absences reduced by $24 \%$ and families choosing to attend a PLA school increased $117 \%$. A possible explanation for the difference in findings across studies is the variation in the design and implementation of SIG interventions across districts and states (Sun et al., 2017). Even with the statistically significant gains, the SIG schools still lagged far behind the comparison schools in academic achievement after three years. Interview and perception survey findings illustrate that principal leadership played an important role in the successful administration of SIG across all schools. Since there was not a significant increase in student achievement, the perceived "successful administration" could be tied to improved school climate, since respondents revealed that all principals in the SIG case study schools implemented some form of distributed leadership. Respondents at the case study schools also reported mixed results regarding the performance evaluation systems and their contribution to school improvement. Some feedback showed that the evaluation systems improved teacher accountability through improved feedback. However, across all year three case study schools, teachers indicated that incentives tied to evaluation, particularly financial incentives, did not play a role in teacher motivation or SIG success. 
An examination of the use of SIG to close achievement gaps and determine leadership activities that support school improvement led Moro (2017) to perform a qualitative phenomenological study on New England schools. For this research, 15 school administrators from the New England area participated in the semi-structured interviews. Participants were selected purposefully based on their success with implementing transformational or turnaround SIG models. Participants were identified as successful administrators - either as a superintendent or as a principal - through the U.S. ED website. The interviews focused on four main questions. What strategies or practices did schools use in implementing the SIG; what challenges were faced by participating schools in implementing those strategies or practices; how did participating schools measure the success of the SIG at their respective schools; and based on their experiences, what recommendations would participating schools make to other schools who will implement a similar SIG?

Moro (2017) centered on four distinct strategies that SIG administrators used when creating and implementing the grant. These strategies were collaboration, having a common mission, common vision, and support. Staffing, adapting curriculum to meet student needs, growth, budgeting, and managing student behavior were identified as common areas of concern. The participants used formal teacher evaluations, classroom observations, climate and culture indicators, and attitudes of people to measure success. While student assessment was identified by some administrators as a success measurement, other participants felt that assessment was not as important as the previous four factors. Lastly, the administrators identified six recommendations for future SIG administrators as they begin the design and implementation process, which were plans for 
sustainability; proactive staffing; leadership that embraced change and teacher-leader; focusing on positive personality traits; flexibility; and communication. Limitations of this study, as noted by the researcher, are that results were specific to the urban, public schools in the New England states who received SIG funding. The findings of this study were further limited by the information provided by the administrators and school superintendents and any information that was public record.

\section{Kentucky Cohort I}

In Kentucky, 10 schools were identified as PLA schools and participated in the state's first SIG cohort, with each school receiving $\$ 500,000$ per year over a three-year period (see Table 1). All 10 schools were from the secondary level. Elementary schools were not included in the first cohort. Six of the Cohort 1 schools resided in the JCPS district, which is a large urban district encompassing the city of Louisville. The remaining schools were from smaller, rural districts located in two specific regions of the state, the east region and the west region. Five JCPS schools qualified for SIG as Tier I (schools that qualified for Title I and amongst the lowest-achieving 5\%), while one JCPS school and all non-JCPS schools qualified as Tier II (schools among the lowest-achieving $5 \%$ that are eligible for, but do not receive, Title 1). All six JCPS schools implemented the turnaround model with the four non-JCPS schools opting for the transformation model. Under the guidelines of the turnaround model, the JCPS schools were required to replace the principal if they had three or more years in the position and rehire no more than $50 \%$ of the staff. Following the mandates of the transformation model, the nonJCPS schools were required to: replace the principal and take steps to increase teacher 
and leader effectiveness; institute comprehensive instructional reforms; increase learning time; and provide operational flexibility and sustained support (Quillen, 2011).

Table 1. Kentucky cohort 1 schools

\begin{tabular}{llll}
\hline Schools & District & Region & Tier \\
\hline Caverna High & Caverna Independent Schools & West & II \\
Fern Creek Traditional High JCPS & Central & II \\
Frost Middle & JCPS & Central & I \\
Lawrence County High & Lawrence County Schools & East & II \\
Leslie High & Leslie County Schools & East & II \\
Metcalfe County High & Metcalfe County Schools & West & II \\
Shawnee High School & JCPS & Central & I \\
Valley Traditional High & JCPS & Central & I \\
Western High & JCPS & Central & I \\
Western Middle & JCPS & Central & I \\
\hline
\end{tabular}

In 2012, Rhodes, Bower, McKay, and Adams, submitted the 2012 Annual Evaluation Report for the Kentucky School Improvement Grant. This report examined the impact of SIG on instructional and leadership climates in Kentucky schools and its impact on student outcomes. Rhodes et al. (2012) used a mixed method design to examine the evaluation questions from four perspectives from each region (Western, Eastern and Central): School instructional and leadership climates from the ERT perspective; from the principal perspective; from the teacher perspective, and academic and non-academic student outcomes. Schools were divided into three regions based upon 
their physical location throughout the state. The JCPS schools were located in the Central region, Leslie County High School and Lawrence County High School were in the Eastern region, and Metcalfe County High School and Caverna High Schools were located in the Western region. Data were collected on instructional and leadership climates through semi-structured interviews with ERTs and principals and through teacher surveys. Annual state assessment data were analyzed to examine the impact of the SIG on student outcomes.

Analysis of interviews and surveys resulted in four main themes. Across all SIG schools: data were being used to drive decisions and processes; embedded professional development (PD) was implemented to build teacher capacity; student engagement had increased; and external barriers, such as lack of urgency for reform, feeder schools with a disproportionate number of struggling students, and low parental involvement, were still a concern. In the Eastern and Western regions, ERSs defined their roles as collaborative with teachers. They provided embedded PD, facilitated collaborative inquiry groups known as Professional Learning Communities (PLCs), and monitored instructional practices. In both regions, ERSs felt that teachers were receptive, but that expectations for student outcomes were low and that there was a lack of urgency. In the Central region, ERSs' roles varied per building, and they described their role based on the tasks they performed such as PD provider or data support. In some settings, they helped with PLCs, developed intervention systems, and monitored instruction. However, in other settings, the ERSs were not part of the school's leadership team and had no active part in decision making or monitoring. Central region ERSs also noted concerns in the areas of student behavior, teacher readiness, and teacher turnover. 
Across all three regions, there was some variation on how ERLs viewed themselves and how schools were supported. In the Eastern and Central regions, ERLs viewed themselves as mentors or coaches. Western ERLs shied away from the term mentor and described themselves more as providing support. Relationships between ERLs and principals were viewed very positively in the West and East. This was true of some Central region schools, but in others ERLs felt the principal was not open to their advice because of conflict concerning what their roles should be (Rhodes et. al., 2012).

Rhodes et al. (2012) found principals in the Eastern region, viewed their roles as collaborative with the ERT. They were positive about the SIG process and thought their teachers and students had benefited. Eastern region principals were concerned about sustainability, due to funding restraints when the grant ended. Western region principals were also positive regarding the SIG process, and felt that the areas of school culture and instruction were improving. However, the principals were concerned about parent apathy and sustainability. In the Central region, principals emphasized their management and leadership roles. Some shared positive views of their ERTs, while others described issues in collaborating. Central region principals thought the SIG had contributed to improved school climate (improvements in teacher and student attitudes), instruction, and intervention. Central region principals identified a number of challenges including the skill gap of their students, community apathy, and inexperienced teachers. The lack of experienced teachers could have been a bi-product of the turnaround model due to the mandate to replace a significant portion of school staff. Principals also expressed concerns about sustainability of initiatives when the SIG funding ends. 
With the selection of different intervention models (transformation and turnaround), one might expect to see distinct differences in SIG activities; however, that was not the case. Across all regions, PD, PLCs, and classroom walkthroughs were common SIG activities; however, their implementation varied. In the Eastern region, PD was focused on data analysis and data driven decision. The ERSs agreed that prior to receiving PD, teachers lacked the capacity to use data effectively. In the Western region, modeling was the primary way in which teachers received PD. By modeling, the ERSs felt that teachers were more aware of the expectations within the classroom.

Classroom walkthroughs were also a common practice across regions. In the Eastern region, walkthroughs were the main mechanism for ensuring best practices were being implemented in daily lessons. All Eastern region schools had a formal walkthrough process that included the ER staff, administrators and district personnel. However, the ER team, with concerns over consistency and capacity to provide effective feedback, questioned the fidelity of the walkthroughs. In the Western region, walkthroughs were used to identify gaps in teacher training. In two schools a walkthrough tool was used that aligned with the principals' goals for instruction. Feedback from Central region ER teams revealed that walkthroughs occurred in some schools, but not all. In several of the schools, the ER staff was not part of the formal walkthrough process. In the Central region, individual feedback was limited, and walkthrough data was used mainly to identify school-wide gaps in their instructional systems.

PLCs were incorporated across schools in all three regions. In the Eastern region, PLCs were the main place where PD was delivered. ER staff directly led or participated 
in creating PLC agendas and activities. Western ER staff also reported that PLCs were the main venue for PD and for analyzing student data. Unlike the Eastern region where PLCs met weekly, Western PLCs met every other week. In the Central region, some PLCs met weekly and others met every other week. The fidelity of the PLC process fluctuated from school to school, with some PLCs being very structured and data driven, while others were more like extended planning opportunities.

Academic outcomes were difficult to interpret due to a change in Kentucky's assessment and accountability system. As Rhodes et al. (2012) noted, the average percent of students scoring proficient in reading and mathematics in SIG Cohort I significantly declined in 2012, trends noted across the rest of the state as well. In 2012, $34.4 \%$ of students in the Cohort 1 Eastern region high schools scored proficient or distinguished (P/D) in reading on the state assessment, 34.75\% of Western region students scored P/D, and 25.87\% of Central region students scored P/D, compared to the state average of $38.4 \%$. In mathematics, the Central and Eastern regions again lagged behind the state average with $21.63 \%$ of Central region students scoring P/D and $13.75 \%$ of Eastern students scoring P/D. The Western region scored higher than the state average in mathematics with $37.7 \%$ of students scoring P/D in mathematics. An examination of high school graduation rates showed an increase at four of the eight Cohort I high schools (Metcalfe High School, Lawrence High School, Fern Creek High School, and Western High School).

\section{Contingency Theory}

Contingency theory served as the overarching theoretic lens for this analysis. Contingency theory makes it clear that there is no one best way to organize (Hatch, 
2018). Depending upon the environment, there can be many different ways for organizations to organize successfully or unsuccessfully. This viewpoint is supported by Friedberg (1997), who concluded that there is no one best way or approach in management or doing things, different situation calls for different approach to handle, manage, and solve arising issue concerned.

A contingency is any variable that moderates the effect of an organization characteristic on organizational performance (Donaldson, 2001). These contingency variables are situational variables that influence the relationship between managerial strategy or organizational structure and organizational outcomes (Hanson, 1979). A derivation of contingency theory, structural contingency theory, was used to narrow the focus of this analysis. With structural contingency, contingency factors include the environment, organizational size, and organizational strategy. As explained by Donaldson (2001), structural contingency theory contains three fundamental components that together form its foundational model. First, there is a relationship between contingency and the organizational structure. Second, contingency determines the organizational structure, because an organization that changes its contingency must change its structure. Third, there is a fit of some level of the organizational structure variable to each level of contingency. Organizational fit leads to higher performance, while misfit leads to lower performance. Figure 1 illustrates a model of how contingency change leads to structural change and adaptation to regain fit. Contingency variables can be internal or external. In the school setting, an example of an external variable could be parent pressures, while internal environment variables could be teacher autonomy or racial tension (Hanson, 1979). The contingency approach states that the effect of one variable on another 
depends on some third variable, therefore the effect of $\mathrm{A}$ on $\mathrm{B}$ when $\mathrm{C}$ is high is different than the effect A on B when C is low (Donald, 2001).

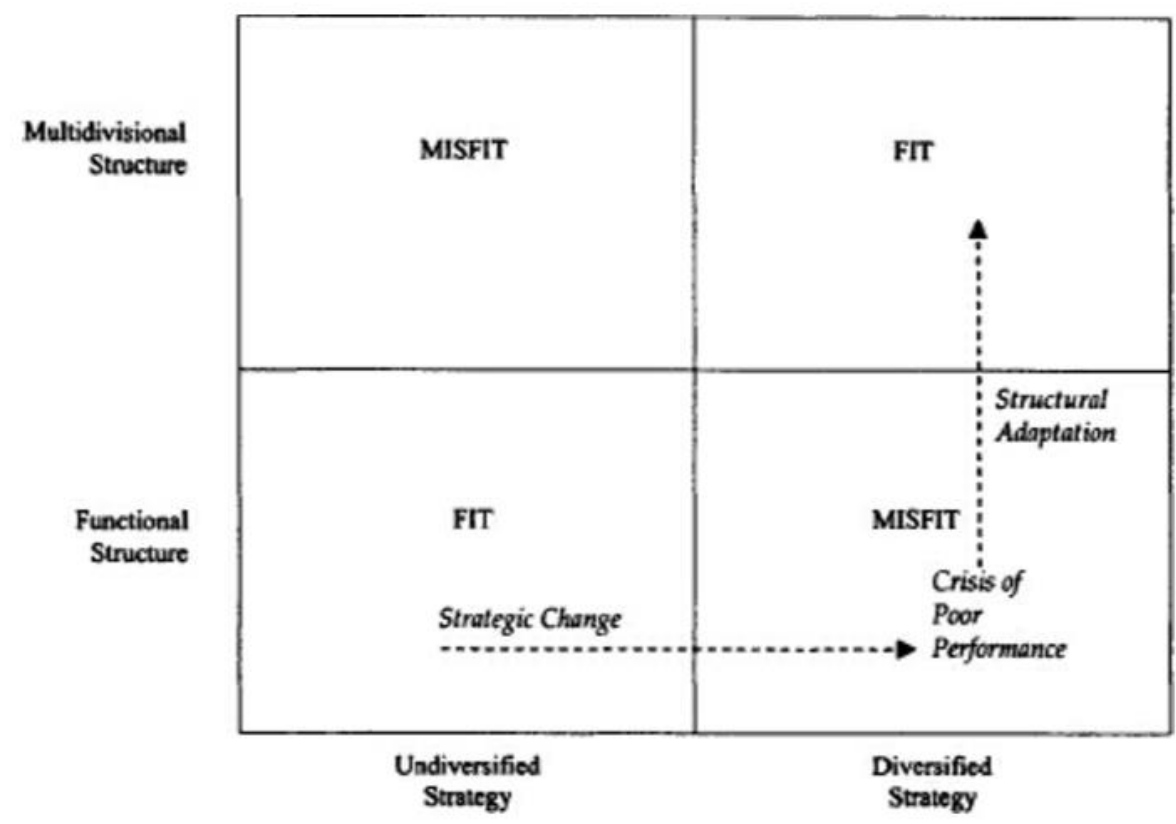

Figure 1. The contingency theory of structural adaptation to regain fit (SARFIT)

\section{Summary}

This literature review revealed that the impact of SIG on schools and districts is mixed. While some findings show promising outcomes, others reveal no increase in student achievement, incoherent plans, and program sustainability issues after the threeyear funding window closed. During the 1970s and 1980s, much research was done on school and district effectiveness to help improve outcomes for low-income and minority students. However, critics pointed to several methodological and conceptual limitations of these studies (Trujillo \& Renee, 2012). These critics found that the methodologies relied on small, skewed samples, focusing on unusually high-test scores. The studies 
frequently used convenience samples or anecdotal reports instead of systematically selected cases. What is less clear is why so many of the policies pursued by the federal government and major foundations have proven so unsuccessful in producing improvement in a greater number of schools (Steen \& Noguera, 2010).

Evidence suggests that past reforms have largely failed to improve schools in urban areas (Noguera \& Wells, 2011). The authors contend that prior efforts failed because they did not address the numerous ways that past research has shown poverty influences student academic outcomes and school performance. The author's call for a new approach to school improvement, one that draws upon the principles advocated by the Broader and Bolder Approach, and includes: evidence-based instruction, community engagement, and the strategies pursued by the Harlem Children's Zone, the Children's Aid Society, and a small number of similar efforts that attempt to mitigate the effects of poverty. Steen and Noguera (2010) contend that the reason for failure in past reforms is that they do not adequately address the multi-layered challenges students face that impact the schooling process. Trujillo and Renee (2012) support this stance in that many studies did not examine the social and political factors that affect schools, instead focusing on the technical changes and student learning.

A further examination of the intervention models found that firing and replacing school staff, as directed by various models, usually failed to achieve the intended effects. The belief regarding school turnarounds - fast, substantial changes in staffing and management can fundamentally improve persistently low-performing schools, is illogical. Such reforms result in the conditions that research have linked with persistent low performance, high turnover, instability, poor climate, inexperienced teachers, and racial 
and socioeconomic segregation (Trujillo, 2012). While SIG funds were significant for schools in financial crisis, since the recipients reverted to their original funding levels after the three-year federal stimulus, the program fails to change basic spending structures, nor correct the inequities for schools with high poverty and minority populations (Trujillo \& Renee, 2012).

In Kentucky, 10 schools were selected to participate as part of the first cohort, with each school receiving $\$ 500,000$ per year for three consecutive years. Six of the original Cohort 1 schools were from the Jefferson County Public School (JCPS) district and the other four schools were from smaller, rural districts throughout the state. After three years of SIG implementation, no JCPS school successfully exited PLA status; however, three (75\%) of the non-JCPS schools did. A 2012 annual assessment report evaluating the impact of SIG on Kentucky Cohort I schools revealed little to no variation in SIG activities being implemented by the schools even though different intervention models were selected. Furthermore, research by Dragoset et al. (2017) concluded that implementing any SIG-funded model had no significant impacts on math or reading test scores or high school graduation. Results from previous studies regarding the impact of SIGs are mixed and gaps still exist in the research. Using structural contingency theory as the theoretical lens, the purpose of this qualitative study is to determine how some Kentucky Cohort I schools were able to exit PLA status successfully within the threeyear timeframe outlined in the SIG application, while others were not successful in exiting PLA status. 


\section{CHAPTER III: METHODS}

The purpose of this qualitative study was to determine how some Kentucky Cohort I schools were able to exit PLA status successfully within the three-year timeframe outlined in the SIG application, while others were not successful in exiting PLA status. To guide this exploration, this study sought to answer four research questions:

- How were district SIG plans for the Transformation Model similar in the support of the school turnaround work?

- How were district SIG plans for the Turnaround Model similar in the support of the school turnaround work?

- How were school SIG plans for the Transformation Model similar in the support of the school turnaround work?

- How were school SIG plans for the Turnaround Model similar in the support of the school turnaround work?

In this chapter, I discuss: the research design; the selection criteria for Cohort I schools; data sources; data collection; data analysis; limitations; researcher positionality; strategies for ensuring credibility, transferability, dependability, and confirmability; and foreshadowing the presentation of findings. 


\section{Research Design}

A qualitative research methodological approach was utilized for this study. The qualitative method implemented was a document analysis. This process incorporated coding content into themes. This research study explored how some Kentucky SIG Cohort I schools were able to successfully exit PLA status, while others were not. Organization theory, specifically contingency theory, served as the underlying framework for this study. Organization theory is the study of the structure, functioning, and performance of organization and the behavior of individual and groups within it. Modern, symbolic, and postmodern are the three main perspectives that have prevailed over the past 50 years in organization theory (Hatch, 2018). The modern perspective creates theories that result in causal explanations. General systems, socio-technical systems, and contingency are the three core theories that make up the modernist organizational perspective (Hatch \& Cunliffe, 2006). As Hatch and Cunliffe (2006) summarize, general systems theory assumes that anything can be classified as a system. Through the lens of this theory, systems are made up of subsystems and can be understood fully only if all subsystems and their relationships are understood. The sociotechnical systems theory focuses on the relationship between technology and employees. This theory examines the impact technology has on productivity and motivation, and calls to attention the benefits of group work and delegation of responsibility. Contingency theory, which served as the underlying theoretical framework for this research study, is a class of the behavioral theory that claims there is no best way to organize (Hatch, 2018). Contingency theorists believe that depending on the environment in which the organization operates, there could be many different ways to 
organize successfully. Furthermore, this theory informs the theory of organizational design by providing a comprehensive framework that relates variations in organizational design to variations in the situation of the organization.

Contingency theory suggests there are both internal and external considerations and that both may influence the organizational behavior and design. For instance, all Cohort I schools have a superintendent and were funded in a similar manner according to state guidelines. However, JCPS has 21 high schools to support whereas other Cohort I districts may have as few as one high school to support. In both cases, the high schools have the same guidelines, however, the supports in which the systems work can be quite different due to different needs on the organization to be successful.

\section{Participating Districts}

In January 2010, the Kentucky legislature passed HB 176, defining Kentucky's persistently low-achieving (PLA) schools (Kentucky Schools' Improvement Grant Application, 2010). KDE applied that definition to the process outlined in the School Improvement Grants Guidance and Application document and opened up the application

process. Only Tier I, Tier II, and Tier III schools were eligible to receive SIG funding. A total of 51 school districts encompassing 108 schools applied to be part of the first cohort (See Table 2). JCPS had 26 schools qualify as PLA, which was the most of any school district. The Hardin County Schools district, which had eight school qualify, had the second largest number of PLA schools. Of the 108 identified schools, only 10 qualified as Tier I or Tier II.

As detailed by the Kentucky Schools' Improvement Grant Application (2010), the procedures in identifying Tier I schools were: Identify all Title I schools that are 
identified for improvement, corrective action, or restructuring; determine the average percent of proficient or higher in reading and mathematics on the state assessments; determine which schools failed to make AYP for three consecutive years; and determine if any high schools have a graduation rate of $60 \%$ or less for three consecutive years that are not identified in the previous steps. The process in identifying Tier II schools were: Identify all schools that have any combination of grades 7-12 and are eligible to receive Title I funds but are not served by Title I; determine the average percent of proficient or higher in reading and mathematics for all groups on the state assessment; determine which schools failed to make AYP for three consecutive years; and determine if any high schools have a graduation rate of $60 \%$ or less for three consecutive years that are not identified in the steps above. Finally, Tier III schools were selected by identifying all Title I schools that are identified for improvement, corrective action, or restructuring and are not in Tier I. Kentucky's first SIG cohort was selected for this study for two key reasons. First, all Cohort I schools received the same funding during the three-year grant. This was not the case for future cohorts. Also, all Cohort I schools received equivalent resources from the state. Again, this was not the case for future cohorts. 
Table 2. Total SIG applications cohort I

\begin{tabular}{|c|c|c|c|}
\hline District & School & Tier & Awarded Funding \\
\hline Adair County & Adair Co. MS & III & No \\
\hline Allen County & Allen Co. Intermediate & III & No \\
\hline Berea Independent & Berea Community MS & III & No \\
\hline Boone County & Hillard Collins Elem & III & No \\
\hline Bowling Green Ind. & Bowling Green MS & III & No \\
\hline Boyd County & Boyd Co. MS & III & No \\
\hline Breckinridge County & Breckinridge Co. MS & III & No \\
\hline \multirow[t]{3}{*}{ Bullitt County } & Bullitt Lick MS & III & No \\
\hline & Hebron MS & III & No \\
\hline & Zoneton MS & III & No \\
\hline Calloway County & Calloway Co. HS & III & No \\
\hline Carroll County & Carroll Co. MS & III & No \\
\hline \multirow[t]{2}{*}{ Carter County } & East Carter MS & III & No \\
\hline & Heritage Elem & III & No \\
\hline Caverna Ind. & Caverna HS & II & Yes \\
\hline \multirow[t]{4}{*}{ Christian County } & Christian Co. MS & III & No \\
\hline & Hopkinsville MS & III & No \\
\hline & Martin Luther King JR. & III & No \\
\hline & North Drive MS & III & No \\
\hline Clark County & Central Elem & III & No \\
\hline Clay County & Clay Co. MS & III & No \\
\hline Cumberland County & Cumberland Co. Elem & III & No \\
\hline Estill County & Estill Co. HS & III & No \\
\hline \multirow[t]{6}{*}{ Fayette County } & Bryan Station HS & III & No \\
\hline & Cardinal Valley Elem & III & No \\
\hline & Crawford MS & III & No \\
\hline & Leestown MS & III & No \\
\hline & Russel Cave Elem & III & No \\
\hline & Tates Creek MS & III & No \\
\hline \multirow[t]{2}{*}{ Floyd County } & Betsy Layne HS & III & No \\
\hline & South Floyd HS & III & No \\
\hline Fulton County & Fulton County HS & III & No \\
\hline Garrard County & Garrard MS & III & No \\
\hline Grayson County & Grayson Co. MS & III & No \\
\hline \multirow[t]{4}{*}{ Hardin County } & Bluegrass MS & III & No \\
\hline & Central Hardin MS & III & No \\
\hline & East Hardin MS & III & No \\
\hline & James T Alton MS & III & No \\
\hline
\end{tabular}


Table 2. (Continued)

\begin{tabular}{llll}
\hline District & School & Tier & Awarded Funding
\end{tabular}

\begin{tabular}{|c|c|c|c|}
\hline \multirow[t]{7}{*}{ Hardin County } & John Hardin HS & III & No \\
\hline & Meadow View Elem & III & No \\
\hline & North Hardin HS & III & No \\
\hline & Parkway Elem & III & No \\
\hline & Radcliff MS & III & No \\
\hline & Vine Grove Elem & III & No \\
\hline & West Hardin MS & III & No \\
\hline Henderson County & Henderson Co. South MS & III & No \\
\hline \multirow[t]{2}{*}{ Hopkins County } & Browning Springs MS & III & No \\
\hline & James Madison MS & III & No \\
\hline \multirow{2}{*}{ Jackson County } & Jackson Co. HS & III & No \\
\hline & Jackson Co. MS & III & No \\
\hline \multirow[t]{25}{*}{ Jefferson County } & Shawnee HS & $\mathrm{I}$ & Yes \\
\hline & Western MS & I & Yes \\
\hline & Frost MS & I & Yes \\
\hline & Western HS & I & Yes \\
\hline & Valley HS & I & Yes \\
\hline & Fern Creek & II & Yes \\
\hline & Thomas Jefferson MS & III & No \\
\hline & Doss HS & III & No \\
\hline & Iroquois HS & III & No \\
\hline & Knight MS & III & No \\
\hline & Stuart MS & III & No \\
\hline & Conway MS & III & No \\
\hline & Fairdale HS & III & No \\
\hline & Lassiter MS & III & No \\
\hline & Myers MS & III & No \\
\hline & Westport Trad MS & III & No \\
\hline & Moore Traditional & III & No \\
\hline & Waggener Trad HS & III & No \\
\hline & Central HS & III & No \\
\hline & Farnsley MS & III & No \\
\hline & Southern HS & III & No \\
\hline & Stonestreet Elem & III & No \\
\hline & Whitney Young Elem & III & No \\
\hline & Lincoln Elem & III & No \\
\hline & Rangeland Elem & III & No \\
\hline
\end{tabular}




$\begin{array}{llll} & \text { Coral Ridge Elem } & \text { III } & \text { No } \\ \text { Jessamine County } & \text { East Jessamine MS } & \text { III } & \text { No } \\ \text { Table 2. (Continued) } & & & \end{array}$

\begin{tabular}{llll}
\hline District & School & Tier & Awarded Funding
\end{tabular}

\begin{tabular}{|c|c|c|c|}
\hline & Rosenwald Dunbar Elem & III & No \\
\hline Knott County & Beaver Creek Elem & III & No \\
\hline \multirow[t]{4}{*}{ Knox County } & Knox Central HS & III & No \\
\hline & Knox Co. MS & III & $\mathrm{No}$ \\
\hline & Lynn Camp HS & III & No \\
\hline & West Knox Co. Elem & III & No \\
\hline Lawrence County & Lawrence Co. HS & II & Yes \\
\hline Lee County & Lee Co. MS & III & No \\
\hline Leslie County & Leslie Co. HS & II & Yes \\
\hline Livingston County & Livingston Co. MS & III & No \\
\hline \multirow[t]{2}{*}{ McCreary County } & McCreary Central HS & III & No \\
\hline & McCreary Co. MS & III & No \\
\hline Metcalfe County & Metcalfe High School & III & Yes \\
\hline Middlesboro & Middlesboro HS & III & No \\
\hline Monroe County & Monroe Co. MS & III & No \\
\hline Morgan County & Morgan Co. MS & III & No \\
\hline Newport Independent & Newport MS & III & No \\
\hline Oldham County & South Oldham MS & III & No \\
\hline Owsley County & Owsley Co. HS & III & No \\
\hline \multirow[t]{2}{*}{ Paducah Independent } & Paducah MS & III & No \\
\hline & Paducah Tilghman HS & III & No \\
\hline Robertson County & Deming School & III & No \\
\hline Russellville Ind. & R E Stevenson Elem & III & No \\
\hline Silver Grove Ind. & Silver Grove School & III & No \\
\hline \multirow[t]{2}{*}{ Taylor County } & Taylor Co. HS & III & No \\
\hline & Taylor Co. MS & III & No \\
\hline Trimble County & Trimble Co. MS & III & No \\
\hline \multirow[t]{2}{*}{ Union County } & Morganfield Elem & III & No \\
\hline & Union Co. MS & III & No \\
\hline Whitley County & Whitley Co. MS & III & No \\
\hline Wolfe County & Wolfe Co. HS & III & No \\
\hline
\end{tabular}




\section{Data Sources}

The data sources used for this analysis were all archived, publicly accessible documents. These documents included the 2010 School Leadership Assessment and 2010 District Leadership Assessment, SIG applications, Comprehensive School Improvement Plans (CSIPs), Comprehensive District Improvement Plans (CDIPs), and Kentucky’s 41 Priority Schools: What the Data Tell Us. The School Leadership Assessment and District Leadership Assessment were similar in structure, with one providing specific recommendations to the school and the other to the district. Both assessments were conducted by KDE and identify the most relevant facts and next step recommendations. In response to the assessment, the school and district were to identify action steps, the timelines established for those steps, and the person(s) responsible for overseeing the action steps, with the goal of improving student achievement as soon as practicable.

The SIG applications had specific information for the SEA and LEA to identify. The SEA was to identify eligible schools, evaluation criteria, capacity, timelines, assurances, reservation, consultation with stakeholders, and waivers. The LEA was tasked with identifying schools to be served, descriptive information, budget, assurances, and waivers.

CSIPs and CDIPs were one-year school and district plans that were to be developed in collaboration with multiple stakeholders. Through the improvement planning process, leaders focused on priority needs, funding, and closing achievement gaps around identified subgroups of students. When implemented with fidelity, the CSIP 
and CDIP were meant to cultivate an environment that promoted student growth and achievement.

Kentucky's 41 Priority Schools: What the Data Tell Us, was a report published in 2012 by KDE. The report included the 2012 Annual Evaluation Report for School Improvement Grant from the University of Kentucky, which served as the external evaluator of the SIG program. In addition to the evaluation, the document also explored: what questions were we trying to answer with the data; what did the data tell us; what were causes for celebration; and what were the opportunities for improvement? Kentucky’s 41 Priority Schools: What the Data Tell Us also examined progress and trends of PLA schools over the three-year period.

\section{Data Collection}

The documents used for this research study included the 2010 School Leadership Assessment and 2010 District Leadership Assessment, SIG applications, Kentucky’s 41 Priority Schools: What the Data Tell Us, CSIPs, and CDIPs. All documents used for this analysis were archived and a matter of public record. Requests were submitted to KDE for document access according to their guidelines.

\section{Data Analysis}

A qualitative approach was taken in that data were examined and interpreted in order to elicit meaning and develop knowledge about why some Kentucky Cohort I schools were able to successfully develop and implement systems of support for sustained school improvement, while others were not. These documents included the 2010 School Leadership Assessment and 2010 District Leadership Assessment, SIG applications, CSIPs, CDIPs, and Kentucky's 41 Priority Schools: What the Data Tell Us. 
A deductive thematic analysis (TA) method was used to analyze the documents in this study. Deductive TA views the data through a theoretical lens, so that existing theoretical concepts inform coding and theme development (Smith, 2015).

Braun and Clarke (2006) defined TA as a method for identifying, analyzing, and reporting patterns within data. Over the past decade, TA has become a widely used and recognized method in psychology, social, and health sciences. The most common approach to TA, known as Big Q, provides an accessible, systematic, and rigorous approach to coding (Smith, 2015). The Big Q approach to qualitative research emphasizes the role of the researcher and the importance of embracing researcher subjectivity, and their organic approach to coding and theme development, rather than viewing it as a problem (Smith, 2015). As further described by Smith (2015), TA is a method that allows the researcher to decide what theoretical assumptions will guide the research, what your research questions will be, what type of data you will collect, and how exactly to implement TA.

Pajares (2007) states:

In qualitative inquiry, the use of theory and of a line of inquiry depends on the nature of the investigation. In studies aiming at "grounded theory," for example, theory and theoretical tenets emerge from findings. Much qualitative inquiry, however, also aims to test or verify theory, hence in these cases the theoretical framework, as in quantitative efforts, should be identified and discussed early on. (2007, p. 1)

Contingency theory served as the theoretical framework to guide the research. Contingency theorists suggest that as some parts of the environment becomes unstable, 
the appropriate subsystem is in place and can emerge to treat the issue, thus time and energy from the entire organization do not have to be diverted from various priorities (Hanson, 1979). Through TA, themes were developed by exploring the various organizational subunits through six phases: familiarization, coding, searching for themes, reviewing themes, defining and naming themes, and writing the report, with the goal of determining why some Kentucky Cohort I schools were able to successfully exit PLA status within the three-year grant timeframe, while others were not. Figure 2 provides an example of organizational subunits in an educational setting.

Given the use of contingency theory as the guiding theoretical framework, with structural contingency as a further defining lens, coding procedures were initially theorydriven, focusing on the contingencies of environment, organizational size, and organizational strategies (Donaldson, 2001). This process included identifying individual school deficiencies and examining school and district plans to determine if they addressed the various contingencies. Furthermore, Kentucky's 41 Priority Schools: What the Data Tell Us, which was authored by KDE and includes reports from the independent program evaluator, was examined to corroborate the data. To these initial codes, any additional codes that emerged inductively through iterative coding were added to the a priori deductive codes until the final code list was composed.

In addition, member checking was used to triangulate the findings. Member checking, also known as participant or respondent validation, is a technique used for exploring the credibility of results (Birt et al., 2016). Creswell (2005) describes member checking as follows: 
Member checking is the process in which the researcher asks one or more participants in the study to check the accuracy of the account. This check involves taking the findings back to the participants and asking them, in writing or in an interview, about the accuracy of the report. You ask participants about many aspects of the study such as whether the description is complete and realistic, if the themes are accurate to include, and if the interpretations are fair and representative. (p. 252)

For this study, I supplied memos to participants with a summary of school and district findings. Specifically, I wanted see if Cohort I participants found the summary accurate or if important factors were omitted or inaccurate. Participants for inclusion were purposefully selected from each of the three regions (Central, Eastern, and Western) from a pool of educational leaders that worked directly with the turnaround work in a Cohort I school and/or district. As described by Patton (2001):

The logic and power of purposeful sampling lies in selecting in formation-rich cases for study in depth. Information-rich cases are those from which one can learn a great deal about issues of central importance to the purpose of the research.

Potential participants included principals, education recovery staff, Kentucky Department of Education staff, and district level leaders directly assigned to work with the turnaround schools in Cohort I. Participant feedback was sought on an individual basis through written communication. 


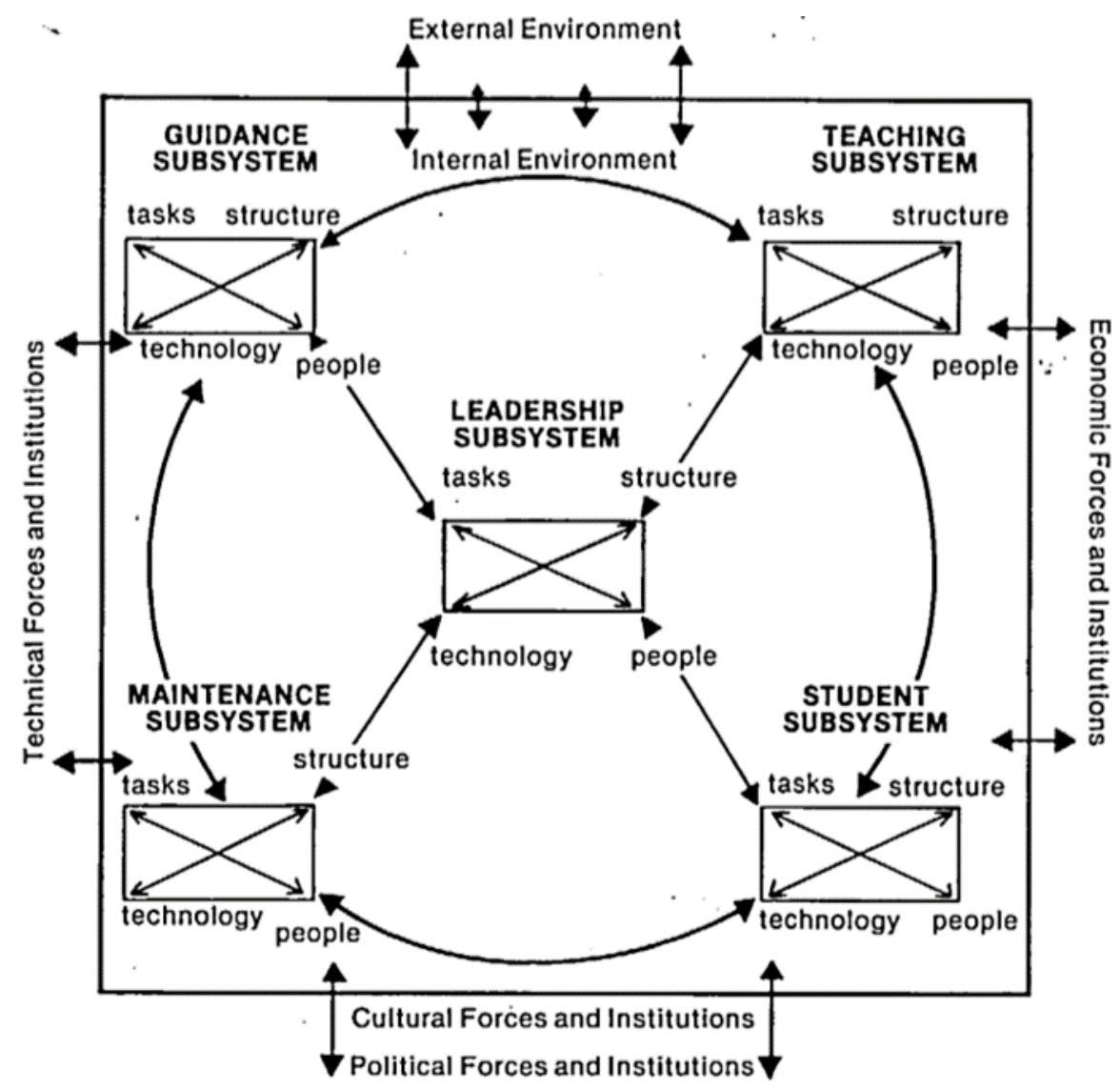

Figure 2. Hanson's (1979) Differentiated and Integrated Subsystems

\section{Limitations}

The purpose of this qualitative study was to determine how some Kentucky

Cohort I schools were able to exit PLA status successfully within a three-year timeframe while others were not. The data were specific to Kentucky's first SIG cohort, which was comprised of eight PLA high schools and two PLA middle schools. Elementary schools were not in included in Cohort I. Although limited to Kentucky's first SIG cohort, the findings may have implications for current educational leaders considering implementing school-wide reform models. 
Document analyses was conducted to determine the findings of this study. Merriam (1992) alliterates both limitations and benefits of using documents. Limitations include: the data attained from certain documents are not developed for research purposes and therefore could be incomplete from a research perspective; and it is often difficult to determine the authenticity and accuracy of documents. Member checking, through a process of written feedback, was implemented to further validate the document findings. Member checking feedback was limited for multiple reasons. First, this work took place a decade ago, resulting in a turnover of personnel at the state, district, and school levels. Furthermore, due to the current Covid-19 pandemic, there was moratorium on research activities within the JCPS district, where many of the schools in this study reside.

Although there are limitations, documents are an appropriate source of data if it contains information or insights relevant to the research questions and if it can be acquired in a reasonably practical systematic manner. Merriam (1992) notes that documents often yield better and more data than other methods. Documents may be the only means of studying particular problems, such as historical events. Furthermore, documents can be used in the same manner as data from interviews or observations, and data can produce descriptive information, which is useful for theory building.

\section{Researcher Positionality}

Merriam (1992) notes that in qualitative studies, the researcher is the primary instrument for gathering and analyzing data, which can maximize opportunities for collecting and producing meaningful information. However, this can also lead to personal bias that can impact findings. Therefore, the extent to which a researcher has certain personality characteristics for the type of research they pursue needs to be 
assessed (Merriam, 1992). Milner (2007) introduced a framework to guide researchers through this process as they conduct educational research. The steps in this framework include: researching the self, researching the self in relations to others, engaged reflection and representation, and shifting from self to system. Researching the self involves the researcher reflecting on racially and culturally grounded questions about themselves. Researching the self in relation to others leads the researcher through a process of reflecting about themselves in relation to the communities and people involved in the study. Through engaged reflection and representation, the researcher and participants collaboratively reflect on engage on what is happening in a particular research community. The final step, shifting from self to system, involves the researcher grounding their personal views into the larger context. In addition, a Structured Ethical Reflection Grid was completed and can be found in Appendix A.

\section{Strategies for Ensuring Credibility, Transferability, Dependability, and Confirmability}

Data trustworthiness has four key components, which are credibility, transferability, dependability, and confirmability. Triangulation of data was used to ensure credibility. The multiple sources of data for this research study included the 2010 School Leadership Assessment and 2010 District Leadership Assessment, SIG applications, CSIPs, CDIPs, and Kentucky’s 41 Priority Schools: What the Data Tell Us. A process of member checking was also conducted to further validate the findings. By triangulating the data, the potential problems of construct validity were addressed, due to the multiple sources of evidence providing multiple measures of the same phenomenon (Yin, 2009). Transferability generalizes study findings and attempts to apply them to 
other situations and contexts. As noted by Creswell and Creswell (2018), qualitative generalization is a term used in a limited way since the purpose of qualitative research is not to generalize findings, but instead to provide particular description and themes developed in the context of a specific site. However, rich and thick description was used in this study, which assisted to convey findings and provide potential applications to other districts and schools. In order to establish dependability, I had a fellow researcher who is familiar with SIG, review my data findings to ensure accuracy. Finally, data sources, collection methods, and analyzing techniques were detailed to ensure confirmability.

\section{Foreshadowing the Presentation of Findings in Chapter IV}

The goal of this chapter was to outline the research methods that were used to answer the four research questions. This study was designed to explore how some Kentucky Cohort I schools were able to exit PLA status successfully within the threeyear timeframe outlined in the SIG application, while others were not successful in exiting PLA status. In addition, the research design, data sources and analysis, researcher positionality, and strategies for ensuring credibility, transferability, dependability, and confirmability were discussed.

This research should benefit two primary audiences, which are practitioners and policy makers. The intended effect of this study and the findings discussed in the next section were to provide insight on the factors and actions that lead to effective and / or ineffective school turnaround. Six phases of TA were used to analyze and present the findings through the lens of the contingency theoretical framework. As described by Smith (2015), the six phases of TA were: familiarization, coding, searching for themes, 
reviewing themes, defining and naming themes, and writing the report. In Chapter IV, findings are presented based on the major themes that emerge from the 2010 School Leadership Assessment and 2010 District Leadership Assessment, SIG applications, Kentucky's 41 Priority Schools: What the Data Tell Us, CSIPs, and CDIPs documents. 


\section{CHAPTER IV: FINDINGS}

The purpose of this qualitative study was to explore how some Kentucky Cohort I schools were able to exit PLA status successfully within the three-year timeframe outlined in the SIG application, while others were not successful in exiting PLA status. To guide this exploration, this study sought to answer four research questions:

- How were district SIG plans for the Transformation Model similar in the support of the school turnaround work?

- How were district SIG plans for the Turnaround Model similar in the support of the school turnaround work?

- How were school SIG plans for the Transformation Model similar in the support of the school turnaround work?

- How were school SIG plans for the Turnaround Model similar in the support of the school turnaround work?

In this chapter, I present the findings of my study. First, I began with an exploration of my positionality as a scholar practitioner researching school turnaround. Next, I provide an overview of the findings beginning with an examination of the district and school leadership assessments. I then structured my analysis of findings around the research questions by examining the turnaround plans for the districts and schools. The chapter concludes with a summary of the findings. 
Throughout my analysis, I examined the work through the lens of the contingency theory, specifically structural contingency. As explained by Donaldson (2001), structural contingency theory contains three fundamental components that together form its foundational model. First, there is a relationship between contingency and the organizational structure. Second, contingency determines the organizational structure, because an organization that changes its contingency must change its structure. Third, there is a fit of some level of the organizational structure variable to each level of contingency. Organizational fit leads to higher performance, while misfit leads to lower performance. In the school setting, an example of an external variable could be parent pressures, while internal environment variables could be teacher autonomy or racial tension (Hanson, 1979). The contingency approach states that the effect of one variable on another depends on some third variable, therefore the effect of $\mathrm{A}$ on $\mathrm{B}$ when $\mathrm{C}$ is high is different than the effect A on B when C is low (Donald, 2001). It is important to note that contingency variables can be internal or external.

\section{An Exploration of Researcher Positionality}

Using Milner's researcher positionality framework (2007), I investigated myself as a researcher. Through this process, I sought to increase personal, professional, racial, and cultural consciousness in regards to my research study. In this section, I discuss my personal and professional identities, and how these identities shape my research topic. I begin this exercise by researching the self and then the self in relation to others.

I am a Caucasian male in my mid-forties. I have been married for 14 years and have two school-aged children. My parents, former JCPS employees, divorced when I was in elementary school, but both remained constant parental figures throughout my life. 
I am a product of the JCPS school system, having attended elementary, middle, and high school within the district. My ancestors come from German and Polish descent. Both of my parents graduated from Ohio State University, becoming the first college graduates from their families.

I grew up in a pretty typical middle class setting. Following high school, I attended Western Kentucky University (WKU) on a soccer scholarship, where I majored in economics and marketing. After graduating WKU, I began a career in sales and marketing working for a couple regional companies over a seven-year span. It was during that time that it became evident that my life's passion did not lie in the world of business. After careful reflection, I decided to follow in the path of my parents and become a practitioner in the education field.

My teaching career began as a special education teacher at Southern Leadership Academy (SLA), a former JCPS middle school. SLA was a persistently low achieving middle school that would be reconfigured and renamed Frederick Law Olmsted Academy North (OAN) during my second year of teaching. OAN became the first all-boys public middle school in the state of Kentucky. OAN enrolled approximately 700 students, of which $85 \%$ qualified for free - reduced lunch and $33 \%$ qualified for special education and / or English language (ELL) supports. In all, there were over 25 different countries represented in our ELL student groups. During my five years as a special education teacher, I worked primarily with students with behavior disorders (EBD) and mild-mental disabilities (MMD) in self-contained settings. 
After my fifth year of teaching, I was asked to become OAN's first master teacher of special populations. My focus in this role was to coach and support teachers that served our special populations. Following three years in the master teacher role, I was hired as an assistant principal and then principal a year later. In total, I served five years as principal at OAN. During that time, we restructured our instructional systems and formed professional learning communities (PLCs). We also rebranded the school, becoming a STEAM (science, technology, engineering, art, and mathematics) magnet. Through community partnerships, we were able to acquire over 1.5 million dollars in grants and donations, including partnerships with Verizon Innovative Learning and the Jimmy Johnson Foundation.

These efforts had many positive outcomes, including increased teacher retention and stakeholder (staff, students, and parents) satisfaction. We also saw gains in student achievement data; however, OAN remained a PLA school even with the gains. Although our STEAM program was technically a magnet program (meaning students could apply to attend the school), we were unable to consistently attract students from across the city. The majority of our students, similar to other Tier I JCPS schools, were assigned to OAN according to the district's student assignment plan, which relied on home addresses. This resulted in certain schools like OAN having high concentrations of students living in poverty, along with other variables that may contribute to low achievement.

It was the first-hand experiences that I had as principal in a PLA school that led me to my research topic. Despite extensive efforts and SIG funding, we were unable to make significant and sustained academic gains, as measured by KPREP. This has been a common reality for many other JCPS Tier I schools over the past decade and why I chose 
to examine Kentucky's first SIG cohort. My objective for this research is to determine the factors that resulted in no JCPS schools exiting PLA status within the three-year window, as opposed to $75 \%$ of the rural Cohort I schools successfully achieving the goal.

As a practitioner with first-hand experience as a teacher and administrator in a PLA school, I will need to negotiate and balance my own interests when analyzing the study documents in order to not predetermine the study findings based on my experiences. Through my experiences, I have formed opinions regarding why some schools were able to exit PLA status and others were not. In order to negotiate and balance my interests and opinions, I will carefully code content from the documents into themes and validate my findings through the member checking protocol.

\section{School Leadership Assessment}

In the spring of 2010, KDE conducted leadership assessments at each Cohort I school and district. The school / district leadership assessment team activities included: a review of the documents collected for the school / district portfolio and profile; classroom observations; and formal interviews and informal discussions with teachers, students, parents, community members, Family Resource / Youth Services Center staff members, central office personnel, support staff members, assistant principals, counselors, and the principal. The Standards and Indicators for School Improvement (SISI) rubric served as the primary assessment instrument used during the visits. The SISI rubric included nine standards (see Table 3) and 88 indicators. Schools received ratings on each indicator ranging from: little to no development and implementation; limited development or partial implementation; fully functioning and operational level of development and implementation; or exemplary level of development and implementation. A deficient 
rating was assigned when there was little to no development and implementation for a given indicator.

Table 3. SISI standards

\begin{tabular}{ll}
\hline Standard & Description \\
\hline Standard 1 & $\begin{array}{l}\text { The school develops and implements a curriculum that is rigorous, } \\
\text { intentional, and aligned to state and local standards. }\end{array}$ \\
Standard 2 & $\begin{array}{l}\text { The school utilizes multiple evaluation and assessment strategies to } \\
\text { continuously monitor and modify instruction to meet the student } \\
\text { needs and support proficient student work. }\end{array}$
\end{tabular}

Standard 3 The school's instructional program actively engages all students by using effective, varied, and research-based practices to improve student academic performance.

Standard $4 \quad$ The school/district functions as an effective learning community and supports a climate conducive to performance excellence.

Standard 5 The school/district works with families and community groups to remove barriers to learning in an effort to meet the intellectual, social, career, and developmental needs of students.

Standard 6

The school/district provides research-based, results driven professional development opportunities for staff and implements performance evaluation procedures in order to improve teaching and learning.

Standard $7 \quad$ School/district instructional decisions focus on support for teaching and learning, organizational direction, high performance expectations, creating a learning culture, and developing leadership capacity.

Standard 8 There is evidence that the school is organized to maximize use of all available resources to support high student and staff performance.

Standard 9

The school/district develops, implements, and evaluates a comprehensive school improvement plan that communicates a clear purpose direction and action plan focused on teaching and learning. 


\section{SISI Standard One}

An analysis of SISI Standard 1 revealed five Cohort I schools were deficient on indicator 1.1d. Curriculum at Leslie County High School, Lawrence County High School, Fern Creek High School, Western Middle School, and Valley High School lacked evidence of vertical communication with an intentional focus on key curriculum transition points within grade configurations. A common theme across the JCPS schools was that the principals did not initiate or conduct systematic discussions between schools to address key curriculum transition points. Although the district curriculum was aligned, the principals did not facilitate ongoing communication to ensure curricular gaps and overlaps were addressed. Similarly, findings at Lawrence County High School revealed that the school leadership team had not facilitated discussions between grade levels to identify key curriculum transition points. At Leslie County High School, staff members were not using a curriculum that was fully aligned to Kentucky's curriculum documents.

\section{SISI Standard Two}

Standard 2, which focused on evaluation and assessment strategies, found deficiencies on indicator 2.1f for Fern Creek High School, Western Middle School, Metcalfe County High School and Valley High School. At Western Middle School, student performance level descriptors and models of proficient work were rarely communicated to students prior to assignments and assessments. Furthermore, the principal did not ensure that the rigor of most assignments and assessments match the appropriate Depth of Knowledge for core content for assessment. Similar findings were discovered at Fern Creek High School and Valley High School, along with inconsistent use of classroom rubrics and a lack of performance expectations. 
Western High School's council did not monitor the principal's implementation of the assessment policy (2.1a, 2.1d). In addition, the principal did not formally collect and analyze classroom assessment data. The principal did use the classroom instructional framework (CIF) learning walk instrument to conduct classroom walkthroughs, but the instrument did not include a component for monitoring frequent, rigorous, or authentic assessments. Furthermore, the principal did not involve the school council and all certified staff in disaggregating state assessment data. Instead, the principal and instructional coach disaggregated achievement data and shared the results with instructional staff at a faculty meeting.

\section{SISI Standard Three}

On Standard 3, instructional programming, Leslie County High School and Western Middle School each had two deficiencies (3.1a, 3.1e). Leslie County High School's council had adopted an instructional practice policy, but the policy was not reviewed or updated to address emerging student needs. Also, while many teachers used whole-group instructional strategies for delivery of the curriculum, little consideration was given to student readiness or learning styles. Further findings showed the principal did monitor classroom instruction through walkthroughs, but did not consistently provide meaningful feedback to assist teachers in modifying instruction to meet diverse learning needs.

Findings at Western Middle School revealed that the principal did not monitor classroom practices to determine the use of effective and varied instructional strategies. Teacher-directed activities, such as lecture and whole group instruction from textbooks and worksheets, were the most common methods used to deliver instruction. 
Furthermore, the principal did not ensure that all teachers challenge their students through active student-centered, culturally responsive, instructional strategies to address the type and range of diversity of the student body.

\section{SISI Standard Four}

Leslie County High School, Metcalfe County High School, Western Middle School, and Western High School each received multiple deficiencies on Standard 4 indicators. An analysis of Leslie County High School's deficiencies (4.1d, 4.1i, 4.1k) revealed that the school council had developed and adopted committee policy, but the process did not include participation of all stakeholder role groups. Also, teaching and non-teaching staff were rarely involved in making decisions that affected the teaching and learning environment. Regarding communication, the school council had not adopted policy and the principal had not developed a comprehensive plan to guide communication with all school stakeholders. Finally, while some structures were in place to reduce the impact of socio-economic, physical, and intellectual barriers on learning, multicultural education was not intentionally recognized and celebrated.

Metcalfe County High School's report (4.1d, 4.1i, 4.1j) noted that the school council had not established, and the principal had not implemented, a systematic process to meaningfully involve all staff in decisions related to teaching and learning. While the council had adopted a student assignment policy, the policy did not ensure assignments factored student learning needs and the instructional strengths of staff. Instead, student assignments were computer generated and based on student preference forms.

Furthermore, the school council and principal had not adopted as school communications plan. 
At Western Middle School (4.1b, 4.1i), the principal did not demonstrate the commitment that all students could learn at high levels. While the CSIP reflected the collaborative development of a new vision and mission statements, which fostered the belief that all students could learn at high levels, the principal did not ensure that classroom environments and instruction support the new vision and mission statements. Classroom instruction was often interrupted and instruction was found to lack rigor. Regarding the assignment of staff, it was found that the principal did not ensure that the scheduling consideration for individual student needs occurred consistently based on student performance. Similar to the findings at Leslie High School, the principal did not have a written formal communication plan to provide information to all stakeholders. Findings at Western High School (4.1d, 4.1i) noted that teaching and non-teaching staff had limited participation in the development of the CSIP. The instructional leadership team did meet monthly, but the other subcommittees had yet to be established. In addition, the principal had not developed a comprehensive communications plan that ensures the dissemination of information with all stakeholders.

Contrary to the deficiency ratings, a further analysis of Standard 4 revealed fully implemented indicators for Caverna High School (4.1a), Metcalfe County High School (4.1j), Fern Creek High School (4.1a, 4.1i, 4.1j), and Western High School (4.1a). At all four schools, leadership was found to support a safe, orderly, and equitable learning environment. Fern Creek High School's leadership had a communication plan that incorporated multiple means of communicating with parents. In addition, the principal expected teachers to make one positive phone contact each day. The principal and school council regularly recognized and celebrated student achievement through formal and 
informal means. At Metcalfe County High School, there was evidence that student achievement was highly valued and publicly celebrated.

\section{SISI Standard Five}

Lawrence County High School and Leslie County High School received deficiencies in Standard 5. Leslie County High School (5.1a) lacked procedures for resolving parent issues and complaints, while Lawrence County High School's (5.1e) student record system was found to be deficient. A total of seven Cohort I schools were identified as having a fully implemented student record system (5.1e). Shawnee High School had the most fully implemented indicators (5.1a, 5.1d, 5.1e) in Standard 5. It was noted that the Home School Coordinator and staff members from the Youth Service Center, with active support of the principal, had collaborated to establish multiple committees and organizations that included parents, community members, and representatives from community agencies in order to provide programs and services for all students. The school also had active programs in place to re-engage students who had chronic attendance problems.

\section{SISI Standard Six}

An examination of Standard 6, school and district professional development and performance evaluation systems, found multiple deficiencies for Caverna High School (6.1b, 6.1e, 6.2b, 6.2f), Metcalfe County High School (6.1b, 6.2c, 6.2f, 6.2b), and Leslie County High School (6.1c, 6.1f). Caverna High School's council had adopted a professional development policy; however, the principal had not complied with the guidelines in planning for professional training activities. Furthermore, the principal did not ensure professional development facilitated a process for continuous growth. 
Regarding personnel evaluations, the principal did not consistently monitor or provide timely feedback on individual progress on professional growth targets following the evaluation period. At Metcalfe County High School, the principal had not developed or implemented an intentional plan to build instructional capacity through job-embedded professional development. Also, the principal had not identified professional development priorities that supported the school improvement plan, individual growth plans, or professional evaluations of staff. Regarding program development, the principal was found to rarely analyze the impact of past and current professional development on staff behavior and student achievement. The findings for Leslie County High School revealed the principal had not established a systematic process to connect professional development activities with the school's learning goals, individual growth plans, or personnel evaluations. Also, the principal did not require teachers to develop 2009 2010 individual professional growth plans until February of 2010. The late development of the plans restricted meaningful feedback on their implementation.

Western Middle School had the most fully implemented indicators within Standard $6(6.1 \mathrm{~b}, 6.1 \mathrm{e}, 6.2 \mathrm{a}, 6.2 \mathrm{~b}, 6.2 \mathrm{~d})$. The principal collaborated with the administrative team and the ILT to establish professional development priorities for the school. An emphasis had been placed on providing job-embedded professional development. The principal initiated a plan where all teams incorporated 30 minutes of job-embedded professional development activities into team common planning time on Monday and Tuesday of each week. These activities were facilitated by the instructional coach, highly skilled educators, and district resource personnel. 


\section{SISI Standard Seven}

Caverna High School (7.1g), Fern Creek High School (7.1i, 7.1j), Metcalfe County High School (7.1a, 7.1b, 7.1c, 7.1g, 7.1k), and Western High School (7.1j, 7.1k) each received deficiencies on indicators within Standard 7. At Caverna High School, the principal did not engage the school community in using the comprehensive planning process as an ongoing and systematic way of driving school improvement. In addition, the principal and school council did not systematically monitor the implementation of strategies in the comprehensive plan for measurable impact on student achievement and school improvement. At Fern Creek High School, the principal did not ensure all required and best practice council policies be developed, approved, implemented, and monitored. The school council rarely focused on developing and revising policies or engaging in discussions regarding improving student achievement. Metcalfe High School's principal and school council used limited data to inform programmatic and academic decisions. Also, data was not frequently and consistently analyzed in order to assess or modify the school's curriculum, assessment, and instructional programs. It was also found that while the principal did have a professional growth plan that focused on improving leadership skills, the principal did not effectively address the goals within the plan. Western High School's report noted the school council did not have an intentional focus on improving student academic performance. Instead, meetings focused on operational items, such as hiring, management, and organizational issues like dress code

and graduation planning. Furthermore, the principal's focus over the previous two years had been on establishing and monitoring behavioral expectations. The staff seldom engaged in discussions regarding what it took for all students to reach proficiency or 
higher in all content areas. It was noted that visitors familiar with "how it was" expressed wonder at the difference in student behavior since the arrival of the principal; however, few visitors indicated the principal had engaged them in conversations about student academic achievement.

Western Middle School (7.1a, 7.1b, 7.1c, 7.1f), Shawnee High School (7.1b, 7.1c, 7.1g), and Fern Creek High School (7.1c, 7.1e, 7.1h) all had fully implemented indicators within Standard 7. At Western Middle School, district leadership had directed the principal and priority manager to establish a design team for the purpose of developing the plans for transition of Western Middle School to a Visual and Performing Arts Magnet Middle School. The findings for Western Middle School also highlighted: the principal's collaboration with the instructional leadership team to regularly review, disaggregate, and analyze student performance data; the development and implementation of individualized professional growth plans; and common planning time for teachers.

At Shawnee High School, the principal led efforts to use the analysis of a variety of data to guide decisions within the school, including student performance data, teacher grade distributions, attendance data, discipline data, and student demographic data. The principal worked to build the capacity of staff and school council members to understand how to effectively use the data for decision making. In addition, administrative professional growth plans focused on enhancing the leadership skills required to be effective instructional leaders. As part of this focus, assistant principals were empowered to lead their respective academies. The findings also highlighted how resources were 
allocated. The report noted that the principal "thinks and plans holistically" to prioritize the allocation of resources to maximize their impact on performance.

Comprehensive individual professional growth plans were noted as an area of strength at Fern Creek High School as well. The principal, under the mentorship of the district assistant superintendent, had focused extensively on identifying and addressing areas of growth in his leadership development. Part of this development process was participating in the Vanderbilt Assessment of Leadership in Education Project. It was also noted that the principal and leadership team provided teachers with curricular resources and ensured that teachers had access to district pacing guides, Kentucky's combined curriculum documents, and sample assessments and implementation guides. Fern Creek High School was also found to have a safe and effective learning environment.

\section{SISI Standard Eight}

Fern Creek High School and Metcalfe County High School were the only two Cohort I schools with more than one deficient indicator in Standard 8. In total, Fern Creek High School had seven deficiencies within the standard (8.1a, 8.1c, 8.1d, 8.2a, 8.2b, 8.2c, 8.2d). Findings revealed that the principal did not recognize the school council as playing a major role in the leadership of the school. Also, school council policies were out of date or nonexistent in some areas. For example, the school council had adopted policy for the assignment of instructional staff, but the policy was out of date and not revised to reflect the new $3 \times 5$ trimester schedule. The school council had not adopted policy to protect instructional time, but the principal had implemented some procedures to facilitate efficient operation of the school. In regards to funding, the 
principal established an informal group of volunteers to serve as a budget committee, but the committee did not conduct formal needs assessments to ensure purchase requests were connected to student learning goals. Metcalfe County High School's report identified five deficiencies on Standard 8 (8.1a, 8.2a, 8.2b, 8.2c, 8.2d). The principal and school council had not reviewed and revised school council by-laws to ensure that the governing structure of the school was meeting the changing needs of the learning community. Also, the principal had not implemented clear budgeting procedures to ensure that all decisions about resource allocations were fair and equitable. In addition, the principal did not ensure allocations of instructional funds, professional development funds, and other resources were connected to the school plan or individual professional growth goals.

Valley High School had three fully implemented indicators in Standard 8 (8.2a, 8.2b, 8.2c). Contrary to the findings at Fern Creek High School, Valley High School's council policy required an ad hoc Budget Committee to develop a budget with resources allocated in adherence with the CSIP goals. The policy also mandated that the committee present the proposed budget to the school council for approval.

\section{SISI Standard Nine}

An analysis of Standard 9 revealed multiple deficiencies for Leslie County High

School, Metcalfe County High School, and Caverna High School. At Leslie County High School (9.1a, 9.2a, 9.4a, 9.5, 9.6a, 9.6b, 9.6c, 9.6d), the principal had collaborated with the Assistance and Support School Improvement Success Team (ASSIST) along with some certified staff on the development of the school's mission statement, but the school council was not involved in the planning. The monthly ASSIST plan was adopted as the 
school's CSIP, but it did not meet the requirements of the state-required improvement plan. The ASSIST plan did not include improvement goals that were clear and measurable. In addition, benchmarks were not established to measure progress toward achieving the improvement goals. It was noted that during monthly ASSIST meetings, members discussed the progress of activities within the plan, but most discussions centered around the implementation of activities rather than the evaluation of the impact on student achievement. Also, the principal had not led a process to collaboratively develop a CSIP in order to sustain a commitment to continuous school improvement. However, it was noted that the principal had begun to challenge the status quo by establishing professional learning communities and creating an administrative team.

Metcalfe County High School (9.1a, 9.2a, 9.4a, 9.5c, 9.6a, 9.6b, 9.6c, 9.6d) had a total of eight deficiencies in Standard 9. The vision, beliefs, and goals of the school had not been developed. School planning documents revealed the use of little or no data when formulating the plans. In addition, the principal and school council had not ensured the school improvement plan included a method of revaluation the plan's effectiveness or for monitoring if the activities were being implemented as developed. Lastly, the principal and school council had not sustained a commitment to the continuous improvement in the targeted areas of reading and math as required by NCLB benchmarks.

Caverna High School (9.5c, 9.6b, 9.6c) was found deficient on three indicators in Standard 9. The analysis found that Caverna High School's CSIP was not developed to the degree with which action components for improving instructional practices could be monitored to gauge the impact on classroom instruction and student achievement. The 
principal did not collect data at frequent intervals, and there were no benchmarks or comparisons of levels of student performance to evaluate the degree to which the goals and objectives for the school improvement were being achieved throughout the school year. Overall, there was no protocol in place to evaluate the ongoing impact of the CSIP on classroom practices and student performance.

Western Middle School (9.1a, 9.4a, 9.5a) was the only Cohort I school to have fully implemented indicators in Standard 9. Their mission statement reflected the school's new design that was scheduled to be phased in beginning the fall of 2010 . The design team was composed of faculty members and community members. Students were also given opportunities for input. Regarding student achievement, the principal assigned four committees (Reading, Math, School Culture, and Academic Achievement) the task of determining existing strengths and limitations of the instructional and organizational effectiveness of the school. In addition, the principal worked with the four component committees to assign benchmarks for each goal based on data generated from the district's proficiency calculator.

In summary, all Cohort I schools received at least one deficiency, with the exception of Shawnee High School, which had zero. Leslie County High School (19) and Metcalfe County High School (26) had the most deficiencies. Table 4 provides a summary of deficiencies by SISI standard. 
Table 4. Number of Deficiencies per SISI Standard - School Level

\begin{tabular}{|c|c|c|c|c|c|c|c|c|c|c|}
\hline \multirow[t]{2}{*}{ School } & \multicolumn{10}{|c|}{ SISI Standards } \\
\hline & 1 & 2 & 3 & 4 & 5 & 6 & 7 & 8 & 9 & Total \\
\hline$\overline{\text { Caverna H.S. }}$ & 0 & 1 & 1 & 0 & 0 & 4 & $\overline{1}$ & 1 & 3 & 11 \\
\hline Fern Creek & 1 & 1 & 0 & 1 & 0 & 0 & 2 & 7 & 1 & 13 \\
\hline Frost M.S. & 0 & 0 & 0 & 0 & 0 & 1 & 0 & 0 & 0 & 1 \\
\hline Lawrence H.S.1 & & 0 & 0 & 0 & 1 & 1 & 0 & 0 & 0 & 3 \\
\hline Leslie H.S. & 1 & 1 & 2 & 3 & 1 & 2 & 0 & 1 & 8 & 19 \\
\hline Metcalfe H.S. & 0 & 1 & 0 & 3 & 0 & 4 & 5 & 5 & 8 & 26 \\
\hline Shawnee H.S. & & 0 & 0 & 0 & 0 & 0 & 0 & 0 & 0 & 0 \\
\hline Valley H.S. & 1 & 1 & 0 & 0 & 0 & 0 & 0 & 0 & 0 & 2 \\
\hline Western H.S. & 0 & 2 & 0 & 2 & 0 & 0 & 2 & 0 & 0 & 6 \\
\hline Western M.S. 1 & 1 & 1 & 2 & 3 & 0 & 0 & 0 & 0 & 0 & 7 \\
\hline
\end{tabular}

\section{District Leadership Assessment SISI Standard One}

At the district level, Caverna (1.1a, 1.1f), Leslie (1.1b, 1.1c, 1.1d), and Lawrence (1.1d) had deficiencies on indicators in Standard 1. Caverna's district leadership did not ensure that curriculum documents in all schools were based on and aligned with the content standards. Also, while the board of education had adopted a curriculum policy, district leadership had not ensured the procedures were being followed. At Leslie, district leadership did not regularly initiate or facilitate discussions between the high school and the middle school (even though both were located upstairs in the same building) to ensure that curriculum standards be properly sequenced between grade level 
and content areas. In addition, district leadership did not develop a process for eliminating gaps and overlaps in the curriculum. At both Leslie and Lawrence, district leadership had not consistently facilitated discussions to examine key transition points within grade configurations, and there was no systematic plan to sustain efforts in identifying issues with transition points to address curricular issues.

JCPS (1.1a, 1.1e) and Metcalfe (1.1a, 1.1e, 1.1g) were the only districts with multiple fully implemented indicators in Standard 1. Findings from both reports revealed district leadership facilitated the development of a district-wide curriculum aligned with the Program of Studies for Kentucky Schools, Academic Expectations, and Kentucky Core Content for Assessment Version 4.1. It was also noted that district leadership reviewed school curricula and collaborated with community partners, in order to provide students with learning experiences that exposed them to a variety of career options and post-secondary education opportunities.

\section{SISI Standard Two}

JCPS (2.1c, 2.1f), Caverna (2.1a, 2.1b, 2.1c, 2.1f, 2.1h), Leslie (2.1a, 2.1b, 2.1c, 2.1d, 2.1e, 2.1f, 2.1h), Lawrence (2.1a, 2.1h), and Metcalfe (2.1f) all had deficiencies in the area of classroom assessment and evaluation. JCPS and Metcalfe's district leadership did not ensure that Student Level Performance Descriptors were clearly communicated to students. Efforts by district and school leadership to monitor professional practice of teachers did not include a process to measure whether students were able to articulate the characteristics of proficiency. Further findings revealed that although the district and school leadership conducted learning walks, they were not intentionally used to determine if teachers had communicated the characteristics of proficient work to students. 
Caverna's district leadership conducted and completed a book study on instructional rounds, but the practice had not been fully implemented. It was also noted that district leadership rarely collaborated with teachers to design authentic assessment tasks or monitor schools to determine if students could articulate the academic expectations in each class. In addition, professional development had not been provided for teachers to acquire the skills needed to effectively analyze student work.

Findings from Leslie revealed that district leadership did not regularly interview high school students to determine if they knew what was required to be proficient in all content areas. While district leadership provided the high school with some progress monitoring resources, they did not consistently monitor how the programs were used to generate student achievement data that could be used to identify curricular gaps. Furthermore, district leadership did not have a systematic process for monitoring the design and use of multiple types of classroom assessments.

Lawrence's district leadership did provide limited support to classroom teachers in implementing rigorous, authentic assessments, including informal feedback to teachers regarding oral questions strategies and formative assessments. However, the district walkthrough instrument did not formally address summative assessment or Depth of Knowledge questions to be used with assessing core content. The district leadership did communicate expectations that teachers analyze student work to inform instructional practices, but there was not a formal protocol to guide teachers in analyzing student work.

\section{SISI Standard Three}

Caverna $(3.1 \mathrm{~g}, 3.1 \mathrm{~h})$ and Leslie $(3.1 \mathrm{a}, 3.1 \mathrm{c}, 3.1 \mathrm{~g})$ were each found to have multiple deficiencies in Standard 3. Caverna's district leadership did not provide 
direction or support to school leadership for the purpose of collaboratively analyzing student. Also, the leadership did not regularly review school council policies and teacher practices. Findings from Leslie revealed that the policies adopted by the board of education regarding instruction did not require teachers use effective and varied instructional strategies. Furthermore, while district and school leadership occasionally conducted walkthroughs, little specific feedback was given to teachers.

\section{SISI Standard Four}

An examination of Standard 4 found multiple deficiencies for Leslie (4.1d, 4.1e, 4.1f, 4.1g, 4.1i). District leadership did not demonstrate the need to include a variety of stakeholders in decision making. While district leadership was aware of the importance of all staff recognizing and accepting their professional role in student success and failure, they failed to communicate or model the expectation. Also, the board of education did not adopt a policy to address student progress reports and district leadership did not develop procedures for a comprehensive communications plan, even though this was identified as a deficiency in the October 2006 district scholastic audit report.

Caverna (4.1a, 4.1g, 4.1h, 4.1i, 4.1k) and Lawrence (4.1i, 4.1j) had fully implemented indicators in Standard 4. Both leadership teams ensured effective communication with stakeholder. In addition, Caverna's board of education had adopted safety, emergency, behavior, and discipline policies and district leadership had implemented the procedures to provide students a safe and orderly learning environment. Also, student progress reports were sent home as required by district policy. Caverna's 
district leadership actively participated in the community and verbally communicated confidence in their students' ability to achieve.

\section{SISI Standard Five}

Leslie $(5.1 \mathrm{~b}, 5.1 \mathrm{c}, 5.1 \mathrm{~d})$ was the only Cohort I district to receive deficiencies in Standard 5. District leadership had not developed procedures to ensure all students had access to needed services provided by the school. It was also noted that while the Leslie High School Youth Services Center collaborated with community agencies to implement programs to reduce barriers to learning, the district's partnership was minimal.

\section{SISI Standard Six}

Caverna $(6.1 \mathrm{~b}, 6.2 \mathrm{~d}, 6.2 \mathrm{e})$ received multiple deficiencies on indicators in Standard 6. Conversely, JCPS $(6.2 \mathrm{a}, 6.2 \mathrm{~b}, 6.2 \mathrm{e})$ was the only district to be recognized with multiple fully implemented indicators. At Caverna, professional development planning occurred at the school level, but there was no evidence of formal collaboration with district leaderships. The professional development activities lacked continuity from year to year and seldom scaffolded on previous training experiences. Also, the Caverna Independent District Certified Personnel Evaluation Plan, adopted in 2007, had yet to be approved by KDE.

The JCPS board of education had adopted a Supervision and Evaluation of Teachers policy and district leadership implemented procedures for the evaluation of all certified and classified staff. Furthermore, the board of education had adopted the Budget Allocation policy, which established procedures meant to ensure the equitable allocation of appropriate resources among all schools. Also, JCPS assistant superintendents reviewed the school improvement plans of their PLA schools to ensure 
that professional development offerings had the funding needed to significantly impact the identified needs of students.

\section{SISI Standard Seven}

A review of Standard 7 revealed five deficient indicators for Leslie (7.1a, 7.1b, 7.1d, 7.1e, 7.1k). The district had multiple versions of the mission and vision statements posted within the central office facility and on their website. District leadership made little effort to communicate and sustain the vision and mission of the district. Regarding the use of data, district leadership provided over 100 questions to guide data disaggregation at the school level, but they did not use individual school disaggregated data to intentionally inform the district's improvement planning process. Lastly, district leadership provided little assistance to the high school council in their efforts to adopt a policy focused on the protection of instructional time.

JCPS (7.1b, 7.1i), Metcalfe (7.1c, 7.1h, 7.1k), and Lawrence (7.1a, 7.1b, 7.1d, 7.1e) all had multiple fully implemented indicators in Standard 7. The JCPS board of education, superintendent, and district leadership collaborated with school leadership to regularly analyze data. Also, the superintendent had assigned mentors to assist school councils in PLA schools.

Metcalfe's superintendent collaborated with district-level administrators and school principals to develop individualized professional growth plans that were based on the needs identified during the evaluation process. Furthermore, the board of education adopted several policies to ensure a safe environment for students and staff. There was also evidence of the principal demonstrating leadership skills in the areas of academic 
performance, learning environment, and efficiency. It was noted that the superintendent made many difficult decisions, anchored in advancing student achievement.

Lawrence had four fully implemented indicators in Standard 7, the most of any Cohort I school. The board of education had adopted policy that required district and school leadership to regularly provide updates on students' academic progress. Furthermore, district leadership used the Measures of Academic Progress (MAP) assessment program as its primary tool to gather continuous data relative to student progress over time. In $2007-2008$, district leadership initiated a revision of the district's curriculum, during which various grade level teams took part in the curricular revisions.

\section{SISI Standard Eight}

Caverna (8.1d, 8.1e) and Leslie (8.1a, 8.1e, 8.1f) each had multiple deficiencies on indicators in Standard 8. Caverna's district leadership considered the efficient use of instructional time as the responsibility of school leadership, not the district. In addition, Caverna's district leadership did not promote or facilitate team planning at all schools. It was found that the district leadership provided limited training and resources to assist high school leadership in creating and effectively managing the efficient use of collaborative planning time.

At Leslie, district leadership did not have a systematic process to evaluate or monitor the use of resources in the school. Also, district support certified staff (curriculum coach, technology integration specialist, and school resource officer) assigned to the high school were not monitored by district leaders. The district leadership did not assist school leadership at the high school in developing a master schedule that would have provided common planning for all content area teachers. 
Both Lawrence (8.2a, 8.2b, 8.2c, 8.2d) and Metcalfe (8.1b, 8.1f, 8.2a) had multiple fully implemented indicators in Standard 8. Lawrence's board of education had adopted a Budget Planning and Adoption Policy to guide the allocations of all council funds. The budgeting process was clearly defined and monitored by the district finance officer. The superintendent and local board established priorities for allocating discretionary funds for additional school staff to assist schools in meeting the individual learning needs of struggling students. The superintendent, finance officer, and program coordinator ensured categorical funds were appropriately allocated based on the school needs assessments, student achievement data, and school improvement plans. Metcalfe's district leadership collaborated with school leadership to determine specific needs related to staffing and master schedule. The district provided a clearly defined process to provide equitable and consistent use of fiscal resources.

\section{SISI Standard Nine}

An examination of Standard 9 found multiple deficiencies for Leslie, Caverna, and Metcalfe. Leslie had the most deficiencies of any of the districts (9.1a, 9.2a, 9.2b, 9.3b, 9.3c, 9.4a, 9.4b, 9.5a 9.5b, 9.5c, 9.5d, 9.6a, 9.6b, 9.6c, 9.6d). A deficiency noted in the 2006 Leslie Scholastic Audit stated the need for involving all stakeholders in developing beliefs statements that should be the foundation of school improvement. As of 2010, the beliefs statements had not been developed and the process of revising previously adopted vision and mission statements had just begun. Findings showed that the district leadership collected limited student achievement data from state assessments to use in developing goals and action steps. While state assessment data was analyzed, additional data sources were not used to determine root causes of student failure. 
Overall, goals for student learning were not clearly stated or defined in measurable terms. The district leadership did not intentionally collaborate with the high school leadership for the purpose of assessing instructional and organizational strengths and weaknesses. Most goals in the CDIP were not stated in clear and concise terms and focused solely on increasing the Annual Measurable Objectives as identified on NCLB reports. The CDIP placed some emphasis on the elimination of achievement gaps, but all goals and activities were not congruent with objectives identified in the high school's ASSIST plan. Lastly, district leadership had not designed a process to measure and evaluate the effectiveness of strategies and goals of the CDIP.

Caverna's $(9.4 b, 9.5 a, 9.5 b, 9.6 b, 9.6 c)$ district leadership did not identify specific district goals to enhance the leadership, instructional, and organizational capacities of the district or schools in the CDIP. Also, district leadership did not ensure that schools identify all achievement gaps within the student population. Timelines and resources needed for implementation of CDIP goals were not identified. District leadership did not ensure the goals and objectives of the CDIP and Caverna High School's improvement plan be accompanied by benchmarks for regular monitoring. Similar to the findings for Leslie, district leadership did not ensure that systematic processes be in place for monitoring instructional practices and student achievement.

Metcalfe's (9.1a, 9.3a, 9.3b, 9.3c, 9.4b, 9.5a, 9.5d) district leadership goals were not articulated in the district improvement plan. The Board of Education adopted three goals designed to build instructional capacity and advance student achievement at the November 16, 2009 meeting; however, district leadership did not assist the high school leadership team or school council in developing clear, concise and measurable goals to 
significantly impact student achievement. The action components of the district improvement plan did not have an intentional focus on closing achievement gaps. Each school developed a gap reduction plan in January 2010; however, the goals from these plans were not integrated into the district improvement plan. The strategies included in the district improvement plan did not intentionally align to those in the high school improvement plan. Although a few strategies included in the district improvement plan were research-based, they were not intentionally selected to impact achievement gaps and support district or school needs. The action components (academic performance, culture, community education, efficiency, and wellness) in the district improvement plan were not strategically aligned with the mission and vision statements, goals, and beliefs of the district. The strategies of the district improvement plan lacked the specificity necessary to significantly and positively impact student learning or improve instructional and organizational practices.

Findings from Lawrence revealed four fully implemented indicators (9.1a, 9.2a, 9.6a, 9.6d). The district's mission statement had been in existence many years. A district committee established in August 2010 consisted of multiple stakeholders, including students, parents, community representatives, board members, teachers, principals, student support personnel, and central office administrators. District goals were developed through a collaborative process and supported by the activities found in the district improvement plan. The district had timelines to evaluate the improvement plan through the use of the implementation and impact checks twice a year. In addition, the superintendent provided direction and support for implementation of district and school plans. 
JCPS had four fully implemented indicators (9.1a, 9.2b, 9.5a, 9.5d) and two exemplary indicators $(9.2 \mathrm{a}, 9.4 \mathrm{a})$ in Standard 9. It was noted that district leadership created an extensive data management system which generated student achievement and performance data for developing district and school improvement plans. Data from the Interim Performance Report, Core Content Assessments, student demographic reports, and comprehensive school surveys were reviewed to determine strengths and limitations in instructional areas. The superintendent led the leadership team in a collaborative process to develop core beliefs that guided the work of the district. In 2008, the leadership team collaborated and developed a theory of action, which included long and short-term district goals. The district needs assessment process consisted of a review and analysis of multiple sources of data. Findings from the needs' assessment were used to develop and define goals, priorities, and action steps for inclusion in the district improvement plan. Many action components of district and school plans were designed to close achievement gaps for targeted groups of students. The district goals and objectives addressed by the action components were broad enough to encompass school goals and objectives.

In summary, all Cohort I districts were found to be deficient in at least one standard. Leslie County (45) had the most deficiencies, while JCPS (2) had the least. Table 5 provides a summary of the district deficiencies by SISI standard. 
Table 5. Number of Deficiencies per SISI Standard - District Level

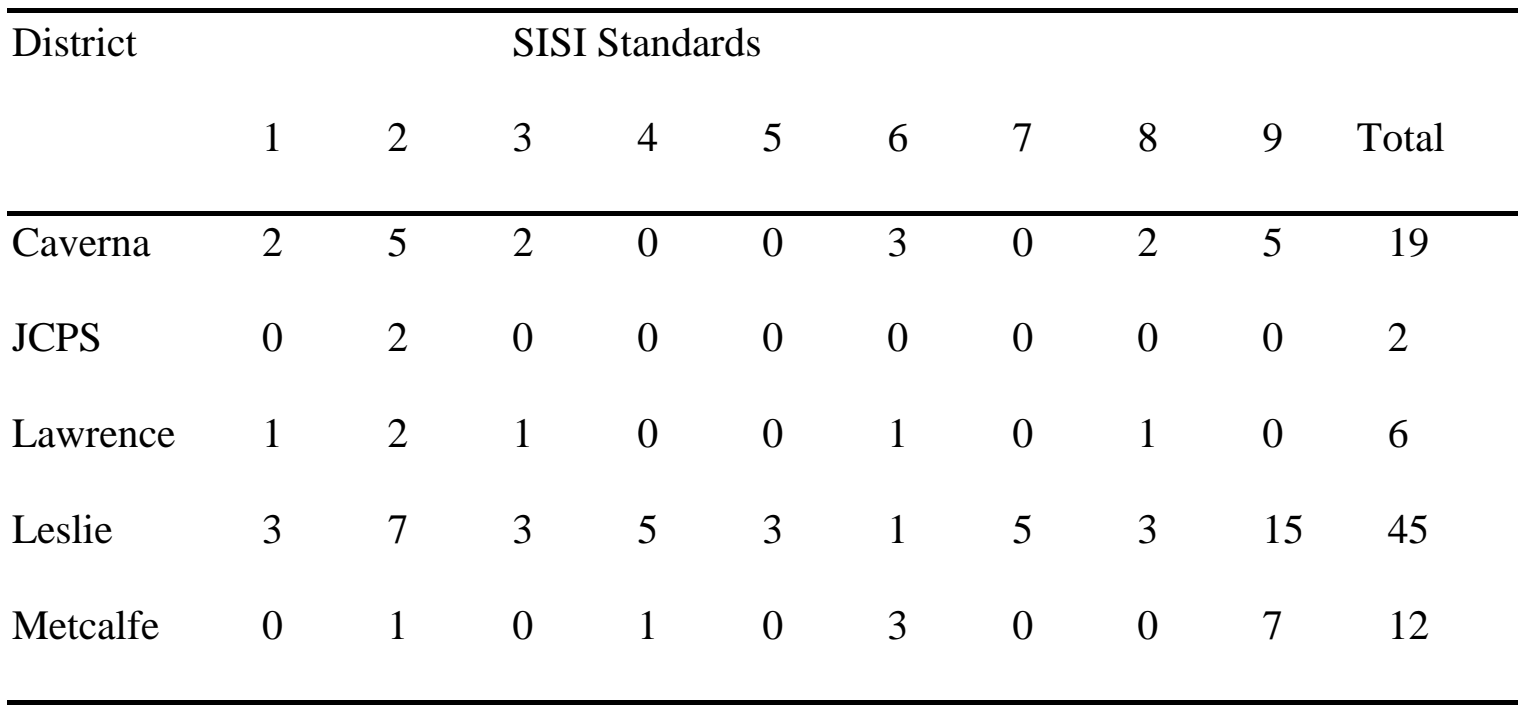

\section{School SIG Plans}

In this section, I examined how the school SIG plans for the Turnaround model were similar in support of the school turnaround work. This process included an analysis of the school leadership structures, instructional planning and support systems, and how schools used SIG funds to impact student achievement.

\section{Turnaround Model}

At all JCPS Cohort I schools, SIG funds were used to bolster staffing, particularly in the areas of reading and math. Fern Creek High School allotted \$299,306 on staff salaries during FY2010, the most of any Cohort I school. With this funding, Fern Creek High School added two additional math teachers, three reading teachers, and a math interventionist. Frost Middle School also allotted heavily in staff, adding an additional reading teacher, two math teachers, reading and math interventionists, and an RTI teacher. Conversely, Shawnee High School allotted \$126,358 to staffing during FY2010, which was the least of any JCPS Cohort I school. With that funding, Shawnee High 
School added a School Administrative Manager (SAM) to meet the managerial needs of the school and an instructional coordinator to oversee the instructional program implementation. With the exception of Western High School, all Cohort I JCPS schools invested in educational consultants, with Fern Creek High School $(\$ 60,000)$ and Shawnee High School $(\$ 72,000)$ allotting the most funds to this endeavor. Fern Creek High School also invested the most in the areas of professional development and tutoring, allotting $\$ 50,000$. All schools, with the exception of Western High School and Fern Creek High School, used SIG funds to improve instructional technology. Valley High School invested $\$ 210,000$ in this area, outspending the next highest school by more than $\$ 140,000$. Fern Creek High School earmarked $\$ 50,000$ for permanent substitute teachers to work one-on-one with students and Shawnee High School invested \$30,000 in new library books.

An examination of instructional systems showed some commonalities and differences between the JCPS Cohort I schools. Shawnee High School created The Urban Teacher Institute (UTI) to accelerate teaching and learning. The institute was designed to address each of the first four deficiencies related to teaching and learning found in the leadership assessment. UTI was an ongoing and responsive mechanism that provided professional development, in-class support, critical feedback, and paths for personal and organizational growth. In addition, Shawnee also formed a partnership with the University of Louisville ( $\mathrm{U}$ of $\mathrm{L}$ ) that included the schools of Social Work, College of Engineering, Office of Community Development, College of Medicine, and dental and nursing programs. As needs arose, the $\mathrm{U}$ of $\mathrm{L}$ liaison working directly with the teachers to identify those students who needed access to university resources. The College of 
Education and Human development also worked to recruit and retain high quality staff at Shawnee High School. U of L sponsored a National Board cohort group and provided a mentor for these teachers.

Western High School also put an emphasis on teacher development and retention with the creation of the Early College Initiative. Through the Early College Initiative, teachers were offered the opportunity for tuition reimbursement as they took Master's level courses in their content area. This was an opportunity for professional development and incentive to continue working at Western High School. It was theorized that this heightened education in math, reading, and other content areas would ultimately increase rigor and knowledge of the respective content areas. To assist students transitioning to ninth grade, Western High School created the Freshman Academy. The Freshman Academy was designed to provide more personal guidance, attention and supervision as students made their transition from middle to high school.

Valley High School developed three "Big Rocks" as part of their improvement plan. These focus areas were ritual and routines, improving instruction, and developing a culture of collaboration. Valley High School's ILT became the vehicle through which plans were developed and monitored. The ILT led the development, implementation, and monitoring of curriculum, assessment, and instruction in the school. In addition, PLCs were formed. Department heads, with assistance from the ERS and assistant principals, were responsible for facilitating PLCs on a weekly basis. Their weekly functions included unpacking learning standards, creating varied and frequent formative assessments for learning, analyzing data, and determining adjustments in instruction and direct student interventions and enrichment opportunities. 
Valley High School had multiple community partnerships designed to improve student achievement and career readiness. The College Readiness Program coordinated post-secondary, community, businesses, and political resources to support students in arranging college visits, gaining access to higher education/admission, financial aid, and scholarships. As part of Valley High School's medical magnet, the school developed several partnerships (i.e. Allied Health, Jewish Hospital, Spencerian College, St. Catherine College, etc.) that provided resources, job shadowing experiences, and speakers.

Fern Creek High School's plan revealed an emphasis on PLCs and data analysis. The development of PLCs was designed to provide a structure for collaboration among teachers to create a synergetic environment. In addition, the school made a concerted effort to include parents and teachers in the decision-making process. This led to the formation of a Parent Advisory Council and school design community.

Frost Middle School made significant adjustments to its master schedule and curriculum in order to try to boost student achievement. School leaders implemented a master schedule with an 8-period day. This schedule allowed students to have 86 minutes of reading, 86 minutes of math, 43 minutes of social studies, 43 minutes of science, and two related arts periods daily. Additionally, this schedule allowed for common planning time for grade level teachers teaching the same subject. As part of the plan, the ERS, district resource teachers, and school-based reading and math intervention teachers were to collaborate daily with classroom teachers to assist them in planning standards-based instruction. In language arts, Frost Middle School adopted the Springboard curriculum as their literacy framework. All students were to receive 
instruction through a core program aligned with the Kentucky Program of Studies and Core Content for Assessment. In addition to Springboard, the adopted master schedule included a supplementary class period of reading instruction for every student. During this class period, students received additional instruction and support for mastery of learning targets and objectives taught in the core language arts program. Frost Middle School's master schedule revisions also provided a dedicated 18-minute CARE time each morning. The CARE sessions, similar to an advisor-advisee program, focused on modeling and positive social interactions, goal setting, and emotional intelligence principles as well as providing a "safe place to land" for students needing a supportive environment.

As part of the school improvement grant, Western Middle School put an intentional focus on improving the collaborative work of the school faculty. A team of in-house and district support teachers, certified in literacy and mathematics, worked collaboratively with the ERL and the math and reading ERS to support teachers at Western Middle School in an on-going and "just in time" fashion. The coaches worked with teachers primarily by department and modeled, co-taught, reflected, and assisted teachers in their classrooms. Embedded professional development occurred twice weekly with all teachers and focused on topics, such as instruction, assessment, analysis of student work, and classroom management. Members of the instructional support team mentored new teachers to Western Middle School. In addition, each teacher was assigned to a team and had the support of other team members.

It should also be noted, that the district designed a new student assignment plan for Western Middle School. The plan was to convert the school to a whole school 
magnet with an innovative theme and sufficient resources, with the hope of achieving greater student diversity and higher academic achievement. During the 2010 - 2011 school year, Western Middle School became a district-wide Visual and Performing Arts Magnet School. The school's previous resides area was reassigned to four other district middle schools. Students enrolled at Western Middle School during the 2009-2010 school year were permitted to continue enrollment at the school, unless the student chose to attend the newly assigned resides school, or the student applied for and is granted a transfer.

\section{Transformation Model}

In this section, I examined how the school SIG plans for the Transformation model were similar in support of the school turnaround work. This process included an analysis of the school leadership structures, instructional planning and support systems, and how schools used SIG funds to impact student achievement. At all Transformation model Cohort I schools, SIG funds were used to bolster staffing, particularly in the areas of reading and math. Caverna High School $(\$ 107,761)$ used SIG funds to hire a math interventionist and SAM. The purpose of the SAM was to allow the principal the autonomy to focus on instructional initiatives outlined in the improvement plan. Of the four Transformation model schools, Lawrence County High School, Leslie County High School, and Metcalfe County High School each allotted over $\$ 200,000$ of their SIG funding to staffing needs. Lawrence County High School added a Director of Pupil Intervention (DPI), literacy and math interventionists, a part-time resource teacher, and a math/science teacher. The DPI was established to provide services to struggling learners. At Leslie County High School, two highly qualified teachers were hired for the purpose 
of forming English and math laboratory classrooms. The laboratory classrooms would serve as model classrooms for all teachers. These teachers worked with their ERS to ensure that strategies and methods produced positive student results. In addition, Leslie County High School used SIG funding to hire a School Intervention Manager (SIM) and Director of Academic Performance. Metcalfe County High School used SIG funds to hire a SIG Coordinator, two SAMs, two instructional coaches, a Read 180 teacher, a math teacher, a part-time English teacher, and two interventionists. Two schools, Caverna High School $(\$ 56,817)$ and Metcalfe County High School $(\$ 25,000)$, used SIG funds to secure the services educational consultants; however, Lawrence High School and Leslie High School did not include consultants in their plans. All Cohort I Transformation model schools used SIG funding to increase instructional technology in their buildings. Lawrence County High School allotted the most funding $(\$ 213,620)$, while Leslie County High and Caverna High School both allotted approximately \$60,000.

An examination of instructional systems showed some commonalities and differences between the schools implementing the Transformation model. The recommendations from the audit team at Caverna High School provided a clear picture of needs which included, but was not limited to: curriculum alignment, identification of key transition points between the middle and high school, rigorous assessments, continual tracking of student progress through both formative and summative assessments, and monitoring by the administration. To address the monitoring of their instructional systems, the leadership team, which included representatives from both the school and district, conducted walkthroughs of each classroom on a daily basis and provided timely, either the same day or the next day, descriptive feedback to each member of the 
instructional staff observed. Prior to a formal evaluation, the teacher and principal were to conduct a pre-observation interview and complete the necessary form. The monitoring plan also included a formative evaluation for each tenured member of the instructional staff and two for each instructional staff member who did not have tenure. Annual summative evaluations were completed for each teacher at the end of the evaluation cycle.

Teachers deemed as master teachers at Caverna High School were eligible for the rewards set forth in the district rewards program. These rewards, such as partial tuition, money for purchase of books or ancillary materials, national professional development opportunities, assistance in pursuit of National Board Certification and enhanced pay, were designed to further assist teachers in meeting the needs of students. Master teachers were used as lead teachers or mentors for struggling teachers. Master teachers were recognized in the school and community through the media.

In literacy and math, Caverna High School implemented Reading Plus to serve as an intensive and supplemental intervention in language arts classes across all grade levels. Data generated from this program was used to guide teachers in the development of student specific intervention strategies. Carnegie Math (Algebra I) was implemented and expanded to include Algebra II and Geometry. MAP was used as a universal screener to measure and predict student performance in reading, math, and science in order to allow ongoing process monitoring. Using data from MAP, students were grouped and regrouped based on performance and placed into intervention classes that were built into the master schedule. Novel Star was used to promote graduation for students who had experienced failure in the regular classroom. Finally, Silver and Strong 
(Thoughtful Classroom) instructional strategies were integrated into units of study in order to meet diverse learning styles of students. To assist students with the transition from eighth to ninth grade, Caverna High School established a two week "camp" to target math and reading skills. The goal was to include up to half of the incoming freshmen in the camp.

Lawrence County High School's plan focused on four key areas: increase teacher and administrator effectiveness; develop and implement organizational structures to facilitate the reform; meet the needs of struggling learners; and support structures for all stakeholders. To monitor instruction occurring at Lawrence County High School, the principal actively participated on the district walkthrough team. Team members, visited each classroom at least monthly to inform instruction and enable the principal to coach individual staff on a consistent basis, providing appropriate supports as necessary. In addition, the principal was to complete, within five school days of the walkthrough, individual teacher coaching sessions with written comments that would impact positive change in instruction and are observable in follow up walkthroughs or observations. To further support instruction, teachers with zero to three years' experience participated in TARGET (Training and Resources for Growing Effective Teachers). This multi-year induction model (TARGET I, II, and III) provided teachers new to the profession and/or district needed support. During this time induction teachers met and worked with district resource teachers creating a system of networking, resources and professional growth. With the additional SIG funding, TARGET was expanded to include training for marginal teachers identified through the walkthrough process, regardless of experience (TARGET IV). To increase stakeholder involvement and ensure that plans were 
implemented with fidelity, school-level teams met regularly to focus on curriculum, assessment, and instruction directly tied to the School Improvement Plan. Lawrence High School's principal determined school teacher leaders that would serve on the ILT.

Lawrence County High School implemented a freshman academy in order to meet the transition needs of its students. The purpose of this initiative was to; provide intensive interventions to assist students who enter high school with reading/language arts or math skills that are significantly below grade level and attain proficiency by the end of the 10th grade; enroll students in a coherent sequence of rigorous English language arts, mathematics, and science courses; provide tutoring and other academic; deliver comprehensive guidance and academic advising to students and their parent that included assistance in selecting courses and planning a program of study; and increase opportunities for students to earn postsecondary credit through Advanced Placement courses, or dual credit programs.

Following the 2009-2010 Leadership Assessment Reports, Leslie County High School formed a leadership team whose sole purpose was to analyze the audit results and to plan methods for addressing each of the suggested growth areas. This leadership team met weekly in order to develop and carryout an action plan. As part of their plan, an emphasis was placed on job-embedded professional development. This process, through the PLC, allowed time for teacher collaboration and embedding of skills immediately into developing curriculum. A systematic approach was set in order to monitor the extent to which professional development actually impacted teacher practice through weekly learning walks utilizing a specific walk-through instrument and debriefing. 
Leslie County High School also made changes to their master schedule. The new schedule contained a six-period day with a modified block period to allow greater flexibility with student interventions. A Response to Intervention (RTI)/Advisory period was added to the beginning of the school day at so that all students would receive extended learning for forty-five minutes per day. Also, ninth-grade students were provided a thirty-minute slot per day for transition, individual learning plan (ILP) work, RTI work and/or accelerated reader in addition to the other learner extension time slots. The Discovery Education Assessment was adopted as the universal screener to measure and predict student performance, and allow ongoing process monitoring. This predictive assessment measured knowledge, determine areas for growth, and provided supplemental resources to help bridge learning gaps. Using the data from students were grouped and regrouped based on performance and placed into intervention classes that were built into the master schedule.

Metcalfe County High School contracted with national author and consultant Elliot Merenbloom, co-author of Making Creative Schedules Work in Middle and Secondary Schools, in order to collaboratively design a schedule to maximize both teacher and student learning time. Reorganization of the master schedule enabled professional learning communities to engage in the curriculum, instruction, and analysis of data and student work. Teachers were organized into like-content teams to meet at least once each week during common planning time to collaborate and have professional conversations with colleagues, instructional coaches, and leadership. Other partnering professionals such as Green River Regional Education Consortium (GRREC), Caveland Educational Support Center (CESC), Western Kentucky University (WKU), Eastern 
Kentucky University (EKU), and KDE were contracted to provide job-embedded professional development in content, instruction, coteaching models, and assessment for learning.

In the area of literacy, Read 180 was utilized to help struggling readers. Also, new nonfiction library books were purchased to provide a better selection of materials to meet the needs of all students, especially males. The district literacy coach worked closely with teachers in all content levels to implement effective reading strategies in all classes. After school professional development was attended by all classroom teachers for continued support in the effective implementation of reading strategies in all content areas. The MAP assessment was administered three times yearly to check for progress. School and district leadership continually monitored the results and the implementation within the classroom. From the results, RTI groups were identified and the students that needed extra help were given the time to work on the skills needed for improvement.

Also, students that mastered the skills were provided enrichment activities to extend their learning.

\section{District SIG Plans}

In this section, I examine how district SIG plans for the Turnaround model were similar in the support of the school turnaround work.

\section{Turnaround Model}

As previously discussed, JCPS was the only Cohort I school district to choose the Turnaround model as the SIG intervention for their schools. To meet the guidelines of the Turnaround model, the LEA was charged with replacing the principal and rehiring no more than $50 \%$ of the school's staff; adopting a new governance structure; providing job- 
embedded professional development; offering staff financial and career-advancement incentives; implementing a research-based, aligned instructional program; extending learning and teacher planning time; creating a community-orientation; and providing operating flexibility.

According to the KDE guidelines, principals hired, transferred or reassigned after July 2007 qualified as meeting the definition of replacement of the principal under HB176 and as interpreted by the United States Department of Education in their guidance regarding the same definition under the school improvement grant program. This requirement led to principals being replaced at Western Middle School and Frost Middle School. KDE also recommended that the principal at Valley be removed. Their report cited that the principal did not have the capability and capacity to continue the roles and responsibilities established in KRS 160.345. However, upon evidence cited in an appeal letter from the superintendent, the commissioner of education retained the current principal and allowed him one year to show significant gains in reading and math proficiency. Reports also noted that the principal at Western High School had one year to meet requirements or risk being removed due to his initial hire date. All SBDM council authority for Cohort I JCPS schools were granted to the superintendent as a result of the leadership assessments conducted by KDE. In response, all Cohort I principals formed instructional leadership teams (ILT) to serve in an advisory capacity. The ILT became the vehicle through which schools monitored school improvement pertaining to curriculum, assessment, and instruction.

In the spring of 2010, JCPS leadership conducted what they deemed a critical analysis of the district's intervention strategies, with greater intentionality directed 
toward how the district could support struggling students and schools that had not met all of their goals. Their analysis was facilitated by a consultant from Harvard/Wallace and informed by the school and district audits performed by KDE. Through this analysis, the district hoped to answer two key questions, with a specific focus on the schools identified Tier I and Tier II. How was the district's theory of action moving teacher practice and instructional rigor forward and did the practices of each of the schools align with the theory of action, and how would the district mobilize and coordinate services to schools to make the most effective and efficient use of district resources?

District leaders determined that the likelihood of making a turnaround difference in the coming year would be "optimized if they organized, implemented, supported, and monitored a laser-like focus on four strategic approaches to the issues now facing our district." The identified strategies included: promoting students' engagement with schools and their understanding of the long-term benefits of education; providing a system of coordinated support to students and school; owning results; and informing practice. To move this plan from discussion to action, the district established four committees of district-level staff, each chaired by a cabinet member. The four committees were Case Management Coordination for Tier I and Tier II schools, System Support Coordination, Balanced Assessment and Learning Progression, and Improving Practice.

According to CDIP notes, many of the programs and initiatives that were implemented during 2009 - 2010 had been planned or launched in the preceding two years, with one exception. That one exception was at the high school level, where a number of JCPS schools had been identified as PLA. District leadership decided to 
formulate a targeted approach to address students' low rates of proficiency on state assessments of reading and math, which they called Project Proficiency. Through Project Proficiency, the district established three key standards for each six-weeks grading period for Algebra I, Geometry, Algebra II, and Sophomore English. After administering a Diagnostic Assessment early in the grading period, teachers used the results to identify learning gaps, formatively assess understanding, and prescribe intervention strategies to guide each student to demonstrate a level of competency in each of the key standards by the time he/she takes a culminating six-weeks Proficiency Assessment. PLCs of teachers were to collaborate weekly to discuss student learning progression and exchange ideas about instructional implications and potential remediation strategies. Web-based technology was to provide teachers with a system for tracking student demonstration of competency, diagnosing possible content misunderstandings, and converting standardsbased evaluation of student competency into grades. In addition, teachers were to continue to guide each student until he or she achieved at least 80 percent proficiency on the six-weeks assessment. While this initiative was originally formulated for Tier I and Tier II schools, the approach spread to all comprehensive and many of the magnet and alternative high schools.

As noted previously, JCPS selected the Turnaround model as the SIG intervention for all of their Cohort I schools. This intervention required screening the school's existing faculty and staff and retaining no more than 50\%. According to their district plan, JCPS designated all Cohort I schools as priority of the highest level. Because of this designation, when decisions were made relative to facility improvement, staffing and/or support services, Cohort I schools were to be given a greater degree of flexibility, 
support and/or more expedient services. In the area of school staffing, a memorandum of agreement was negotiated between the district administration and the Jefferson County Teachers' Association (JCTA) that exempted the priority schools from the district's transfer agreement. As a result, Cohort I schools were not required to accept transfers from other schools and were given first choice of the early hire candidate pool. Cohort I schools were also exempt from accepting candidates with alternative certification. On May 10, 2010, the Jefferson County Board of Education approved the Kentucky Teacher Standards as the standards used to screen and hire the faculty and staff at JCPS Cohort I schools. These standards were meant to measure the effectiveness of staff who can work within the turnaround environment to meet the needs of students. Each standard had a number of indicators that provided detailed information about the standards and contained a rubric that ranged from initial-level performance to advanced-level performance. The re-staffing process included the following steps:

- Extending the deadline for voluntary transfer and voluntary/involuntary overstaffing to for all middle and high school teachers.

- The schools using the Re-staffing Option overstaffed their certified instructional staff and went through a screening and selection process, using the Kentucky Teacher Standards adopted by the local board, for hiring those teachers currently in the building who wanted to remain. When the selection committee determined which teachers would remain in the school, those not selected had the opportunity to request transfer to selected schools.

- The selection committee was comprised of two Jefferson County Teachers Association representatives and two administration representatives. 
Further supports for all Cohort I principals included an ERL assigned by the Kentucky Department of Education. In conjunction with $\mathrm{KDE}$, the district also assigned a priority manager to provide job performance feedback about the principal and monitor the implementation of all school activities aimed at improving student achievement.

In addition, the district curriculum office implemented multiple strategies to assist Cohort I schools. These supports included having resource teachers and specialists work with school leadership teams to design and deliver job-embedded professional development to teachers throughout the school year. Also, resource teachers and specialists facilitated professional learning communities through lesson study at each school.

\section{Transformation Model}

In this section, I examined how the district SIG plans for the Transformation model were similar in support of the school turnaround work. District leaders at Caverna Independent, Lawrence County, Leslie County, and Metcalfe County each selected the Transformation model as the SIG intervention model for their schools. Per the Transformation model guidelines, the LEA was charged with implementing each of the following strategies: replacing the principal; providing job-embedded professional development; implementing a rigorous teacher-evaluation and reward system; offering financial and career advancement incentives; implementing comprehensive instructional reform; extending learning- and teacher-planning time; creating a community-orientation; and providing operating flexibility and sustained support.

As discussed in the previous section, according to the KDE guidelines, principals hired, transferred or reassigned after July 2007 qualified as meeting the definition of 
replacement of the principal under HB176 and as interpreted by the United States Department of Education in their guidance regarding the same definition under the school improvement grant program. This requirement led to principals being replaced at Caverna High School, Lawrence High School, and Metcalfe High School. Leslie County Schools' leadership assessment team determined that the principal (formerly hired in 2009) had the capability and capacity to continue his roles and responsibilities established in KRS 160.345. Caverna's district leaders petitioned for a waiver to the requirement, but their request was denied and the principal was replaced.

Caverna's district plan highlighted the creation and implementation of schoolwide literacy and mathematics improvement plans. The district purchased MAP to be utilized as a universal screener for grades 8 - 12. In addition, the district supported the school's use and expansion of the Reading Plus program to address the needs identified in the RTI plan and MAP assessment. The master schedule was redesigned to provide an extra period for implementation of the reading intervention program. This program utilized teachers as reading interventionist and paired them with students deemed reading substantially below grade level. Teachers were trained on how to best utilize the Reading Plus and Des Cartes program (associated with MAP) to address the individual student needs. Teachers and school leaders were supported in efforts to align the curriculum resulting in a scope and sequence document insured that students had access to the literacy curriculum. Reading would be emphasized and monitored across the disciplines at the district level as well as the school.

In Math, Caverna's district leadership would again use MAP as the universal screener for grades 8 - 12. The district would support the school's implementation and 
expansion of the Carnegie Math program to address the needs identified in the RTI plan and MAP assessment. The master schedule was redesigned to provide an extra period for implementation of the math intervention program. This program utilized a newly added math intervention teacher and paired them with students deemed substantially below grade level. The district would support the training of math teachers on how to best utilize the Carnegie Math and Des Cartes program (associated with MAP) to address the individual student needs. As with the reading curriculum, the district would support school leaders and teachers in the alignment of the curriculum by helping create a scope and sequence document that insured that students had access to a guaranteed and viable math curriculum. To address teacher attraction and retention, Caverna's district plan noted a collaborative effort with KDE and Western Kentucky University to utilize all available means to find, recruit, train, and place highly effective teachers, including developing a compensation system; however, no further details were provided in the report.

In May, 2010, the Lawrence County's superintendent recommended a new rigorous and equitable evaluation plan for all certified employees that would follow applicable statutes and regulations. According to the district plan, the evaluation process served three purposes: to promote continuation of professional competencies that maximize teacher growth and effectiveness; to identify areas for professional growth; and to assist in making personnel decisions for the purpose of improving instruction, curriculum, assessment; and other professional responsibilities-all focused on helping students learn and succeed. In addition, a district walkthrough team, including the building principal would visit each classroom monthly to inform instruction and enable 
the principal to coach individual staff on a consistent basis. Walkthrough teams assigned to each school collected quantitative and qualitative data (a "snapshot") that was descriptive and focused on Lawrence County’s district-wide priority goals.

In response to the Lawrence County High School leadership assessment, the district formed the District Transformation Team (DTT). The DTT included the following personnel: Superintendent, Director of Personnel, and Director of District-wide Services, Director of Special Education, Chief Academic Officer, Director of Early Learning, Director of Finance, Director of Pupil Personnel, Technology Officer, and District ESS Coordinator/Parent Involvement Coordinator. The DTT met monthly to analyze data to monitor the progress of the initiative, review the progress of the plan's action steps, review quarterly information to be submitted to KDE and the Lawrence County Board of Education, and review the budget as it pertains to implementation. In order to maintain an accurate and useful data system, the Lawrence County Schools added a district Data Analyst to the staff at no cost to the SIG. The district's plan also noted increased implementation of job-embedded professional development. In addition to professional development initiatives facilitated by the district's resource teachers, the district provided training to all certified staff regarding PLCs and implementing district and school instructional leadership teams.

In Leslie County, district leaders changed the length of the school day and school year to increase learning opportunities. The 2010 - 2011 school calendar included 10 extended days for student learning. Furthermore, the district ensured there were an adequate number of staff with appropriate certifications to keep favorable student /teacher ratios; considered calendar options that offered extended time for students who 
needed extra support; provided funding to retain staff for lengthened school days; developed a budget that included adequate funding for technology, supplies, and facilitated discussions between the high school and Leslie County Area Technical Center to make curriculum connections for the purpose of expanding the high school curriculum to encompass career readiness standards. In addition, district agreed to give the school sufficient operational flexibility to fully implement a comprehensive approach to substantially improve student achievement outcomes.

Leslie County's district leaders committed to aligning curriculum taught in its schools, K-12th grades. The district began with summer sessions on the learning standards rollout, to be followed by unpacking these standards through PLC meeting/sessions. The curriculum would be aligned both horizontally and vertically so that there are no gaps in content chunks or between grade levels. Discovery Education was purchased in order to continually assess the success of the instructional programs and to inform the further instruction district-wide. A performance calculator was also used in each classroom to assess learning in chunks of content before moving on to additional concepts.

Metcalfe County district leaders provided additional supports in the areas of PLCs, developing community partnerships and teacher recruitment, and funding. The district pledged over $\$ 150,000$ for additional teachers and staff beyond required allocations, in order to further support the grant plans. In addition, the LEA allocated funds for assessment, professional development, technology procurement, tutoring, and substitute teachers to allow faculty to receive the extensive training necessary for successful implementation. School and district leadership planned and scheduled PLCs 
for the school year. The district PLCs focused on common assessments, formative assessments, examining student work samples using a protocol which included a method for providing specific feedback, questions, and next steps for revision. To further support the work, the district literacy and math coach collaborated with teachers on an individual basis to model and help develop effective classroom instructional techniques.

In order to support professional development opportunities and deepen content knowledge and instructional pedagogy, district leadership partnered with KDE, GRREC, CESC, WKU and EKU. The district's plan for recruiting, placing, and retaining highly effective instructional staff involved expanding the partnerships between Metcalfe County School District and educational cooperatives, colleges, and universities for identifying the most promising teacher candidates. New teacher orientation programs were developed to train and support newly-hired instructional staff. In addition, district leadership planned to form a model Future Educators Association to encourage those with the highest potential for teaching, incorporate strong communication with families of these students, facilitating visits to colleges and universities for outstanding club members, and initiating and sustaining strong relationships between the district and these outstanding students.

In 2010, Metcalfe County was in the second year of their new employee evaluation plan. The plan was developed using multiple documents as guides, including Teacher Standards (2008) and Standards and Indicators for School Improvement. The evaluation process was developed by a committee of five teachers and five administrators. The process, while rigorous and equitable, was meant to maintain accountability and assessment in a clear focus on improving student learning. 


\section{Contingency Factors: Demographic Characteristics of JCPS Cohort I Tier I and Tier II Schools}

A further analysis of study documents revealed that JCPS Cohort I schools qualifying as Tier I (Frost Middle School, Shawnee High School, Valley High School, Western High School, and Western Middle School) had higher percentages of students impacted by variables that contribute to low academic achievement, compared to their Tier II peer (Fern Creek High School). These variables included poverty, students qualifying for special education services (ECE), and student mobility. Tables $6-11$

illustrate the disparities within the JCPS Cohort I schools. This information was included in the district SIG application for the schools in JCPS. No other district application from the other two regions included this information. Given that 12 years has passed since this information was collected, I am not able to recreate this information for the four schools outside of the central region. Schools and districts are only required to maintain that information for seven years.

Table 6. Tier II Fern Creek student variables contributing to low achievement

\begin{tabular}{llll} 
Variable & $\begin{array}{l}\text { School } \\
\text { Average }(\%)\end{array}$ & $\begin{array}{l}\text { District } \\
\text { Average }(\%)\end{array}$ & Difference \\
\hline ECE & 9.5 & 9.7 & -0.2 \\
Free/Reduced Lunch & 52.22 & 50.91 & 1.31 \\
Mobility & 9.68 & 11.95 & -2.27 \\
Suspensions & 22.99 & 16.78 & 6.21 \\
Teacher Retention & 58.33 & 90.53 & -32.2 \\
\hline
\end{tabular}


Table 7. Tier I Frost student variables contributing to low achievement

\begin{tabular}{llll}
\hline Variable & $\begin{array}{l}\text { School } \\
\text { Average (\%) }\end{array}$ & $\begin{array}{l}\text { District } \\
\text { Average }(\%)\end{array}$ & Difference \\
\hline ECE & 15.1 & 12.0 & 3.1 \\
Free/Reduced Lunch & 86.81 & 61.43 & 25.38 \\
Mobility & 20.86 & 9.99 & 10.87 \\
Suspensions & 21.19 & 15.15 & 6.04 \\
Teacher Retention & 73.07 & 88.08 & -15.01 \\
\hline
\end{tabular}

Table 8. Tier I Shawnee student variables contributing to low achievement

\begin{tabular}{llll}
\hline Variable & $\begin{array}{l}\text { School } \\
\text { Average (\%) }\end{array}$ & $\begin{array}{l}\text { District } \\
\text { Average (\%) }\end{array}$ & Difference \\
\hline ECE & 19.5 & 9.7 & 9.8 \\
Free/Reduced Lunch & 88.5 & 50.91 & 37.59 \\
Mobility & NA & 11.95 & NA \\
Suspensions & 34 & 16.78 & 17.22 \\
Teacher Retention & 75 & 90.53 & -15.53 \\
\hline
\end{tabular}


Table 9. Tier I Valley student variables contributing to low achievement

\begin{tabular}{llll}
\hline Variable & $\begin{array}{l}\text { School } \\
\text { Average (\%) }\end{array}$ & $\begin{array}{l}\text { District } \\
\text { Average (\%) }\end{array}$ & Difference \\
\hline ECE & 17.6 & 9.7 & 7.9 \\
Free/Reduced Lunch & 76.5 & 50.91 & 25.64 \\
Mobility & 11.02 & 11.95 & -0.93 \\
Suspensions & 22.71 & 16.78 & 5.93 \\
Teacher Retention & 76.47 & 90.53 & -14.06 \\
\hline
\end{tabular}

Table 10. Tier I Western High student variables contributing to low achievement

\begin{tabular}{llll}
\hline Variable & $\begin{array}{l}\text { School } \\
\text { Average (\%) }\end{array}$ & $\begin{array}{l}\text { District } \\
\text { Average (\%) }\end{array}$ & Difference \\
\hline ECE & 17.9 & 9.7 & 8.2 \\
Free/Reduced Lunch & 82.07 & 50.91 & 31.16 \\
Mobility & 14.98 & 11.95 & 3.03 \\
Suspensions & 42.12 & 16.78 & 25.34 \\
Teacher Retention & 87.36 & 90.53 & -3.17 \\
\hline
\end{tabular}

Table 11. Tier I Western Middle student variables contributing to low achievement

\begin{tabular}{llll}
\hline Variable & $\begin{array}{l}\text { School } \\
\text { Average (\%) }\end{array}$ & $\begin{array}{l}\text { District } \\
\text { Average (\%) }\end{array}$ & Difference \\
\hline ECE & 24.0 & 12.0 & 12.0 \\
Free/Reduced Lunch & 96.94 & 61.43 & 35.51 \\
Mobility & 15.62 & 9.99 & 5.63
\end{tabular}


Table 11. (Continued)

Suspension

26.6

15.15

11.45

Teacher Retention

77.14

88.08

$-10.94$

\section{Contingency Factors: Cohort I District and School Size}

In Kentucky's first SIG cohort, all schools received the same amount of funding regardless of district size or student enrollment. The data revealed that many Cohort I schools actually had similar enrollment sizes, with two notable exceptions, Caverna High School and Fern Creek High School. See Table 12 for total school enrollments by school for FY2009 - 2010. A further examination of the number of schools each district was required to support revealed a large disparity between JCPS and the rural districts (see Table 13).

Table 12. Kentucky cohort I student enrollment 2009 - 2010

School

Caverna High School

Fern Creek High School

Frost Middle School

Lawrence County High School

Leslie County High School

Metcalfe County High School

Shawnee High School
Total Enrollment

227

1,363

430

710

517

478

477 
Table 12. (Continued)

Valley High School $\quad 775$

Western High School 774

Western Middle School 454

Table 13 . Kentucky cohort I district size by school $2009-2010$

District

Total Schools

Caverna Independent 3

JCPS

173

Lawrence County

6

Leslie County

5

Metcalfe County

3

\section{Member Checking}

In order to validate the findings of this study, the process of member checking was completed. As discussed previously, member checking, also known as participant or respondent validation, is a technique used for exploring the credibility of results (Birt et al., 2016). For this study, I supplied memos to participants with a summary of the completed analysis by individual Cohort I school and district (see Appendix B D). Specifically, I wanted see if Cohort I participants found the summaries accurate or if important factors were omitted or inaccurate. Participants for inclusion were purposefully selected from each of the three regions (Central, Eastern, and Western) from 
a pool of educational leaders that worked directly with the turnaround work in a Cohort I school and/or district. Potential participants included principals, education recovery staff, KDE staff, and district level leaders directly assigned to work with the turnaround schools in Cohort I. Participant feedback was sought on an individual basis through written communication. A total of eight member checking requests were submitted, of which four participants responded. The four respondents were all former members of an ERT. Each region was represented by member checking feedback.

\section{Eastern Region}

In FY2009 - 2010, across the three regions, the Educational Recovery Directors (ERDs) developed their plans of support based on their own beliefs toward school turnaround and findings from the leadership assessments. At the state level, consistent systems / processes were not fully developed and implemented across all three regions until years later. In the East, the ERD valued a systems approach to sustained school improvement. There was a belief that a school's success was linked to how closely they deployed the original model and eternalized ownership over their own systems. Participant feedback from the East noted strong leadership at Leslie County High School. Their school and district leadership embraced the systems' approach immediately. The school's leadership, having been found to have capacity during the leadership assessment, was already in place and performing at a high level. In addition, the school's counselors were pivotal in helping form an RTI schedule that met the individual needs of students. At Lawrence County, the systems approach took longer to catch on than at Leslie County; however, after approximately 15 months their efforts started to become apparent. KDE had difficulty keeping a consistent, highly trained, recovery team at 
Lawrence County High School. Finally, due to a lack of highly skilled teacher applicants, the Turnaround model was not an option at either Lawrence County High School or Leslie County High School.

\section{Central Region}

At JCPS, KDE was not able to deploy their model of support as designed, due to the bureaucratic structure of the large district. Similar to Lawrence County High School, KDE was unable to support each of the six Cohort I schools with consistent, high quality, three-person educational recovery teams. This became a further challenge as future cohorts of JCPS schools were identified for support. Also, the priority manager position was jointly "owned" by JCPS and KDE. The priority manager reported directly to the superintendent and KDE and was funded by KDE. Participant feedback noted that the Turnaround model for JCPS initially made sense, but consistent staff turnover eventually undermined the approach. In addition, KDE had concerns regarding the number of feeder schools tied to each Cohort I schools and the high percentage of student mobility. As summarized by one respondent, having too many feeder schools and high student mobility was a systems issue at the district level.

\section{Western Region}

Metcalfe County High School was the only rural school not to exit PLA status within the original three-year timeline. Participant feedback noted a lack of leadership consistency at all levels (school, district, and state). Furthermore, the school's leadership viewed the ERT as a bother and did not embrace their support. These factors resulted in systems work delay. Participant feedback also described poor systems related to PLC implementation. 
Caverna High School's plan noted the use of MAP data for intervention grouping and regrouping. Participant feedback confirmed the use of MAP data in areas, but note fidelity issues with school-wide implementation.

\section{Summary of Findings}

In summary, contingency theory served as the theoretical framework to guide my research. A contingency is any variable that moderates the effect of an organization characteristic on organizational performance (Donaldson, 2001). These contingency variables are situational variables that influence the relationship between managerial strategy or organizational structure and organizational outcomes (Hanson, 1979). Variables examined in this analysis were the district and school leadership structures, instructional planning and support systems, and SIG spending. Furthermore, noncognitive variables, such as school demographics by SIG tier, total school enrollment, and district size were additional variables analyzed.

The specific research questions that guided this analysis were:

- How were district SIG plans for the Transformation Model similar in the support of the school turnaround work?

- How were district SIG plans for the Turnaround Model similar in the support of the school turnaround work?

- How were school SIG plans for the Transformation Model similar in the support of the school turnaround work?

- How were school SIG plans for the Turnaround Model similar in the support of the school turnaround work? 
The purpose of this qualitative study was to determine how some Kentucky Cohort I schools were able to exit PLA status successfully within the three-year timeframe outlined in the SIG application, while others were not. This analysis found that Caverna High School, Lawrence County High School, and Leslie County High School, successfully exited PLA status within the three-year window. All three schools implemented the Transformation model. Metcalfe County High School (Transformation model) and the six JCPS (Turnaround Model) schools did not successfully exit within the three-year window despite the assistance of SIG funding. Conclusions drawn from the findings appear in Chapter $\mathrm{V}$ along with policy and practice implications and recommendations for future research.

In the spring of 2010, KDE conducted leadership assessments at each Cohort I school and district. The leadership assessment activities included: a review of the documents collected for the school / district portfolio and profile; classroom observations; and formal interviews and informal discussions key stakeholders from the school and district levels. The SISI rubric served as the primary assessment instrument used during the visits. This analysis found that, with the exception of Shawnee High School, all Cohort I schools were found to be deficient on a minimum of one SISI indicator. Leslie County High School (19) and Metcalfe County High School (26) had the most deficiencies among the schools. At the district level, all Cohort I districts were found to be deficient on at least one indicator. Leslie County (45) had the most deficiencies, while JCPS (2) had the fewest.

An examination of how the school SIG plans for the Turnaround model were similar in support of the school turnaround work found that all six JCPS Cohort I schools 
implemented the Turnaround model. The analysis of SIG spending revealed that all six schools used SIG funds to bolster staffing, particularly in the areas of reading and math. Fern Creek High School allotted \$299,306 towards staff salaries during FY2010, the most of any Cohort I school. Fern Creek High School also allotted the most funds towards professional development. All schools, with the exception of Western High School and Fern Creek High School, used SIG funds to improve instructional technology. With the exception of Western High School, all Cohort I Turnaround model schools invested in educational consultants.

An examination of how the school SIG plans for the Transformation model were similar in support of the school turnaround work also found that all Transformation model schools used SIG funds to increase staffing. Lawrence County High School, Leslie County High School, and Metcalfe County High school each allotted over $\$ 200,000$ to their staffing salaries. In addition, Caverna High School and Metcalfe County High School used SIG funds to secure the services of educational consultants. All Transformation model schools used SIG funding to increase instructional technology in their buildings.

Regardless of each Cohort I school's selected SIG model, the analysis of schoolbased planning documents revealed similar actions and plans across most schools. Common programs and initiatives included the formation of ILTs and PLCs. The Cohort I school plans also focused on new curricular programs in the areas of reading and math, technology upgrades, the use of universal screeners, the creation of RTI and transition programs, and increased staffing. 
An examination of how district SIG plans for the Turnaround model were similar in support for the school turnaround work found no evidence in the JCPS district plan to differentiate support for the five Tier I schools and the single Tier II school. Project Proficiency, a JCPS district initiative initially designed to help JCPS's Tier I and Tier II schools, quickly spread to all comprehensive and many of the magnet and alternative high schools, a further indication the district did not differentiate support for their Cohort I schools.

Contrary to the JCPS findings, an examination of how district SIG plans for the Transformation model were similar in support of the school turnaround work found differentiated plans designed to meet the individual needs of their Cohort I school. The Transformation model plans described individualized systems of support focused on PLCs, technology, and professional development. It should be noted though, the four districts supporting Transformation model schools only had one school to support in the turnaround work.

The non-cognitive variables analyzed in this study that may have impacted student achievement, included demographic characteristics of JCPS Cohort I Tier I and Tier II schools, total school enrollments, and district size. This examination found that JCPS Cohort I schools qualifying as Tier I (Frost Middle School, Shawnee High School, Valley High School, Western High School, and Western Middle School) had higher percentages of students impacted by variables that contribute to low academic achievement, compared to their Tier II peer (Fern Creek High School). These variables included poverty, students qualifying for special education services (ECE), and student mobility. This information was not available for the four schools outside of the central 
region. In Kentucky's first SIG cohort, all schools received the same amount of funding regardless of district size or student enrollment. An analysis of school enrollments found that many Cohort I schools had similar enrollment sizes, with two notable exceptions, Caverna High School and Fern Creek High School. A further examination of the number of schools each district was required to support revealed a large disparity between JCPS and the rural districts.

Member checking was conducted to further validate my research findings. Participants for inclusion were randomly selected from each of the three regions from a pool of educational leaders that worked directly with the turnaround work in a Cohort I school and/or district. Participant feedback from the eastern region noted a systems approach to the school turnaround work at both Leslie High School and Lawrence High School; however, developing systems at Lawrence High School took longer due to a lack of initial buy-in and KDE recovery team staffing issues. Participant feedback also noted that the Turnaround model was not an option for eastern region schools, because of a lack of highly skilled teacher applicants. Member checking feedback from the Central region noted that KDE was not able to deploy their model of support as designed, due to the bureaucratic structure of the large district. Also, due to the number of schools needing support within the region, KDE was unable to support each of the six Cohort I schools with consistent, high quality, three-person educational recovery teams. Participant feedback from the western region revealed a lack of consistent leadership at all levels in Metcalfe County and poor PLC implementation as variables that impacted student achievement growth. 


\section{CHAPTER V: SUMMARY OF FINDINGS AND IMPLICATIONS}

In 2010, KDE received SIG funding with the goal of moving targeted schools out of PLA status successfully within the three-year window outlined in the federal guidelines found in the SIG application. A total of 10 secondary schools across the Commonwealth of Kentucky were identified as being the bottom $5 \%$ of all schools, and they comprised the first cohort of SIG schools in the Commonwealth. Each school received $\$ 500,000$ per year for three years beginning with FY2010. Of the 10 schools identified for the first cohort, six were from the JCPS district, which is a large urban school district encompassing the city of Louisville, Kentucky and the largest district in Kentucky serving approximately 100,000 students. The remaining four schools were from rural areas of the state with two in the rural eastern half of the state and two in the rural western half of the state. Five of the six JCPS schools were designated as Tier I schools. All other Cohort I schools were designated as Tier II, including those schools in the east and west regions. As part of the application process, schools awarded a SIG had to select and implement one of four SIG required intervention models: Transformation, Turnaround, School Closure, or Restart. At the conclusion of the three-year window, Caverna High School, Lawrence County High School, and Leslie County High School successfully exited PLA status. Metcalfe County High School and the six JCPS schools were not able to meet their benchmarks and remained in PLA status.

The research questions used to guide this study are: 
- How were district SIG plans for the Transformation Model similar in the support of the school turnaround work?

- How were district SIG plans for the Turnaround Model similar in the support of the school turnaround work?

- How were school SIG plans for the Transformation Model similar in the support of the school turnaround work?

- How were school SIG plans for the Turnaround Model similar in the support of the school turnaround work?

\section{Contingency Theory}

Throughout my analysis, I examined the work through the lens of the contingency theory, specifically structural contingency. Contingency theory makes it clear that there is no one best way to organize (Hatch, 2018). Depending upon the environment, there can be many different ways for organizations to organize successfully or unsuccessfully. A derivation of contingency theory, structural contingency theory, was used to narrow the focus of this analysis. With structural contingency, contingency factors include the environment, organizational size, and organizational strategy.

A contingency is any variable that moderates the effect of an organization characteristic on organizational performance (Donaldson, 2001). My findings are consistent with others in the field in that a combination of internal and external variables impacted a Cohort I school's ability to successfully turnaround within the three-year window outlined in the SIG application. As described by Hanson (1979), in the school 
setting, an example of an external variable could be parent pressures, while internal environment variables could be teacher autonomy or racial tension.

\section{Discussion}

In this section I discuss how school and district SIG plans for the Transformation model and Turnaround model were similar in the support of the school turnaround work. This section concludes with a discussion regarding non-cognitive variables that may lead to low student achievement.

\section{School SIG Plans}

Regardless of each Cohort I school's selected SIG model, the analysis of schoolbased planning documents revealed similar actions and plans across most schools. Common programs and initiatives included the formation of ILTs and PLCs, the implementation of new curricular programs in the areas of reading and math, technology upgrades, the use of universal screeners, the creation of RTI and transition programs, and increased staffing. Member checking feedback confirmed similar school-based systems across most Cohort I schools; however, the level of fidelity in which they were implemented may have varied. Member checking feedback did bring to light KDE's struggles to consistently staff highly skilled ERTs at each school. This issue may have played a role in a school's ability to successfully develop and implement school-based systems that result in sustained school improvement.

\section{District SIG Plans}

The results of this study may suggest that the selected SIG model was a contributing factor for Cohort I schools exiting PLA status, since only Transformation 
model schools exited within the three-year window outlined in the grant application. However, as noted previously, a national study by Dragoset et al. (2017) argues otherwise. Their report concluded that implementing any SIG-funded model had no significant impacts on math or reading test scores or high school graduation. Redding and Nguyen (2020) agree with this conclusion, stating there is little indication of one model being more effective than the others. My analysis revealed that the rural districts selected the Transformation model due to a lack of qualified teaching candidates, not because of an implied strategic advantage. This conclusion was confirmed during the member checking process. The Turnaround model, which called for replacing over 50\% of the staff, was simply not an option for those schools.

Participant feedback from member checking noted that implementing the Turnaround model for JCPS Cohort I schools initially made sense, but consistent staff turnover eventually undermined the approach. In addition, KDE had concerns regarding the number of feeder schools tied to each Cohort I school and the high mobility rate of the student population. As summarized by one respondent, having too many feeder schools and high student mobility was a systems issue at the district level. To help with staffing, the JCPS plan included a memorandum of agreement between the district administration and the Jefferson County Teachers' Association (JCTA) that exempted the priority schools from the district's transfer agreement. However, explicit plans to address staff turnover, student mobility, and feeder school transitions were not found.

The JCPS district plans displayed little evidence of differentiated supports for their six Cohort I schools. According to CDIP notes, many of the programs and 
initiatives that were implemented during 2009 - 2010 had been planned or launched in the preceding two years, with one exception, a new initiative called Project Proficiency. This could lead one to conclude that feedback from the KDE conducted leadership assessments were minimally considered when formulating district plans to support their Cohort I schools. Furthermore, there was no evidence in the district plan of differentiated support for the five Tier I schools and the single Tier II school.

As noted earlier, planning documents highlighted Project Proficiency as the new initiative designed to help struggling schools. Through Project Proficiency, the district planned to establish three key standards for each six-weeks grading period for Algebra I, Geometry, Algebra II, and Sophomore English. After administering a Diagnostic Assessment early in the grading period, teachers used the results to identify learning gaps, formatively assess understanding, and prescribe intervention strategies to guide each student to demonstrate a level of competency in each of the key standards by the time he/she takes a culminating six-weeks Proficiency Assessment. PLCs of teachers were to collaborate weekly to discuss student learning progression and exchange ideas about instructional implications and potential remediation strategies. Web-based technology was to provide teachers with a system for tracking student demonstration of competency, diagnosing possible content misunderstandings, and converting standardsbased evaluation of student competency into grades. Teachers were to continue to guide each student until he or she achieved at least 80 percent proficiency on the six-weeks assessment. While Project Proficiency was originally intended to be a mechanism to propel JCPS's Tier I and Tier II schools, the approach quickly spread to all comprehensive and many of the magnet and alternative high schools. This further 
indicates the district did not differentiate support for their Cohort I schools but employ the same supports for all schools across the county.

Contrary to the JCPS, district plans for Caverna Independent, Lawrence County, Leslie County, and Metcalfe County were all crafted to meet the individual needs of their schools. Of course, this would be expected given that each rural Cohort I district had a single school to support. Lawrence County and Leslie County's plans put an emphasis on systems and monitoring. Lawrence County formed a District Transformation Team (DTT), which included multiple district level personnel. The DTT met monthly to analyze data to monitor the progress of the plan's action steps, review quarterly information to be submitted to KDE and the Lawrence County Board of Education, and review the budget as it pertained to implementation. In Leslie county, district leaders also ensured there were an adequate number of staff with appropriate certifications to keep favorable student /teacher ratios; considered calendar options that offered extended time for students who needed extra support; and provided funding to retain staff for lengthened school days.

In the Western region, Caverna's district plan highlighted the creation and implementation of school-wide literacy and mathematics improvement plans. The leadership team included representatives from both the school and district, conducted walkthroughs of each classroom on a daily basis and provided timely descriptive feedback to each member of the instructional staff observed. Metcalfe's district plan allocated funds for assessment, professional development, technology procurement, tutoring and substitute teachers to allow faculty to receive the extensive training 
necessary for successful implementation. School and district leadership planned and scheduled PLCs for the school year. The district PLCs focused on common assessments, formative assessments, examining student work samples using a protocol which included a method for providing specific feedback, questions, and next steps for revision. However, as noted previously via member checking feedback, Metcalfe's efforts may have been undermined due to a lack of leadership consistency at the school, district, and state levels. Furthermore, participant feedback noted that the school's leadership viewed the ERT as a bother and did not embrace their support. These factors resulted in systems work delay.

\section{Contingency Factors}

An examination of SIG tiers revealed inequity in funding and support across Cohort I schools. In JCPS, each school received the same level of funding and KDE support regardless of qualifying tier or the size of the school's enrollment. A closer look at students living in poverty revealed that Fern Creek High School (Tier II) had nearly $34 \%$ fewer students qualify for free / reduced lunch compared to the average of the other five JCPS Tier I schools. In the areas of special education and student mobility, Fern Creek High School again had a smaller percentage of their student population identified in both areas. Another factor that may have impacted JCPS's ability to support the turnaround work could be linked to the number of PLA schools within the district and / or the district's overall size. JCPS had six Cohort I schools to support in 2010. By 2018, the number of PLA schools increased to 31. In addition to the growing number of PLA schools, JCPS had over 170 total schools (elementary through high school) in the district to support. These variables are further discussed at the federal, state, and local levels. 


\section{Implications for Future Policy and Practice}

In this section, I discuss implications for future policy and practice. I examine the implications from the federal, state and local perspective.

\section{Federal Level}

Determining the role of the federal government in local education decisions is an ongoing debate. Education is a reserve power of each state; however, the need for more funding continues to open the door for federal intervention. To date, rather than mandating direct federal oversight of schools, ESEA has provided funding for education programs, as long as participating states meet certain conditions. Examples of these federal funds include Title I, Title VI (which provides aid for disabled children), and Title VII (funds for bilingual education).

In 2001, NCLB established a new level of federal oversight by requiring states to set more rigorous student evaluation standards and, through testing, demonstrate adequate yearly progress in how those standards were met. As discussed previously, while NCLB highlighted the disparities in achievement, an emphasis on high-stakes testing and highly qualified teachers was not enough to eliminate achievement gaps and other social and economic factors that hinder learning (Steen \& Noguera, 2010). When the Obama administration came to office, a priority of Secretary Duncan's agenda was to shut down high school dropout factories and improve educational outcomes for students most in need. The SIG program was one of the federal programs leveraged in hopes of meeting this objective. 
As discussed previously in this study, the impact of SIG on schools and districts is mixed. While some findings show promising outcomes, others reveal no increase in student achievement, incoherent plans, and program sustainability issues after the threeyear funding window closed. In addition, Dragoset et al. (2017) found that implementing any SIG-funded model had no significant impacts on math or reading test scores or high school graduation. Although my research findings support the need for differentiated district support for successful school turnaround, constraints in the SIG application can make differentiation challenging. One could argue that the further you move away from the school level, the less ability there is to provide supports that meet the individual needs of a school. Future SIG policy should consider allowing increased decision-making authority to the SEAs and LEAs on how SIG funds are distributed and utilized. This would allow for equitable funding options that include the consideration of a school's SIG tier. Furthermore, the requirement for schools to select and implement a SIG intervention model should be eliminated. Trujillo and Renee (2012) suggest that reforms such as SIG can result in the conditions that researchers have linked with persistent low performance, high turnover, instability, poor climate, inexperienced teachers, and racial and socioeconomic segregation. While my research did indicate more success for schools using one model over another, factors such as school and district size and support cannot be excluded from the success formula.

\section{State Level}

An essential question arising from this study is can an organization, like a SEA, serve as both the enforcer and support team for an LEA and its schools, or is the conflict of interest too great? Naturally, there is a tendency to have tension between a SEA and 
LEA due to the SEA's ability to enforce state regulations, impose improvement plans and address capacity concerns of district leadership. If the answer is yes, they can serve both roles, policy must be adopted to ensure consistent, highly skilled, support teams are dedicated to each PLA school and that these teams do not take on the role of evaluator or enforcer of policy.

The provision requiring a leadership assessment team provide judgement on a principal's capacity to lead, should be removed from the legislation. While the law has been adapted so that the SEA no longer has the power to remove the principal, they still provide a leadership capacity recommendation to the superintendent. That is not enough change. The recommendation still gets communicated through local media, regardless of a superintendent accepting or declining it. This can result in great setbacks to a school's academic progress, climate, and morale. A group of individuals with minimal involvement in the school should not sit in judgement of the role of the leader after an archival document review, and a brief three-day visit to the school. Further, these teams are often staffed with the ER members from other schools which crosses the line again between support and enforcer. The teams are touted as external teams and if that is true, then the ER members should not be a part of these teams as they are internal to school improvement processes in other schools and districts.

In today's landscape there are too many shared responsibilities, and while the principal is a decision maker in the building, they are not the sole decision maker and thus should not be wholly responsible as the only person to essentially be removed should a school land in repeated PLA status. Alternatively, if it is deemed that serving as the 
enforcer and support partner is too great a conflict, the SEA should be required to seek a third-party school support partner to assist PLA schools in the turnaround work.

\section{Local Level}

My research underscores the need for a deeper understanding of the policies, structures, and processes that lead to successful school turnaround. As noted by Trujillo (2012), the belief regarding school turnarounds that fast, substantial changes in staffing and management can fundamentally improve persistently low-performing schools, is illogical. In Kentucky's Cohort I, SIG funding combined with individualized district plans and supports resulted in only 33\% of the Cohort I schools, $75 \%$ of the non-JCPS schools, exiting PLA status successfully within the three-year timeframe.

Dynamic leadership at the school level is critical for school turnaround to occur. As principal at OAN, I knew that increases in student achievement can be directly connected to our organizational systems. However, due to inequities facing Tier I schools like OAN and the JCPS Title I schools in Cohort I, continuous improvement and program sustainability are greatly diminished. As of 2018, 31 JCPS schools were identified as PLA, of which only three successfully exited (Allred \& Foster, 2018). Of the three, only one, Valley High School, was a Tier I school, and they exited following an appeal to KDE. The inability to move PLA schools out of the bottom 5\% brings to light a systems issue that manifests beyond the school level and should serve as a call-to-action for district and state leaders. Future policy and practice must address the greater systematic issues, such as student assignment, family health and support, and funding formulas that ensure equity not simply equality. These issues are common among many 
schools but they are especially problematic in urban schools, especially the issue of student assignment.

\section{Recommendations for Future Research}

After three years of SIG implementation, 1.5 million dollars, and KDE support, no JCPS school successfully exited PLA status; however, three (75\%) of the non-JCPS schools did. In Kentucky's Cohort I, all JCPS schools implemented the Turnaround SIG model, while the non-JCPS schools implemented the Transformation model. This finding could lead one to infer that the SIG model was the determining factor for a success or lack of success; however, multiple studies (Dragoset et al., 2017; Redding \& Nguyen, 2020) refute this assumption. While the impact of the model cannot be fully

dismissed, my findings revealed, and they were affirmed through member checking, that the rural districts selected the Transformation model due to a lack of qualified teaching candidates, not because of an implied strategic advantage. The Turnaround model was simply not an option.

My interpretation of the data, through the lens of my theoretical framework, structural contingency theory, seemed to indicate to me that the way the district chose to structure their work in the support of their schools mattered. In Kentucky's first SIG cohort, the Transformation model schools received individualized support from their districts, this was not the case for the Turnaround model schools. As noted previously, individualized supports for the Transformation model schools were made easier due to the fact that each of the rural districts had only a single school to support, unlike JCPS, which had six schools Cohort I schools and chose not to form a school-specific, district support team to focus on the needs of individual schools. 
In Cohort I, Metcalfe County High School was the only rural PLA school not to exit PLA status. The analysis of documents did not explicitly reveal the reason for Metcalfe County High School's failure to exit. However, member checking feedback revealed changing leadership at the school, district, and state levels, along with a lack of buy-in at the school and district levels as the main causes for remaining PLA. A lack of buy-in at the district level can also be inferred with JCPS. Their CDIP explicitly stated that many of the programs and initiatives meant to support their PLA schools that were implemented during 2009 - 2010 had been planned or launched in the preceding two years. Again, this could lead one to conclude that feedback from the KDE conducted leadership assessments were minimally considered when formulating district plans to support their Cohort I schools.

An analysis of contingency factors found that non-cognitive student variables that contribute to lower achievement were greater in Tier I schools, whose student populations consist of higher percentages of students living in poverty, receiving special services, and higher rates of student mobility, may need additional supports beyond those found to have work in the Tier II settings. Noguera and Wells (2011) found that many past reforms largely failed to improve schools in urban areas. The authors contend that prior efforts failed because they did not address the numerous ways that past research has shown poverty influences student academic outcomes and school performance. Trujillo and Renee (2012) support this stance noting many studies did not examine the social and political factors that affect schools, instead focusing on the technical changes and student learning. The results of my analysis align with their conclusions. 
With results from prior research, the findings of this study, and my experiences as a practitioner in a Title I school, I implore stakeholders at all levels to use this knowledge as a call to action. The model that has been designed and deployed over the past decade has failed for schools in JCPS. To clarify, this is not due to a lack of effort or ability. I have had the distinct honor of collaborating with many talented and passionate educators within the district. My findings, supported by past research, shows that interventions found to be successful in smaller rural districts have not worked in the large urban district setting.

Under new leadership, JCPS has made many strides over the past few years to change the trajectory of their PLA schools, including the addition of an assistant superintendent assigned directly to PLA schools, adopting a racial equity plan, and bolstering the Department of Diversity, Equity, and Poverty. These are not small undertakings and demonstrate buy-in that appeared to be missing a decade earlier. However, I contend that these initiatives are not enough to change the outcomes of PLA schools throughout the district. My contention is supported by the fact that only three schools have successfully exited PLA status since the first SIG cohort, only one of which was a Tier I school and exited on appeal.

In summary, to lawmakers and practitioners, I recommend significant reforms in the areas of student assignment, family supports, and equitable funding must occur for outcomes to improve at scale. I often hear the counter argument that affluent families will leave the district if this occurs. I have my doubts, but if that is correct, so be it. The needs of our most vulnerable students continue to grow and real reform is needed in order for the existing pattern of results to be remedied. To academia and future researchers, the 
needs of urban schools with higher than normal percentages of poverty, special education, and English language learning needs demand further study in any attempt to positively impact the outcomes for students. In addition, I suggest future research revisit Cohort I plans through all three years of their initial identification to determine if midcourse corrections were made that may have enhanced the exiting schools' ability to exit within the three-year timeframe outlined in the SIG application.

\section{Epilogue}

In 2008, my third-year teaching, OAN was founded as the first all-boys public middle school in Kentucky. Six years later, I made the transition from the classroom to become principal of the school. During that time period, JCPS ranked OAN as the school with the highest needs in the district based on students receiving free / reduced lunch, students with special needs, a high transiency rate, and students whose primary language was not English. Of our 600 students, 64 percent were minorities, 15 percent were English language learners, 16 percent received special education services, and 89 percent qualified for free / reduced lunch. Despite these challenges and the state labeling us a PLA school (Cohort III), we made steady progress.

Great systematic change was needed to ensure the success of our students. Establishing a culture of collaboration and effective systems resulted in many positive outcomes, including our students meeting state accountability targets for the first time ever in 2016. An analysis of state-mandated test scores indicated that student achievement increased again in 2017, but the previous accountability targets were not computed that year due to changes in Kentucky's Senate Bill 1. The following school 
year, we were approved as a school-wide Science, Technology, Engineering, Arts, and Mathematics (S.T.E.A.M.) magnet and began work with the Buck Institute, a national leader in project-based learning. We also received grants from Amazon, JCPS Deeper Learning Department, and the Verizon Innovative Learning Foundation, which brought one-to-one technology to our students and a state-of-the-art makerspace area. As we embraced these exciting changes and continued our shift from students as content consumers to content creators, collaboration and effective school-wide systems continued to be our core guides in our continuous improvement journey.

By my fourth year, contingency variables outside of the school's command began to impede our progress. The number of PLA schools continued to grow throughout the district, resulting in less and inconsistent support from our ERT. Additionally, the needs of our student population continued to grow, and requests for further funding and district support were not granted. The bi-annual KDE leadership assessments, which were initially leveraged to drive positive change, had become a great burden to our school initiatives. The review team members, often from rural areas throughout the state, had little context of the challenges of working in a large, urban, politically bureaucratic district. Following my third leadership assessment in five years as principal, all of which found I had the capacity to lead the turnaround work, the process had become more about survival and less about informing school improvement. Unfavorable assessment results mostly fell at the feet of a single person, the principal. This would often result in a principal being removed and shamed in the local media. KDE and central office, while supposed partners in the school improvement process, did not face the same public repercussions to the negative reports. 
In the summer of 2019, I made the decision to leave OAN and to take a new approach in hopes of impacting school turnaround at scale. This decision ultimately led to my analysis of Cohort I. Looking back over the past decade, it is evident that not much has changed regarding the fortunes of the schools that failed to initially exit. Only two additional Cohort I schools were able to exit PLA status since the inception of the first cohort. Fern Creek High School (2015) and Valley High School (2017) both successfully exited; however, a 2019 KDE report revealed that Valley High School had since fallen back into the bottom 5\% of schools according to the annual accountability assessment. Shawnee High School (now called the Academy @ Shawnee) and Western High School also continue to be ranked in the bottom 5\%.

Frost Middle School and Western Middle School were both reconfigured since 2010. Frost Middle School was closed and reopened as the Robert Frost Sixth Grade Academy in 2014, while Western Middle School was transformed into a magnet school called Western Middle School for the Arts. While neither school is in the bottom 5\%, both have been labeled as Target Support and Improvement (TSI) schools, which a new designation made by the state for schools with gap groups that are significantly behind their non-gap group peers on the state accountability assessment. Fern Creek High School and Lawrence High School were labeled TSI as well.

As discussed in Chapter V, my findings have led me to conclude that a district's ability to support the work and a district's willingness and capacity to differentiate policy and practice to meet the individual needs of its schools is a key factor in a school's ability to successfully turnaround. However, if you recall the disparities discussed between Tier I and Tier II schools in regards to non-cognitive factors that may impact student learning, 
my analysis revealed much higher concentrations of students living in poverty, receiving special services, and higher rates of student mobility at the Tier I schools. There is a growing body of research (Herberger et al., 2020; Wisman, 2020) that note higher concentrations of students receiving free / reduced lunch services is a powerful predictor of school-level academic achievement in JCPS. Therefore, student assignment, such as caps on the percentage of students receiving free-reduced lunch, could play a key role in supporting schools in their turnaround efforts. Lastly, while I looked at this work through the contingency theory framework, there is an emerging body of science called improvement science that might be a better fit for future research. Improvement science advocates believe that rather than implementing fast and learning slow, educators should adopt a more rigorous approach to improvement that allows the field to learn fast to implement well (Bryk et al., 2015). It is my hope that future research around the Kentucky PLA schools, especially the urban schools, dive deeper into causation of factors contributing to their continued struggles and provide insights into potential actions that will mitigate the factors preventing them from moving student achievement so that every student experiences academic success. Improved outcomes for students, after all, is the fundamental reason for school improvement efforts. 


\section{REFERENCES}

Allred, S.G. \& Foster, K. A. (2018) Without trumpets: continuous educational improvement, journey to sustainability. New York, NY: Rowman \& Littlefield.

Birt, L., Scott, S., Cavers, D., Campbell, C., \& Walter, F. (2016). Member Checking: A Tool to Enhance Trustworthiness or Merely a Nod to Validation? Qualitative Health Research, 26(13), 1802-1811. https://doi.org/10.1177/1049732316654870

Braun, V. \& Clarke, V. (2006). Using thematic analysis in psychology. Qualitative Research in Psychology 3(1), 77-101. doi.org/10.1191/1478088706qp063oa

Bryk, A. S., Gomez, L., Grunow, A., LeMahieu, P. (2015) Learning to improve: How America's schools can get better at getting better. Retrieved from https://www.carnegiefoundation.org/resources/publications/learning-to-improve/

Creswell, J. W. (2005). Educational research: Planning, conducting, and evaluating quantitative and qualitative research (2nd ed.). Upper Saddle River, NJ: Pearson.

Creswell, J. W. \& Creswell, J. D. (2018). Research design: qualitative, quantitative, and mixed methods approaches. New York, NY: Sage Publications. 
Donaldson, L. (2001). The contingency theory of organization. Thousand Oaks, CA: Sage Publications.

Dragoset, L., Thomas, J., Herrmann, M., Deke, J., James-Burdumy, S., Graczewski, C., Boyle, A., Upton, R., Tanenbaum, C., \& Giffin, J. (2017). School Improvement Grants: Implementation and Effectiveness: Executive Summary (NCEE 20174012). Washington, DC: National Center for Educational Evaluation and Regional Assistance, Institute of Education Sciences. Retrieved from https://ies.ed.gov/ncee/pubs/20174013/pdf/20174012.pdf

Friedberg, E. (1997). Local Orders. The Dynamics of Organized Action. Greenwich, CT: JAI Press.

Hanson, M. E. (1979). School management and contingency theory: an emerging perspective. Retrieved from https://eric.ed.gov/?id=ED172356

Hatch, M. J. (2018). Organization theory: modern, symbolic, and postmodern perspectives $\left(4^{\text {th }} e d\right)$. New York, NY: Oxford University Press.

Hatch, M. J. \& Cunliffe, A. L. (2006). Organization theory: modern, symbolic, and postmodern perspectives ( $2^{\text {nd }} e d$.). New York, NY: Oxford University Press.

Hermberger, G., Immekus, J., \& Ingle, W. K. (2020). Student, neighborhood, and school factors and their association with college readiness: exploring the implementation of a race - and socioeconomic - based student assignment plan. Education and Urban Society 52(3), $459-488$. 
Kentucky School Improvements Grants Application. (2010). Retrieved from https://www2.ed.gov/programs/sif/summary2010/kyapp10.pdf

Lachlan-Hache, J., Naik, M., \& Casserly, M. (2012). The School Improvement Grant rollout in America's great city schools. Retrieved from https://files.eric.ed.gov/fulltext/ED530694.pdf

Le Floch, K., O’Day, J., Birman, B., Huriburt, S., Nayfack, M., Halloran, C., Boyle, A., Brown, S., Mercado-Garcia, D., \& Goff, R. (2016). Case Studies of Schools Receiving School Improvement Grants: Final Report (NCEE20164002). Washington, DC: National Center for Education Evaluation and Regional Assistance, Institute of Education Sciences, U.S. Department of Education. Retrieved from https://ies.ed.gov/ncee/pubs/20164002/pdf/20164002.pdf

LiCalsi, C., Citkowicz, M., Fridman, L. B., \& Brown, M. (2015). Evaluation of Massachusetts office of district and school turnaround assistance to commissioner's districts and schools: Impact of school redesign grants. American Institute for Research. Retrieved from https://www.air.org/sites/default/files/downloads/report/15-2687_SRG_ImpactReport_ed_FINAL.pdf

Merriam, S.B. (1992). Qualitative research and case study applications in education. Jossey Bass Publishers.

Milner, H. R. (2007). Race, culture, and researcher positionality: working through Dangers seen, unseen, and unforeseen. Retrieved from https://journals-sagepub com.echo.louisville.edu/doi/10.3102/0013189X07309471

Moro, J.M. (2017). School improvement grants at work: a study of urban, public New 
England schools (Doctoral dissertation, Pepperdine University). Retrieved from ProQuest Dissertations and Theses database. (No. 1927182086)

Noguera, P. A. \& Wells, L. (2011). The Politics of School Reform: A Broader and Bolder Approach for Newark. Retrieved from https://files.eric.ed.gov/fulltext/EJ1169709.pdf.

National School Improvement Grant Summary. (2013). Retrieved from https://www2.ed.gov/programs/sif/data/school-impro-grants-nat-sumsy1213.pdf

Obama, B. (2010). President Obama State of the Union address. Retrieved June 11, 2020 from http://stateoftheunionaddress.org/201-barak-obama.

Office of Elementary and Secondary Education. (2000) Comprehensive school reform demonstration program: raising student achievement through research based reforms that strengthen the entire school. Retrieved from https://files.eric.ed.gov/fulltext/ED443145.pdf

Patterson, J. A., Campbell, J. K., Johnson, D. M., Marx, G., \& Whitener, M. (2013). Using policy attributes theory to examine comprehensive school reform implementation in two title I middle schools. Retrieved from https://web-aebscohostcom.echo.louisville.edu/ehost/pdfviewer/pdfviewer?vid=10\&sid=08c01 bbf-aaf9-43af-852f-5abe32a8b90b\%40sessionmgr4006

Patton MQ.Qualitative research and evaluation methods. Sage Publications; Thousand Oaks, CA: 2002. 
Paul, C. A. (2018). Elementary and Secondary Act of 1965. Retrieved from https://socialwelfare.library.vcu.edu/programs/education/elementary-andsecondary-education-act-of-1965/

Pajares, F. (2007). Elements of a proposal. Retrieved from http://des.emory.edu/mfp/proposal.html

Quillen, J. (2011). Snapshot of SIG: A look at four states' approaches to school turnaround. Retrieved from https://www.americanprogress.org/issues/educationk12/reports/2011/06/30/9830/s napshot-of-sig/

Redding, C. \& Nguyen, T.D. (2020). The relationship between school turnaround and Student outcomes: A meta-analysis. Retrieved from https://journals.sagepub.com/doi/pdf/10.3102/0162373720949513

Rice, J., Bojorquez, J.C., Diaz, M., Wendt, S., \& Nakamoto, J. (2014). Evaluation of Michigan's School Improvement Grant: Outcomes after three years. Retrieved from https://www.michigan.gov/documents/mde/Final_MDE_SIG_Outcome_Aft er_Three_Yars_483504_7.pdf

Rhodes, A., Bower, W., Mckay, D., \& Adams, C. (2012). 2012 Annual Evaluation Report: Kentucky School Improvement Grant. University of Kentucky. Human Development Institute. Retrieved from http://68.77.48.18/RandD/Kentucky/KY\%20SIG\%20Eval\%20Report\%20\%202012.pdf

Sharp, L. A. (2016). ESEA Reauthorization: An Overview of the Every Student Succeeds 
Act. Texas Journal of Literacy Education. Retrieved from https://files.eric.ed.gov/fulltext/EJ1110854.pdf

Smith, J. A. (2015). Qualitative psychology a practical guide to research methods. Los Angeles, California: Sage Publication.

Steen, S. \& Noguera, P. A. (2010). A broader and bolder approach to school reform: expanded partnership roles for school counselors. Retrieved from https://journalssagepubcom.echo.louisville.edu/doi/pdf/10.1177/2156759X100140 $\underline{0105}$

Sun, M., Penner, E.K., \& Loeb, S. (2017). Resource and approach driven multi dimensional change: Three-year effects of school improvement grants. American Educational Research Journal, 54(4), 607-643.

Trujillo, T. (2012). The paradoxical logic of school turnarounds: a catch-22. Retrieved from https://larrycuban.wordpress.com/2012/08/13/the-paradoxical-logic-ofschool-turnarounds-a-catch-22-tina-trujillo/

Trujillo, T. \& Rénee, M. (2012). Democratic School Turnarounds: Pursuing equity and learning from evidence. Boulder, CO: National Education Policy Center. Retrieved from http://nepc.colorado.edu/publication/democratic-schoolturnarounds.

United States Department of Education. (n.d.). Retrieved from https://www.ed.gov/essa.

United States Department of Education. (n.d.). Kentucky Department of Education School Improvement Grant practice developing state-level principal pipelines. Retrieved from https://www2.ed.gov/programs/sif/sigprofiles/kypipeline102714.pdf 
United States Department of Education. (2010). Retrieved from

https://www.ed.gov/news/speeches/secretary-arne-duncans-remarks-releaseamerica\%E

\%80\%99s-promise-alliance-report-\%E2\%80\%9Cbuilding-gradnation\%E2\%80\%9D

United States Department of Education. (2016). Retrieved from

https://www2.ed.gov/programs/sif/map/ky.html.

United States Department of Education. (2018). Retrieved from https://www2.ed.gov/programs/sif/sigprofiles/index.html).

Wisman, R. A. (2020). Operationalizing the intersection of racial and socioeconomic Diversity in predicting school-level academic achievement. Education and Urban Society 52(6), $927-961$.

Yatsko, S., Lake, R., Nelson, E. C., \& Brown, M. (2012). Tinkering toward transformation: A look at federal School Improvement Grant implementation. Center on Reinventing Public Education. University of Washington Bothell.

Yin, R. K. (2009). Case study research design and methods. 4th Ed. Thousand Oaks, California: Sage Publications. 


\section{APPENDIX A: STRUCTURED ETHICAL REFLECTION GRID}

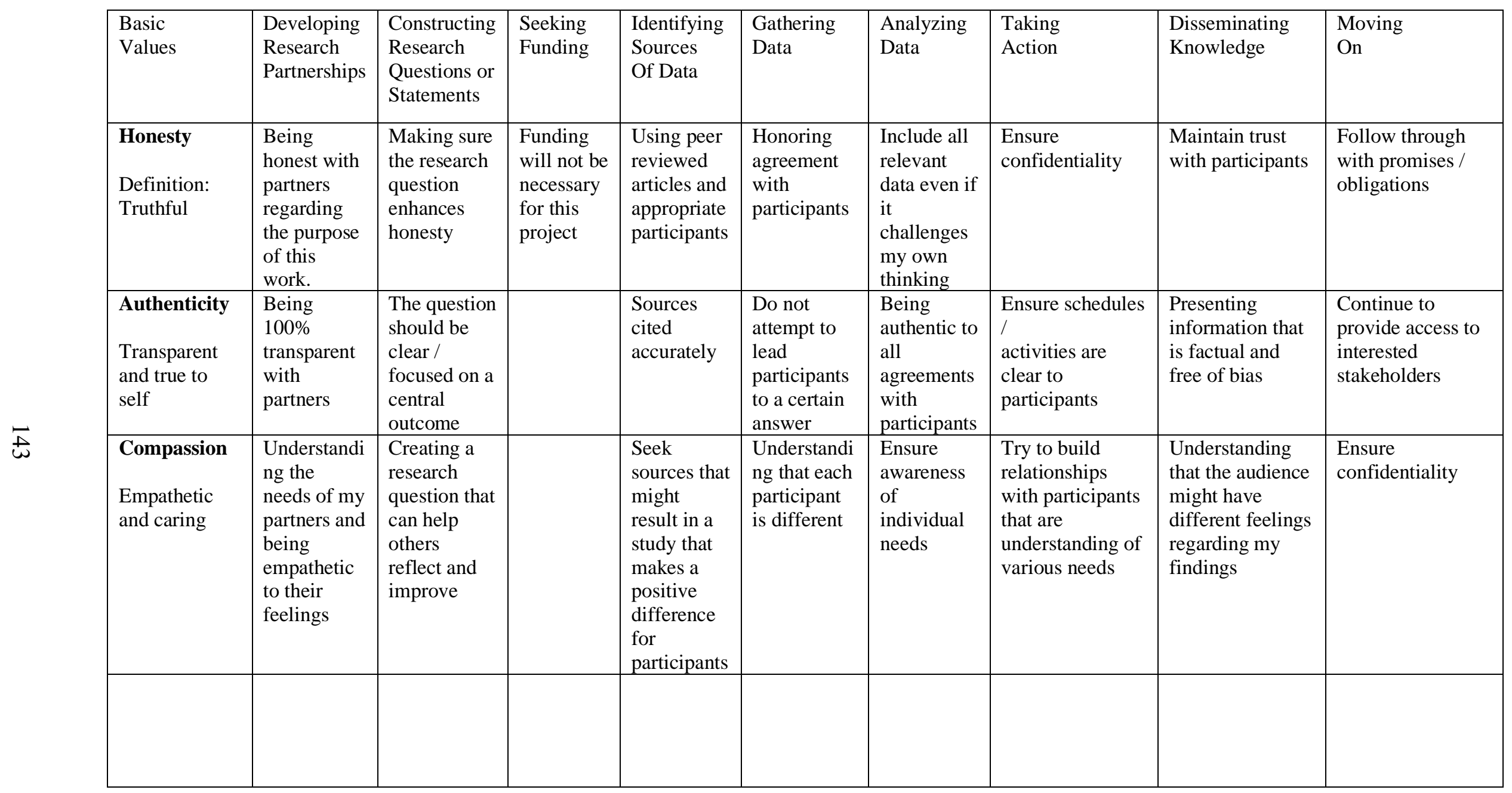




\begin{tabular}{|c|c|c|c|c|c|c|c|c|}
\hline $\begin{array}{l}\text { Critical } \\
\text { Thinking } \\
\text { Data driven }\end{array}$ & $\begin{array}{l}\text { True to the } \\
\text { data } \\
\text { collected } \\
\text { from } \\
\text { partners and } \\
\text { not swayed } \\
\text { by previous } \\
\text { experiences }\end{array}$ & $\begin{array}{l}\text { Creating a } \\
\text { research } \\
\text { question that } \\
\text { will look at } \\
\text { data } \\
\text { differently } \\
\text { than the past }\end{array}$ & $\begin{array}{l}\text { Use data } \\
\text { from } \\
\text { multiple } \\
\text { sources }\end{array}$ & $\begin{array}{l}\text { Be open to } \\
\text { the different } \\
\text { viewpoints } \\
\text { of sources } \\
\text { and } \\
\text { participants }\end{array}$ & $\begin{array}{l}\text { Include all } \\
\text { relevant } \\
\text { data even if } \\
\text { it } \\
\text { challenges } \\
\text { my own } \\
\text { thinking }\end{array}$ & $\begin{array}{l}\text { Listen to } \\
\text { feedback from } \\
\text { experts in field }\end{array}$ & $\begin{array}{l}\text { Be open to } \\
\text { feedback from } \\
\text { the audience }\end{array}$ & $\begin{array}{l}\text { Continue to } \\
\text { engage interested } \\
\text { stakeholders }\end{array}$ \\
\hline $\begin{array}{l}\text { Efficiency } \\
\text { Organized }\end{array}$ & $\begin{array}{l}\text { Respecting } \\
\text { the time of } \\
\text { partners }\end{array}$ & $\begin{array}{l}\text { Creating a } \\
\text { research } \\
\text { question that } \\
\text { can be } \\
\text { efficiently } \\
\text { examined }\end{array}$ & $\begin{array}{l}\text { Present } \\
\text { data in a } \\
\text { way that } \\
\text { can be } \\
\text { effectively } \\
\text { processed } \\
\text { by } \\
\text { consumer }\end{array}$ & $\begin{array}{l}\text { Being } \\
\text { cognizant of } \\
\text { participants } \\
\text { time }\end{array}$ & $\begin{array}{l}\text { Clearly } \\
\text { noting next } \\
\text { steps }\end{array}$ & $\begin{array}{l}\text { Ensure follow } \\
\text { through }\end{array}$ & $\begin{array}{l}\text { Doing further } \\
\text { research based } \\
\text { on feedback }\end{array}$ & $\begin{array}{l}\text { Follow through } \\
\text { with promises / } \\
\text { obligations }\end{array}$ \\
\hline
\end{tabular}




\section{APPENDIX B: CENTRAL REGION MEMOS}

\section{Good Afternoon,}

I hope this note finds you well. I am in the process of conducting research at the University of Louisville that is focused on Kentucky's first SIG cohort, and I'm reaching out to you in hopes of further validating my findings. Please note, I have received IRB approval for this study (20.1083).

For this research, I am seeking to determine how some Kentucky Cohort I schools were able to exit PLA status successfully within the three-year timeframe outlined in the SIG application, while others were not. I am requesting that you review the findings below and reply to this email with the following:

1. Are the findings accurate given your experiences?

2. Were any findings inaccurate, incomplete, or omitted?

3. Did the findings lack an important feature or experience from your recollection of the turnaround work?

Please note, this is one of two emails I will be sending to you requesting information. This email contains findings for the district only. The second email will contain findings for the six Cohort I schools. I know you are very busy. Please know that I appreciate your time and feedback.

\section{Jefferson County Public Schools District SIG Application Findings}

- JCPS chose the Turnaround Model for each of their six Cohort I schools.

- The requirements of the Turnaround Model resulted in principals being replaced at Frost Middle School and Western Middle School.

- KDE also recommended that the principal at Valley be removed.

- However, upon evidence cited in an appeal letter from the superintendent, the commissioner of education retained the current principal and allowed him one year to show significant gains in reading and math proficiency.

- Reports also noted that the principal at Western High School had one year to meet requirements or risk being removed due to his initial hire date.

- All SBDM council authority for Cohort I JCPS schools were granted to the superintendent as a result of the Leadership Assessments conducted by KDE.

- In response, all Cohort I principals formed an instructional leadership teams (ILT) to serve in an advisory capacity. The ILT became the vehicle through which schools monitored school improvement pertaining to curriculum, assessment, and instruction.

- In the spring of 2010, JCPS leadership conducted a "critical analysis" of the district's intervention strategies, with greater intentionality directed toward how 
the district could support struggling students and schools that had not met their goals.

- Their analysis was facilitated by a consultant from Harvard/Wallace and informed by the school and district audits performed by KDE.

- District leaders determined that the likelihood of making a "turnaround" difference in the coming year would be "optimized if they organized, implemented, supported, and monitored a laser-like focus on four strategic approaches to the issues now facing our district." The identified strategies included: promoting students' engagement with schools and their understanding of the long-term benefits of education; providing a system of coordinated support to students and school; owning results; and informing practice.

- To move this plan from discussion to action, the district established four committees of district-level staff, each chaired by a cabinet member. The four committees were Case Management Coordination for Tier I and Tier II schools, System Support Coordination, Balanced Assessment and Learning Progression, and Improving Practice.

- According to CDIP notes, many of the programs and initiatives that were implemented during 2009 - 2010 had been planned or launched in the preceding two years, with one exception (Project Proficiency).

- Through Project Proficiency, the district established three key standards for each six-weeks grading period for Algebra I, Geometry, Algebra II, and Sophomore English.

- After administering a Diagnostic Assessment early in the grading period, teachers used the results to identify learning gaps, formatively assess understanding, and prescribe intervention strategies to guide each student to demonstrate a level of competency in each of the key standards by the time he/she takes a culminating six-weeks Proficiency Assessment.

- PLCs of teachers were to collaborate weekly to discuss student learning progression and exchange ideas about instructional implications and potential remediation strategies.

- Web-based technology was to provide teachers with a system for tracking student demonstration of competency, diagnosing possible content misunderstandings, and converting standards-based evaluation of student competency into grades.

- Teachers were to continue to guide each student until he or she achieved at least 80 percent proficiency on the six-weeks assessment.

- While this initiative was originally formulated for Tier I and Tier II schools, the approach spread to all comprehensive and many of the magnet and alternative high schools.

- In the area of school staffing, a memorandum of agreement was negotiated between the district administration and the Jefferson County Teachers' Association (JCTA) that exempted the priority schools from the district's transfer agreement.

- Further supports for all Cohort I principals included an ERL assigned by the Kentucky Department of Education. 
- The district also assigned a priority manager to provide job performance feedback about the principal and monitor the implementation of all school activities aimed at improving student achievement.

- In addition, the district curriculum office implemented multiple strategies to assist Cohort I schools. These supports included having resource teachers and specialists work with school leadership teams to design and deliver job-embedded professional development to teachers throughout the school year.

- Also, resource teachers and specialists facilitated professional learning communities through lesson study at each school.

Thank you for your time and attention. Your feedback is greatly appreciated.

\section{Good Afternoon,}

I hope this note finds you well. I am in the process of conducting research at the University of Louisville that is focused on Kentucky's first SIG cohort, and I'm reaching out to you in hopes of further validating my findings. Please note, I have received IRB approval for this study (20.1083).

For this research, I am seeking to determine how some Kentucky Cohort I schools were able to exit PLA status successfully within the three-year timeframe outlined in the SIG application, while others were not. I am requesting that you review the findings below and reply to this email with the following:

1. Are the findings accurate given your experiences?

2. Were any findings inaccurate, incomplete, or omitted?

3. Did the findings lack an important feature or experience from your recollection of the turnaround work?

Please note, the findings below are from the six JCPS Cohort I schools.

\section{Fern Creek High School SIG Application Findings}

- Fern Creek High School's plan revealed an emphasis on PLCs and data analysis.

- The development of PLCs was designed to provide a structure for collaboration among teachers to create a synergetic environment.

- The school made a concerted effort to include parents and teachers in the decision-making process.

- This led to the formation of a Parent Advisory Council and school design community.

- Fern Creek High School allotted SIG funds for the following personnel: two math teachers, three reading teachers, and one math interventionist.

- Fern Creek High School hired an educational consultant. 
- Fern Creek High School allotted \$50,000 to hire substitute teachers for the purpose of tutoring students one-on-one.

\section{Frost Middle School SIG Application Findings}

- Frost Middle School made significant adjustments to its master schedule and curriculum to try to boost student achievement.

- School leaders implemented a master schedule with an 8-period day. This schedule allowed students to have 86 minutes of reading, 86 minutes of math, 43 minutes of social studies, 43 minutes of science, and two related arts periods daily.

- Additionally, this schedule allowed for common planning time for grade level teachers teaching the same subject.

- In language arts, Frost Middle School adopted the Springboard curriculum as their literacy framework. All students were to receive instruction through a core program aligned with the Kentucky Program of Studies and Core Content for Assessment.

- In addition to Springboard, the adopted master schedule included a supplementary class period of reading instruction for every student. During this class period, students received additional instruction and support for mastery of learning targets and objectives taught in the core language arts program.

- Frost Middle School's master schedule revisions also provided a dedicated 18minute CARE time each morning. The CARE sessions, similar to an advisoradvisee program, focused on modeling and positive social interactions, goal setting, and emotional intelligence principles as well as providing a "safe place to land" for students needing a supportive environment.

- Frost Middle School allotted SIG funding for the following personnel: one reading teacher, two math teachers, two interventionists, one RTI teacher.

- Frost Middle School used SIG funds to secure the services of an educational consultant.

\section{Shawnee High School SIG Application Findings}

- Shawnee High School created The Urban Teacher Institute (UTI) to accelerate teaching and learning. The institute was designed to address each of the first four deficiencies related to teaching and learning found in the leadership assessment.

- UTI was an ongoing and responsive mechanism that provided professional development, in-class support, critical feedback, and paths for personal and organizational growth.

- Shawnee High School formed a partnership with the University of Louisville (U of L) that included the schools of Social Work, College of Engineering, office of community development, College of Medicine, and dental and nursing programs.

- As needs arose, the U of L liaison working directly with the teachers at the Academy would identify those students who needed access to university resources. The college of education and human development also worked to 
recruit and retain high quality staff at Shawnee High School. U of L sponsored a National Board cohort group and provided a mentor for these teachers.

- Shawnee High School allocated SIG Funds to for the following personnel: School Administrative Manager, two part-time resource teachers, one part-time administrator, and one teacher.

- Shawnee High School hired an education consultant.

- Shawnee High School allocated \$30,000 for library books.

\section{$\underline{\text { Valley School SIG Application Findings }}$}

- Valley High School had multiple community partnerships designed to improve student achievement and career readiness.

- The College Readiness Program coordinated post-secondary, community, businesses, and political resources to support students in arranging college visits, gaining access to higher education/admission, financial aid, and scholarships.

- The school developed several partnerships (i.e. Allied Health, Jewish Hospital, Spencerian College, St. Catherine College, etc.) that provided resources, job shadowing experiences, and speakers.

- Valley High School used SIG funds for the following personnel: one reading teacher, two math teachers, and one data coach.

- Valley high school used SIG funds to secure the services of an educational consultant.

\section{Western High School SIG Application Findings}

- Western High School put an emphasis on teacher development and retention with the creation of the Early College Initiative.

- Through the Early College Initiative, teachers were offered the opportunity for tuition reimbursement as they took master's level courses in their content area.

- This was an opportunity for professional development and incentive to continue working at Western High School. It was theorized that this heightened education in math, reading, and other content areas would ultimately increase rigor and knowledge of the respective content areas.

- To assist students transitioning to ninth grade, Western High School created the Freshman Academy.

- The Freshman Academy was designed to provide more personal guidance, attention and supervision as students made their transition from middle to high school.

- Western High School allotted SIG funding for the following personnel: three reading teachers and two math teachers.

- Western High School did not secure the services of an educational consultant.

\section{Western Middle School SIG Application Findings}

- Western Middle School put an intentional focus on improving the collaborative work of the school faculty. 
- A team of in-house and district support teachers, certified in literacy and mathematics, worked collaboratively with the ERL and the math and reading ERS to support teachers at Western Middle School in an on-going and "just in time" fashion.

- Embedded professional development occurred twice weekly with all teachers and focused on topics, such as instruction, assessment, analysis of student work, and classroom management. Members of the instructional support team mentored new teachers to Western Middle School and first-year teachers.

- The district designed a new student assignment plan for Western Middle School. The plan was to convert the school to a whole school magnet with an innovative theme and sufficient resources, with the hope of achieving greater student diversity and higher academic achievement.

- Western Middle School used SIG funds to secure the following personnel: two resource / RTI teachers, one math interventionist, and one literacy interventionist.

- Western Middle School used SIG funds to secure the services of an educational consultant.

Thank you for your time and attention. Your feedback is greatly appreciated. 


\section{APPENDIX C: EASTERN REGION MEMOS}

Good Afternoon,

I hope this note finds you well. I am in the process of conducting research at the University of Louisville that is focused on Kentucky's first SIG cohort, and I'm reaching out to you in hopes of further validating my findings. Please note, I have received IRB approval for this study (20.1083).

For this research, I am seeking to determine how some Kentucky Cohort I schools were able to exit PLA status successfully within the three-year timeframe outlined in the SIG application, while others were not. I am requesting that you review the findings below and reply to this email with the following:

1. Are the findings accurate given your experiences?

2. Were any findings inaccurate, incomplete, or omitted?

3. Did the findings lack an important feature or experience from your recollection of the turnaround work?

\section{Lawrence County School District SIG Application Findings}

- $\quad$ Selected the Transformation Model for Lawrence County High School.

- The principal was replaced due to SIG requirements.

- In May 2010, the Lawrence County's Superintendent recommended a new rigorous and equitable evaluation plan for all certified employees that would follow applicable statutes and regulations.

- The evaluation process served three purposes: to promote continuation of professional competencies that maximize teacher growth and effectiveness; to identify areas for professional growth; and to assist in making personnel decisions for the purpose of improving instruction, curriculum, assessment; and other professional responsibilities-all focused on helping students learn and succeed.

- A district walkthrough team, including the building principal, would visit each classroom monthly to inform instruction and enable the principal to coach individual staff on a consistent basis. Walkthrough teams assigned to each school collected quantitative and qualitative data (a "snapshot") that was descriptive and focused on Lawrence County's district-wide priority goals.

- The district formed the District Transformation Team (DTT). The DTT included the following: Superintendent, Director of Personnel, and Director of Districtwide Services, Director of Special Education, Chief Academic Officer, Director of Early Learning, Director of Finance, Director of Pupil Personnel, Technology Officer, and District ESS Coordinator/Parent Involvement Coordinator.

- The DTT met monthly to analyze data to monitor the progress of the initiative, review the progress of the plan's action steps, review quarterly information to be 
submitted to KDE and the Lawrence County Board of Education, and review the budget as it pertains to implementation.

- In order to maintain an accurate and useful data system, the district added a Data Analyst at no cost to the SIG.

- The district's plan also noted increased implementation of job-embedded professional development.

- The district provided training to all certified staff regarding PLCs and implementing district and school instructional leadership teams.

\section{Lawrence County High School SIG Application Findings}

- To monitor instruction occurring at Lawrence County High School, the principal actively participated on the district walkthrough team. Team members visited each classroom at least monthly to inform instruction and enable the principal to coach individual staff on a consistent basis (providing appropriate supports as necessary).

- To further support instruction, teachers with zero to three years' experience participated in TARGET (Training and Resources for Growing Effective Teachers).

- This multi-year induction model (TARGET I, II, and III) provided teachers new to the profession and/or district needed support.

- School-level teams met regularly to focus on curriculum, assessment, and instruction directly tied to the School Improvement Plan.

- A freshman academy was developed to meet the transition needs of its students.

- Lawrence County High School used SIG funds to secure the following personnel: Director of Pupil Personnel, one literacy interventionist, one math interventionist, one part-time resource teacher, and one math / science teacher.

- Lawrence County High School did not secure the services of an educational consultant.

\section{$\underline{\text { Leslie County School District SIG Application Findings }}$}

- Selected the Transformation Model for Leslie County High School.

- Leslie County Schools' leadership assessment team determined that the principal (formerly hired in 2009) had the capability and capacity to continue his roles and responsibilities established in KRS 160.345.

- District leaders changed the length of the school day and school year to increase learning opportunities.

- The 2010 - 2011 school calendar included 10 extended days for student learning.

- The district ensured there were an adequate number of staff with appropriate certifications to keep favorable student /teacher ratios; considered calendar options that offered extended time for students who needed extra support; provided funding to retain staff for lengthened school days; developed a budget that included adequate funding for technology, supplies, and facilitated discussions between the high school and Leslie County Area Technical Center to 
make curriculum connections for the purpose of expanding the high school curriculum to encompass career readiness standards.

- Leslie County's district leaders committed to aligning curriculum taught in its schools, K-12th grades.

- The district began with summer sessions on the learning standards rollout, to be followed by unpacking these standards through PLC meeting/sessions. The curriculum would be aligned both horizontally and vertically so that there were no gaps in content chunks or between grade levels.

- Discovery Education was purchased to continually assess the success of the instructional programs and to inform the further instruction district-wide.

- A performance calculator was used in each classroom to assess learning in chunks of content before moving on to additional concepts.

\section{Leslie County High School SIG Application Findings}

- Leslie County High School formed a leadership team whose sole purpose was to analyze the audit results and to plan methods for addressing each of the suggested growth areas.

- A systematic approach was set to monitor the extent to which professional development impacted teacher practice through weekly learning walks utilizing a specific walk-through instrument and debriefing.

- Leslie County High School also made changes to their master schedule. The new schedule contained a six-period day with a modified block period to allow greater flexibility with student interventions.

- A Response to Intervention (RTI)/Advisory period was added to the beginning of the school day, so all students would receive extended learning for forty-five minutes per day.

- Discovery Education Assessment was adopted as the universal screener to measure and predict student performance and allow ongoing process monitoring.

- $\quad$ SIG funds were used to secure the following personnel: two teachers to serve a mentor lab classrooms, School Intervention Manager, and Director of Academic Performance.

- Leslie County High School did not secure the services of an educational consultant.

Thank you for your time and attention. Your feedback is greatly appreciated. 


\section{APPENDIX D: WESTERN REGION MEMOS}

\section{Good Afternoon,}

I hope this note finds you well. I am in the process of conducting research at the University of Louisville that is focused on Kentucky's first SIG cohort, and I'm reaching out to you in hopes of further validating my findings. Please note, I have received IRB approval for this study (20.1083).

For this research, I am seeking to determine how some Kentucky Cohort I schools were able to exit PLA status successfully within the three-year timeframe outlined in the SIG application, while others were not. I am requesting that you review the findings below and reply to this email with the following:

1. Are the findings accurate given your experiences?

2. Were any findings inaccurate, incomplete, or omitted?

3. Did the findings lack an important feature or experience from your recollection of the turnaround work?

\section{Caverna High School SIG Application Findings}

- The leadership team (which included representatives from both the school and district) conducted walkthroughs of each classroom on a daily basis and provided timely (same or next day) descriptive feedback to each member of the instructional staff observed.

- Teachers deemed as master teachers at Caverna High School were eligible for the rewards set forth in the district rewards program.

- In literacy and math, Caverna High School implemented Reading Plus to serve as an intensive and supplemental intervention in language arts classes across all grade levels.

- Carnegie Math (Algebra I) was implemented and expanded to include Algebra II and Geometry.

- MAP was used as a universal screener to measure and predict student performance in reading, math, and science in order to allow ongoing process monitoring.

- Using data from MAP, students were grouped and regrouped based on performance and placed into intervention classes that were built into the master schedule. Novel Star was used to promote graduation for students who had experienced failure in the regular classroom.

- Silver and Strong (Thoughtful Classroom) instructional strategies were integrated into units of study in order to meet diverse learning styles of students. 
- To assist students with the transition from $8^{\text {th }}$ to $9^{\text {th }}$ grade, Caverna High School established a two week "camp" to target math and reading skills. The goal was to include up to half of the incoming freshmen in the camp.

- Caverna High School used SIG funds to secure the following personnel: one math teacher and a School Administrative Manager.

- Caverna High School used SIG funds to secure the services of an educational consultant.

\section{Caverna Independent School District SIG Application Findings}

- Selected the Transformation Model for Caverna High School.

- Caverna's district leaders petitioned to retain the principal, but that request was denied, resulting in the hiring of a new principal.

- Caverna's district plan highlighted the creation and implementation of schoolwide literacy and mathematics improvement plans.

- The district purchased MAP to be utilized as a universal screener for grades 812.

- In addition, the district supported the school use and expansion of the Reading Plus program to address the needs identified in the RTI plan and MAP assessment.

- Teachers were trained on how to best utilize the Reading Plus and Des Cartes program (associated with MAP) to address the individual student needs.

- In Math, Caverna's district leadership would again use MAP as the universal screener for grades 8- 12.

- The district would support the school's implementation and expansion of the Carnegie Math program to address the needs identified in the RTI plan and MAP assessment.

- The master schedule was redesigned to provide an extra period for implementation of the math intervention program. This program utilized a newly added math intervention teacher and paired them with students deemed substantially below grade level. The district would support the training of math teachers on how to best utilize the Carnegie Math and Des Cartes program (associated with MAP) to address the individual student needs. As with the reading curriculum,

- In the area of teacher attraction / retention, Caverna's district plan noted a collaborative effort with KDE and Western Kentucky University to utilize all available means to find, recruit, train, and place highly effective teachers, including developing a compensation system.

\section{Metcalfe County High School SIG Application Findings}

- Metcalfe County High School contracted with national author and consultant Elliot Merenbloom, co-author of Making Creative Schedules Work in Middle and Secondary Schools, in order to collaboratively design a schedule to maximize both teacher and student learning time. 
- Reorganization of the master schedule enabled professional learning communities to engage in the curriculum, instruction, and analysis of data and student work.

- Teachers were organized into like-content teams to meet at least once each week during common planning time to collaborate and have professional conversations with colleagues, instructional coaches, and leadership.

- Other partnering professionals such as Green River Regional Education Consortium (GRREC), Caveland Educational Support Center (CESC), Western Kentucky University (WKU), Eastern Kentucky University (EKU), and KDE were contracted to provide job-embedded professional development in content, instruction, coteaching models, and assessment for learning.

- Read 180 was utilized to help struggling readers.

- New nonfiction library books were purchased to provide a better selection of materials to meet the needs of all students, especially males.

- The district literacy coach worked closely with teachers in all content levels to implement effective reading strategies in all classes.

- After school professional development was attended by all classroom teachers for continued support in the effective implementation of reading strategies in all content areas.

- The MAP assessment was administered three times yearly to check for progress.

- From the results, RTI groups were identified and the students that needed extra help were given the time to work on the skills needed for improvement.

\section{Metcalfe County School District SIG Application Findings}

- Selected the Transformation Model for Metcalfe County High School.

- The principal was replaced due to SIG requirements.

- Metcalfe County district leaders provided additional supports in the areas of PLCs, developing community partnerships, teacher recruitment, and funding.

- The district pledged over $\$ 150,000$ for additional teachers and staff beyond required allocations to further support the grant plans.

- The district allocated funds for assessment, professional development, technology procurement, tutoring and substitute teachers to allow faculty to receive the extensive training necessary for successful implementation. School and district leadership planned and scheduled PLCs for the school year.

- The district PLCs focused on common assessments, formative assessments, examining student work samples using a protocol which included a method for providing specific feedback, questions, and next steps for revision.

- To further support the work, the district literacy and math coach collaborated with teachers on an individual basis to model and help develop effective classroom instructional techniques.

- To support professional development opportunities and deepen content knowledge and instructional pedagogy, district leadership partnered with KDE, GRREC, CESC, WKU and EKU.

- The district's plan for recruiting, placing, and retaining highly effective instructional staff involved expanding the partnerships between Metcalfe County 
School District and educational cooperatives, colleges, and universities for identifying the most promising teacher candidates.

- New teacher orientation programs were developed to train and support newly hired instructional staff.

- District leadership planned to form a model Future Educators Association to encourage those with the highest potential for teaching, incorporate strong communication with families of these students, facilitating visits to colleges and universities for outstanding club members, and initiating and sustaining strong relationships between the district and these outstanding students.

- In 2010, Metcalfe County was in the second year of their new employee evaluation plan implementation. The evaluation plan was meant to maintain accountability and assessment in a clear focus on improving student learning.

Thank you for your time and attention. Your feedback is greatly appreciated. 
Ryan Rodosky

\section{CURRICULLUM VITAE}

801 Glenbrook Rd.

Louisville, KY 40223

(502) 931-9518

ryanrodosky@gmail.com

\section{Research Interests}

Education, School Turnaround, Organizational Systems

\section{Summary of Skills}

- Strong leadership skills and effective communicator

- Experience of working with school leaders, principals, community interest group, and faculty

- Excellent coaching, listening, decision-making, and coordination skills

- Strong knowledge of the education policies of all the governments

- Ability to review and redesign school programs

- Strong ability to gain grant funding and donations for school and district initiatives

\section{Education}

- $\quad$ EdD | May 2021 | University of Louisville

- Superintendent Certification | May 2018 | University of Louisville

- Principal Certification | November 2012 | University of the Cumberlands

- Masters of Education| August 2006 | University of Louisville

- Bachelor of Arts | August 1997 | Western Kentucky University

Experience and Recognitions

Principal: Goshen Elementary - August 2019 - Present

- Engaged diverse groups of educators and other stakeholders to design, implement, monitor and modify systems for continuous school improvement

- Implement vision and goals of the school and ensured compliance with state and federal regulations

- Implement, monitor and support school curriculum and instructional practices 
- Revise policy, manage budget, and staff hiring procedures

- Handle finance and ensured high-quality facilities to deliver effective education to students

- Manage community relationships by meeting and interacting with community leaders

Principal: Frederick Law Olmsted Academy North - August 2014 - 2019

- 2016 Hilliard Lyons Principal Excellence Award

- 2016 Kentucky Department of Education Best Practices Award

- 2010 Kentucky Middle School Association Teaming Award

Assistant Principal: Frederick Law Olmsted Academy North 2013 - 2014

Special Populations Master Teacher: Frederick Law Olmsted Academy North 2010 2013

Special Education Teacher: Frederick Law Olmsted Academy North 2005 - 2010 